\title{
SF523 H3
}



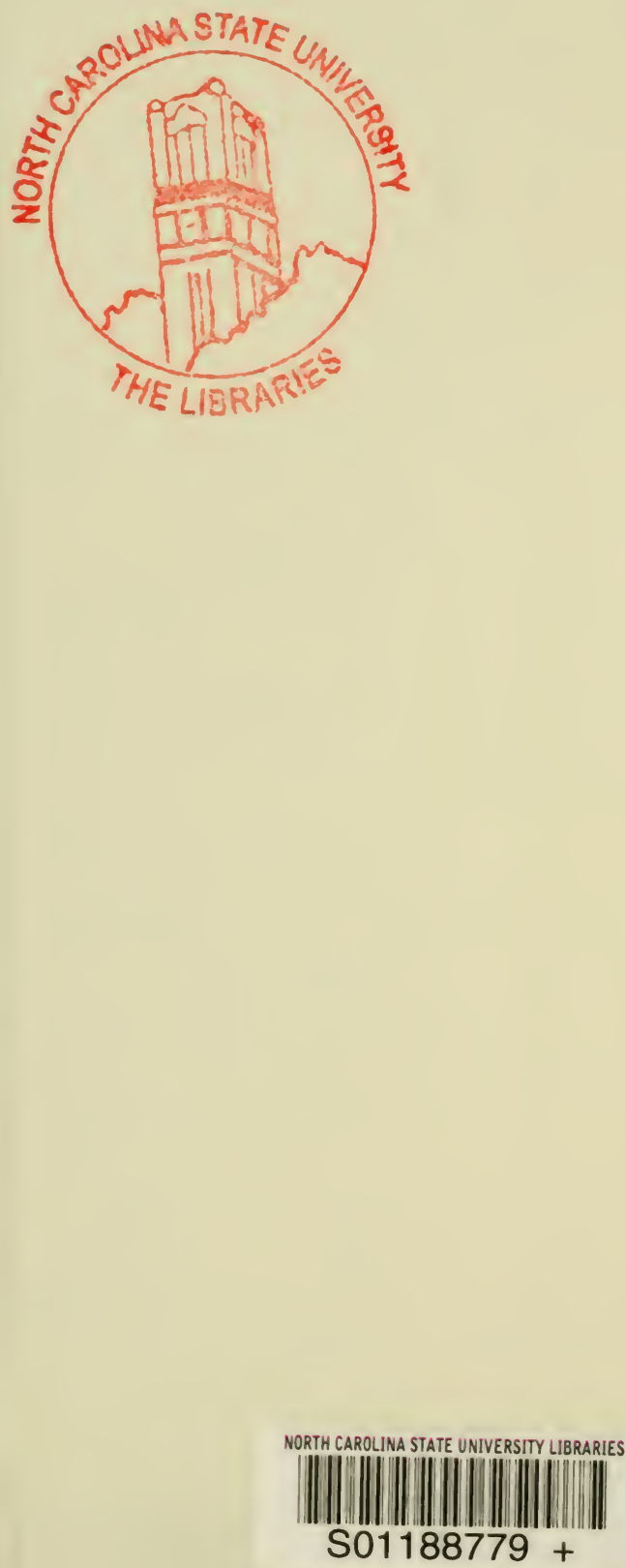
This book is due on the date indicated below and is subject to an overdue fine as posted at the circulation desk.

\section{EXCEPTION: Date due will be earlier if this item is RECALLED.}





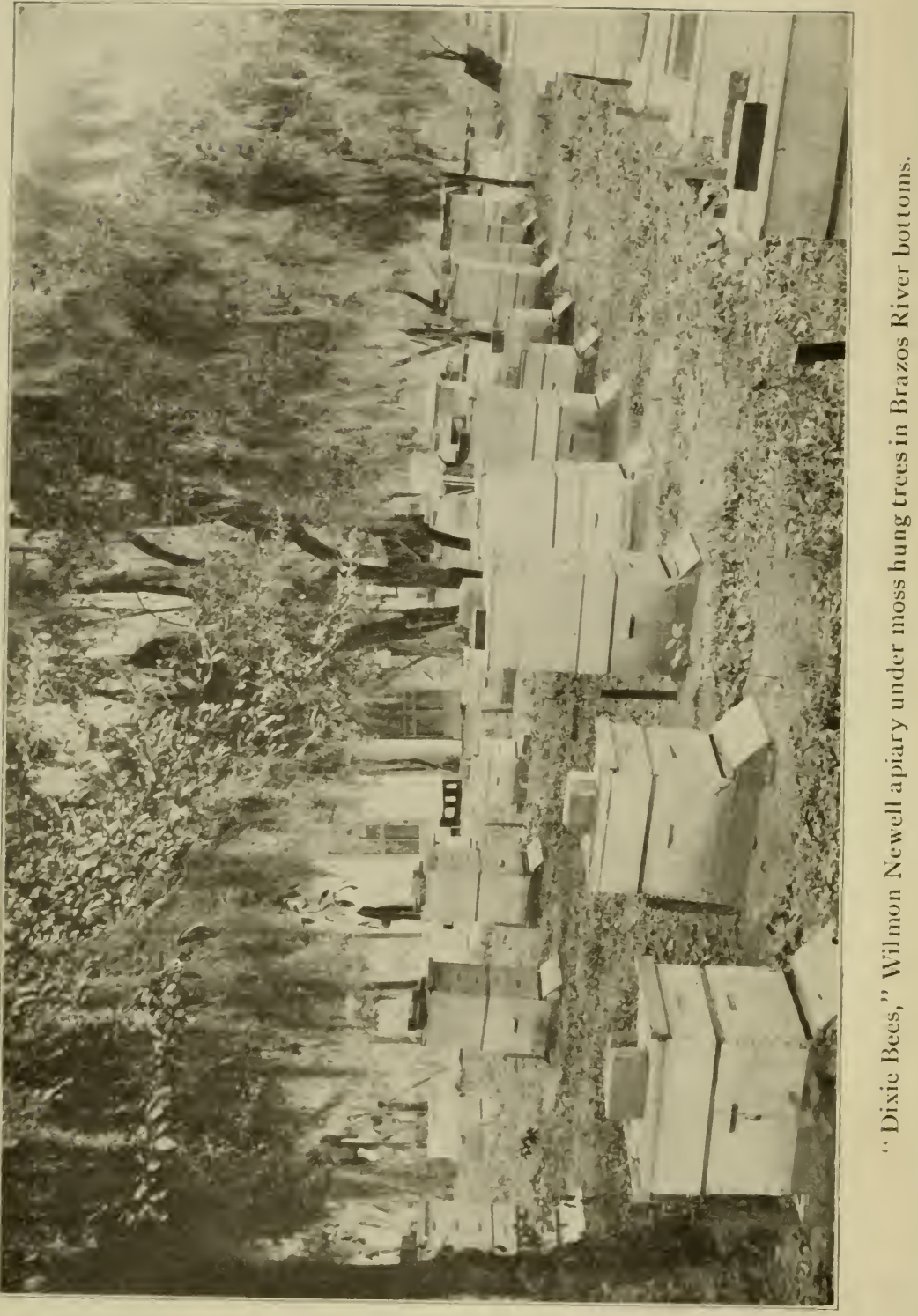




\section{BEEKEEPING}

\section{IN THE}

SOUTH

A Handbook on Seasons, Methods and Honey Flora of the Fifteen Southern States

\section{BY KENNITH HAWKINS}

Beekeeping Specialist for G. B. Lewis Company.

Former Special Agent in Bee Culture

U. S. Department of Agriculture,

15 States South.

AMERICAN BEE JOURNAL

HAMILTON, ILLINOIS 
Copyright, 1920,

BY

AMERICAN BEE JOURNAI. 
This volume is dedicated to my father and mother and to the memory of Sam Mottinger, my first beekeeping teacher. 



\section{PREFACE}

7 HE information given in this book is intended to clear the impressions of many that the South is altogether an undereloped region so far as beekeeping is concerned and that one has only to move to that magic region, "Dixie," to escape the problems common to beekeepers living in the North. It is also intended as a defense of the southern beekeeper, of whose methods and opportunities so much misinformation has been spread. This volume is not intended as a manual for the beginner, but to supplement standard textbooks so as to show what differences exist in beekeeping methods in the North and the South.

An impression gained is that beekeeping operations differ but little in the South from those in vogue elsewhere, except mainly in the time of their application. We have little criticism of methods in vogue in the South, except the lack of winter protection of any sort in too much of this region. Box hives are too prevalent in many areas of the South, but so they are in the North. An impression of southern beekeepers is their eagerness to learn modern methods, where they happen to be unknown, and to put them into practice.

No agency has worked so much for the betterment of southern beekeeping as the extension service, both federal and state. The impressions gained and recorded here, are the result of 17 months travel in the 15 Southern States for the U. S. Bee Culture Laboratory and the U. S. States Relations Service by the writer. We vouch for the attempt at accuracy in these pages and will hope for constructive criticism, as this volume is a pioneer in blazing a way toward accurate information on beekeeping in the Southern States.

In compiling these pages, continual work and correspondence with dozens of southern beekeepers has been necessary, over a period of nearly two years. To credit the information to all the various sources is impossible for the lack of space.

We are indebted to the men of the U.S. Bee Culture Laboratory, Washington, D. C., Dr. E. F. Phillips, George S. Demuth, G. H. Cale and A. P. Sturtevant and to the U. S. States Relations Service, both for the opportunity to work in the Southern States and for guidance regarding these investigations and their record. We are also indebted to each of the bee culture extension men of the South, dozens of county and home demonstration agents of the U. S. government in the 15 states, south, and to each of the state and experiment station entomologists who are interested in bee culture. The Census Bureau, Bureau of Chemistry, Bureau of Plant Industry, Bureau of Entomology and Forest Service of the U. S. Department of Agriculture have given valuable assistance.

Mr. Frank C. Pellett, associate editor of the American Bee Journal, has been an almost constant advisor in the compiling of this volume and without the assistance of Dadant and Sons, of Hamilton, Illinois, and the G. B. Lewis Company, Watertown, Wisconsin, this volume could not have been published.

Kennith Hawkins.

Watertown, Wis. May 18, 1920. 


\section{CONTENTS}

CIIAPTER

PAGE

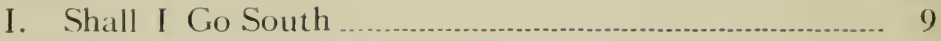

II. What a Beginner Must Learn .................................. 17

III. Apparatus of the South ...................................... 23

IV. Making a Start.................. 29

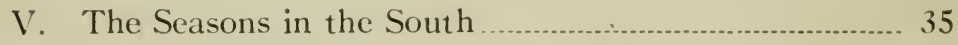

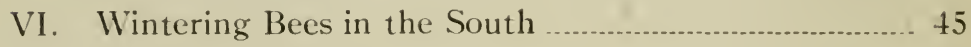

VII. Combless Packages and Queen Rearing ...................... 53

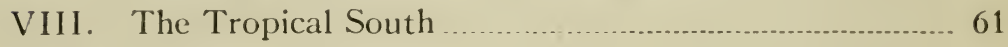

IX. The Alluvial Region _............................................ 69

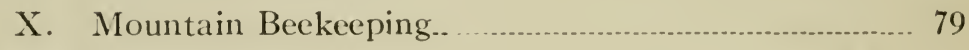

XI. The Lone Star State _.............................................. 87

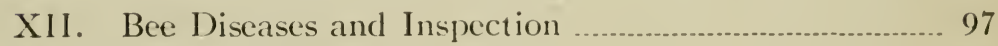

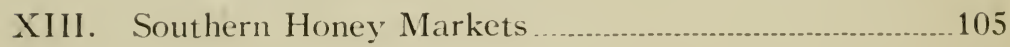

XIV. Honey Plants of the South.........................................111 


\section{ILLUSTRATIONS}

Frontispiece-"Dixie Bees" Apiary of Wilmon Newell under moss hung trees in Brazos River Bottoms. Page

Fig. 1. A small apiary at Macon, Georgia................................ 11

Fig. 2. Table showing census data on southern beekeeping............ 13

Fig. 3. A relic of the old days. Apiary of box hives...__.............. 18

Fig. 4. A modern Texas apiary developed from two box hives....... 19

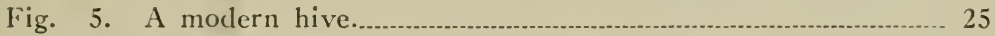

Fig. 6. A Virginia swarm.

Fig. 7. Mrs. Grace Allen's backlot bees................... 33

Fig. 8. It is necessary to guard against high water in many locations 35

Fig. 9. Apiary of P. J. Thullen in Alabama....................... 36

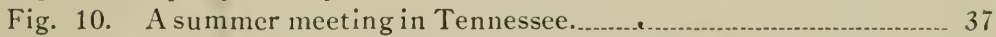

Fig. 11. J. J. Wilder, a prominent Georgia beekeeper....................... 39

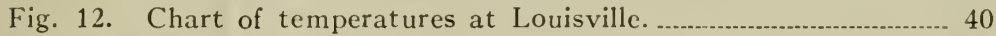

Fig. 13. When a norther hits the South. (Chart)......................... 41

Fig. 14. When snow falls in Tennessee. Photo by Mrs. Grace Allen... 42

Fig. 15. It is a common practice to winter the bees with supers on the hives to prevent loss of combs by moths....................... 47

Fig. 16. A West Virginia apiary in double walled hives.................. 48

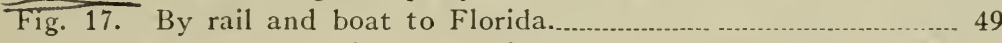

Fig. 18. Walker's mating yard in. Tennessee. Photo by G. M.

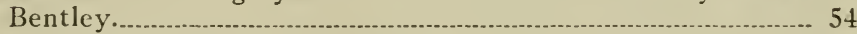

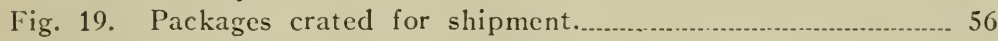

Fig. 20. A handy funnel for filling packaores................................. 57

Fig. 21. Queen mating nuclei in southwest Texas........_._._..... 58

Fig. 22. Home and queen yard of J. L. Leath at Corinth, Miss........ 59

Fig. 23. One of M. C. Berry's Alaba ma yards for breeding package bees. 60

Fig. 24. Apiary of B. M. Caraway at Mathis, Texas..._._._....... 62

Fig. 25. Harry Hewitt's apiary at Lake Apopka in tropical Florida.... 63

Fig. 26. Apiary of J. K. Isbell on the Apalachicola River, Florida...... 66

Fig. 27. Semitropical conditions prevail in Florida and in the lower Rio Grande Valley in Texas.

Fig. 28. The rich flora of a Georgia swamp. ............................ 70

Fig. 29. An up-to-date apiary in the pine woods of Alabama........... 71

Fig. 30. There are many good locations along the strea ms in Georgia. 72

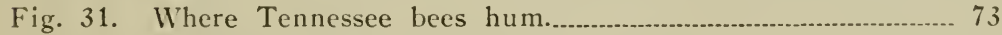

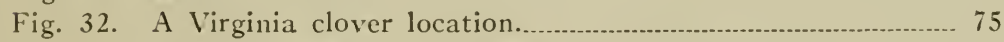

Fig. 33. One of J. J. Wilder's a piaries in south Georgia.................. 77

Fig. 34. Apiary in the Blue Ridge Mountains of Virginia............ 80

Fig. 35. Attractive hillside location in Virginia.........-.-...-.......-....... 81

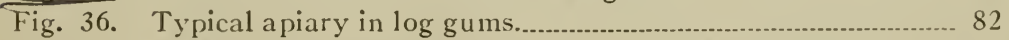

Fig. 37. A Mississippi River bottom location in Arkansas..._.......... 83

Fig. 38. Box hive a piary of a typical mountaineer...................... 84 
Fig. 39. Apiary of a Georgia farmer who is an up-to-date beekeeper... 85

Fig. 40. E. G. LeStourgeon, Manager of the Texas Honey Producers Association.

Fig. 41. Box hives are rapidly being replaced with good equipme:t... 89

Fig. 42. Apiary shown at Fig. 41 after being transferred................ 90

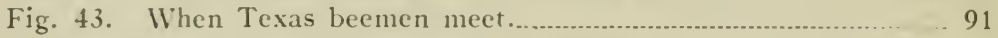

Fig. 44. Combs built in the rocks, by wild bees........................ 92

Fig. 45. L. B. Smith's apiary at Llano, Texas...................... 93

Fig. 46. Apiary in the Rio Grande Valley that produced 20,000 pounds from 90 colonies....................................... 94

Fig. 47. Scholl arranges his hives in groups of five in partial shade... 95

Fig. 48. Florida Bee Inspector's Suit. Photo by Wilmon Newell... 99

Fig. 49. Texas bee inspector demonstrating transferring........... $\quad 100$

Fig. 50. Think of inspecting a yard like this...................... 101

Fig. 51. The wreck that follows an epidemic of disease when left

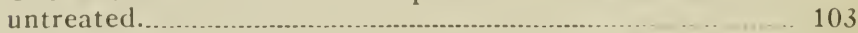

Fig. 52. Gakler's wagon was long a familiar sight on the strects of

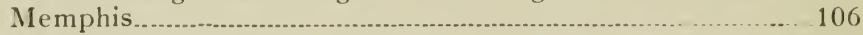

Fig. 53. This Georgia beekeeper has a honey route served direct

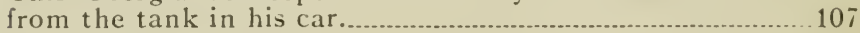

Fig. 54. Lone star label of the Texas Association.......................... 109

Fig. 55. Blossoms of bitterweed in Tennessee...........................11

Fig. 56. Blossoms of black locust in Virginia.............................. 112

Fig. 57. Beehives among the wild asters of Virginia...................114

Fig. 58. Mesquite is an important source of honey in Texas..............115 


\section{BEEKEEPING IN THE SOUTH}

CHAPTER I

\section{Shall I Go South?}

DHIS question has been repeatedly asked by dozens of beekeepers whenever the author has appeared at various beekeepers' conventions in the North, and has prompted, in a measure, the writing of this volume. Many inquiries sent to the United States Bee Culture Laboratory at Washington, D. C., and referred to the author, during his term of government bee culture extension work in the South, showed a country wide interest in southern beekeeping. Probably many of the writers were disappointed at the lack of definite information and the conservative prospects pictured in the answers to these inquiries. However, in this volume, after seventeen months spent in investigating the honey producing resources of the South, the author hopes to give more accurate information about beekeeping prospects of the South, than he was able to do befora.

There are not so many bee locations which are readily accessible and untenanted in the South as the average beekeeper residing elsewhere in the United States might expect. Many of the ideal bee locations are now taken, cxcept in the localities rather remote from modern transportation. In these remote localities there remain many good bee locations. However, one of the facts that should be taken into consideration by every man who has at any time considered going south for beekeeping, is that there are probably more bees in the fifteen southern states, than in all the balance of the United States.

\section{Northern Colonies Outnumbered.}

The figures compiled from the census of 1910, which are 
accurate and indicative of conditions in the localities reported, show the following interesting comparisons:

The number of farms reporting bees in 1910 in the fifteen southern states were 297,511 . In all the other thirty-three states of the union, there were but $288,4+4$ farms reporting bees at the same time.

In the 1910 census the number of colonies of bees reported on farms in the fifteen southern states totalled $1,558,782$, while but $1,886,224$ colonies of bees were reported as the total number on farms in the remaining thirty-three states on the same census date.

When figured out, this shows that the average number of colonies of bees per farm in the fifteen southern states on the 1910 census date, was more than five per farm. This was more than the average per farm in the balance of the United States on the same census date. It must be remembered that southern farms probably cover a smaller acreage than those in the North, and are therefore more numerous.

However, beekeepers of the North may take heart when the production figures are compared, the difference probably resulting because of the number of box hives found in many localities in the South, and the probable greater number of commercial honey producers in the North, compared with the number found in the fifteen southern states.

A total annual production of $16,810,945$ pounds of honey was reported on farms in the fifteen southern states by the census of 1910 , while in the other thirty-three states of the union, a total yield of $38,003,945$ pounds of honey produced on farms was reported for the same period. The average yield per colony on farms in the fifteen states, south, as reported to 1910 census enumerators was fifteen pounds, while for the balance of the country, the average yield reported by the census was a trifle over nineteen pounds per colony, or practically $331-3$ per cent more than in the South.

These figures show conclusively, in the author's opinion, that the South has many more bees than the balance of the country. It is also known as a certainty from personal observation, that if 
Another feature which must be taken into consideration is that in some portions of the South, especially in the lowlands, much of the honey produced year in and year out, would average darker in color than in the clover regions of the North. Still another feature is that in many parts, particularly Alabama, Mississippi, Louisiana, Arkansas, and east Texas, there are vast beekeeping regions where bitterweed honey must be reckoned with. This is covered more fully in the chapter on "Sources of Honey in the South." This honey is bitter, unpalatable and unsalable. However, bees do not work bitterweed when other equal nectar sources are available and the season is usually short when bitterweed honey is stored. This enables the careful beekeeper to separate the flows. A feasible plan which is now being used by some beckeepers of the bitterweed region, is to extract and store away the entire crop of bitterweed honey. At the end of the season the frames of the brood chamber which may contain a fair grade of honey may be extracted, and the bitterweed honey fed back to the bees for winter stores. The use of bitterweed honey for winter stores has never proved unsatisfactory, to the knowledge of the author.

We have often wondered why some enterprising patent medicine man did not buy up quantities of this bitterweed honey, which tastes like liquid quinine, and put it on the market as a cold "cure." It would certainly have a "punch" with it.

\section{Honey, Bees or Queens?}

A problem which must be considered by any "foreign" beekeeper, is whether or not he wishes to go south for the production of honey, bees or queens? Good honey producing regions are found in nearly all portions of the southern states. Queens can usually be raised successfully for early shipment to the North in April and May without fail, in all the territory below a line which might be drawn through Charleston, South Carolina, Birmingham, Alabama, and Austin, Texas. North of this line queen breeding is carried on just as successfully, but breeders in this northern belt often experience sudden changes of 


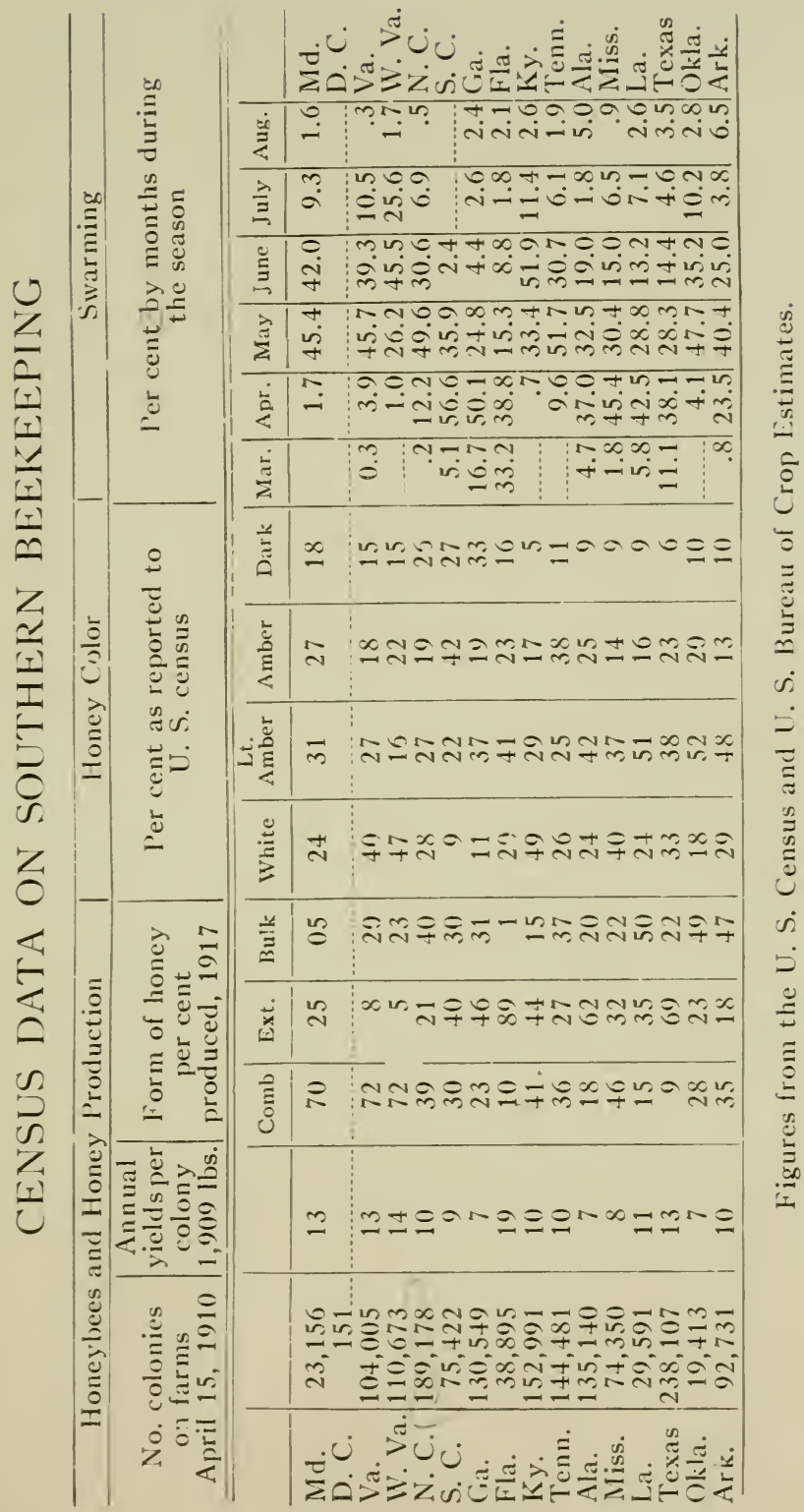


weather in the spring of the year, which may delay cell building, the mating of queens, and the rapid building of colonies. To locate in Dixie for queen breecing, it would be the advice of the author to go south of the line mentioned. This was the advice of Ben G. Davis, H. D. Murry, and several other southern queen breeders, at the time the author made his first trips to Dixie, with the intention of becoming a southern queen bee breeder.

If the motive of moving south is primarily for the production of bees, either for the nucleus or pound package trade, then by all means one should locate as far south as is possible. It probably would not be advisable for a beekeeper to locate north of a line which might be drawn through Charleston, South Carolina, Birmingham, Alabama, and Fort Worth, Texas, if he wishes to engage in the pound package business. See especially charts on winter temperatures at these points in the chapter on "Wintering Bees in the South." Even at these points, there are some years when unusual weather in April may delay the shipment of packages for several days. Zero temperatures have been recorded near Goldsboro, North Carolina, Augusta, Georgia. River Junction, Florida, Alexandria, Louisiana, Waco, Texas, and El Paso, Texas. If one is going south to engage in beekeeping in any branch which primarily requires continued warm weather early in the spring, the beekeeper should go down into the real South.

\section{Visit the Locality.}

If beekeepers from other paits of the country wish to locate in Dixie land, they should by all means make a careful study of the average annual temperatures and rainfall, for a period of years, at the point of interest. This information is obtainable from the U.S. Weather Bureau at Washington, D. C.

Then one should visit the locality he has in mind for at least one winter if possible, before moving. In this way one may study local conditions, talk with local beekeepers and in many other ways, ascertain whether or not he is likely to make 
a go of the move, and whether or not he will like the community into which he settles. Beekeepers who have gone south to engage in our industry and who have been dissatısfied, have only themselves to blame in many cases. Insufficient investigation of every feature of the locality selected is probably the reason for most of the ultimate dissatisfaction which results. The South has been given a "black eye" by many a man who went down there chasing a "pot of gold," rather than a rational proposition.

\section{Morley Pettit's Opinion.}

The ultimate opinion that may be voiced by some northerners, was summed up by Morley Pettit, well known beekeeper of Georgetown, Ontario, Canada, in the April, 1919, number of the "Domestic Beekeeper." After spending the winter in Florida he wrote: "Outside of the Appalachicola districts this is said to be one of the best honey producing districts of the state; but with all its uncertainties, strange pests, and the long active season, the total surplus is probably no more than we get in a short sharp season and have done with it. This northern beekeeper is satisfied to raise his honey and make his money in good old Ontario, where he knows what to expect, and where Jack Frost compels bugs and bees to take a few months rest in the year. Lake Worth, Florida, February 21, 1919.'

\section{Treating Him "Handsome."}

While once the guest of a well known Tennessee beekeeper the author was being entertained by the lady of the household with tales of exploits of her brothers in the war between states. In mentioning the army of the North, the hostess always said, "The Enemy." Knowing the army of the North would always be "The Enemy" to this good woman, nothing was thought of the term until the young man of the household, who breeds good queen bees, and likes a joke as well, said: "Hawkins, do you know I was fifteen years old before I knew that 'damn Yankee' was not all one word?" 


\section{What You May Expect.}

So if you would go south to take up beekeeping, don't impose yourself upon an already well settled bee location. Find one of the many locations open, investigate it thoroughly, then move down and determine to be a booster. Your business is certain to grow in the South, if your choice is a good one. The South has probably made more progress agriculturally, than the North in the past five years. Careful investigation insures success. Your chosen home in the South is then certain to make of you an unqualified booster for Dixie beekeeping, as the author hats long since become. 


\section{CHAPTER II.}

\section{What a Beginner Must Learn.}

7 HE fundamentals of beekeeping are simple. Only the details require time to learn. To be successful in beekeeping, one must accomplish these three things: 1-Build up your colonies to the peak of storing strength coincident with the beginning of bloom of your most important honey plants; 2-Prevent any division of the strength or storing instinct of the colonies thereafter; 3 -Conserve the strength of the colony at all other seasons of the year, to prepare again for No. 1 the next bee season. Anyone who can master those three details will be a successful beekeeper anywhere. This is particularly true of the South.

There are several ways these methods can be learned in detail. One is to work for a season in the bee yard of a successful beekeeper, after you have first mastered the theory of beekeeping. Another, harder, but often best in the long run, is to buy a few bees and work it out yourself, with the aid of other beekeepers and by attending conventions and beekeeping demonstrations.

\section{Building Up Colonies.}

Stimulating colonies is a good deal like giving a man medicine. If the conditions are right, the medicine stimulates the body to action. If conditions are wrong, no medicine will help. So in beekeeping, one must suipply a few simple conditions and let the bees do the rest. No colony will build up well in spring to reach proper strength at the right time without a young queen. Therefore, requeen at least every two years. No colony can build up if not supplied with sufficient food, either natural or artificial, secured the fall before, to last through the period of rest and until natural stores are available again in spring. There- 


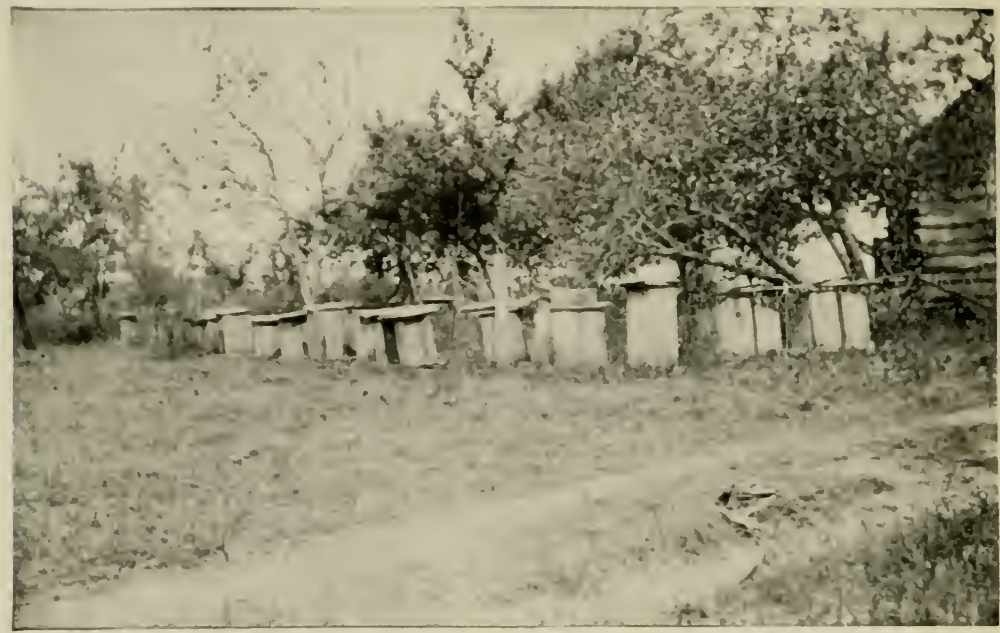

Fig. 3. A relic of the old days. Bees in box hives are being transferred so rapidly that in many localities an apiary like this is a curiosity.

fore, one must learn to gauge the amount of supplies within the hive and to feed the bees when necessary. No colony can build up properly unless the queen and bees have ample comb room for brood and surplus honey. Therefore, one must learn to enable the bees to produce really good combs and learn how to supply them at the right time to expand the brood nest and storage room. Given a young queen, ample stores and sufficient room, the swarming problem becomes less. The proper presentation of these necessities to the bees most frequently stops swarming.

\section{Preventing Swarming.}

Of as much importance as room, stores, and a young queen, is the time of giving this additional room so vital to swarm prevention. A beekeeper should figure that he has failed in the case of every swarm which issues. Giving the needed brood or surplus room too late is certain to induce swarming. Every beekeeper must have an acquaintance with the principal honey plants of 
his locality and the time of their bloom. When this is available, he can tell just when to give added brood room and can gauge the building up of his colonies to have the peak of this expansion coincident with the first honey flows. The added surplus room must follow then, else all previous efforts are lost. The method of giving this additional surplus room, especially in comb honey production, bears vitally on the success of swarm prevention

\section{Getting the Maximum Crop.}

Given "strong colonies of strong bees," as Dr. Miller says and after giving the bees ample brood room ard the first storage room, a crop failure still looms ahead for the beginner, if he does not gauge the speed of the incoming honey. Too much surplus room will result in unfinished sections; too little, in swarming and a loss of part of the crop which might have been secured. No beekeeper can succeed in honey production or in swarm

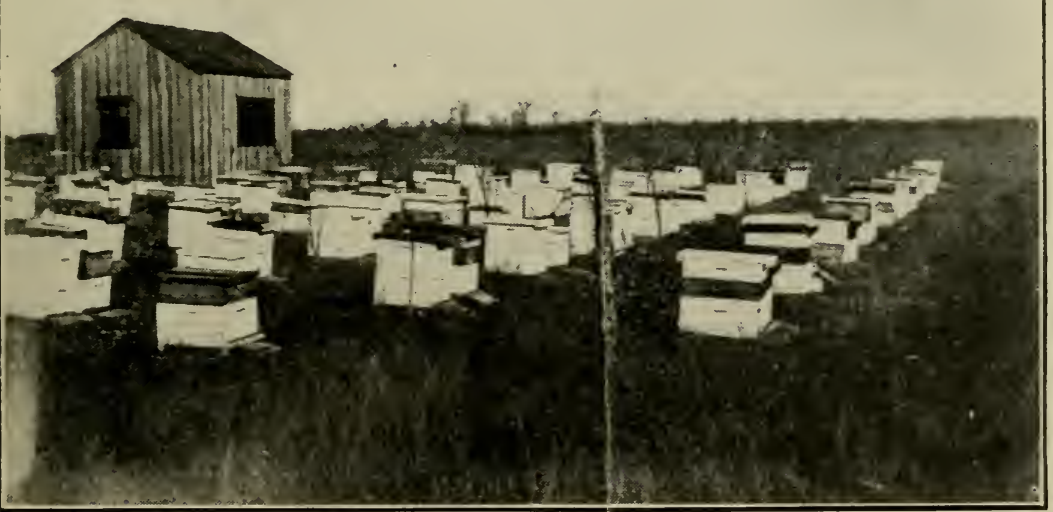

liig. 4. A modern Texas apiary developed from two box hives. 
prevention, if he tries to operate his bees without sufficient supers and hive bodies. Penurious beekeepers who try to run the season through with only two supers, juggling these between the hives and the honey house for filling and emptying, are in the class with the beekeeper who puts on one super and who takes it off only in the "full moon in June." Sufficient equipment is absolutely essential. Better run fewer colonies with ample equipment, than so many with a shortage of things essential to good beekeeping practice.

\section{Conserving the Bees.}

The beekeeper's "New Year" begins with the cessation of the honey flow for the season. His efforts from then on gauge far more than is frequently credited, the success he may have another season. Toward the end of the honey flow is the best time to requeen colonies, when the period of broodlessness coincident with requeening does not interfere with the strength of the colony immediately before a honey flow. This is also a time to discourage too much brood rearing, when there is nothing ahead to demand more bees. The introduction of young queens insures brood later, in the fall, when young bees are so essential to produce a strong colony to live through the period of rest, whether winter temperatures are low or not. This is also the period for removing supers and preparing the bee yard for another season, as well as preparing the honey crop for the market. Cooperative marketing associations will soon enable the beekeeper to sell his crop at a fair price without the losses incident to poor salesmanship so frequent in the beekeeping past.

\section{Wintering the Bees.}

Whether the beekeeper be in a land where snows fall and temperatures drop low in winter, or in a land of sunshine, winter is the time for the conservation of the bees. At this time good beekeeping makes definite plans for the next spring. Ample stores for winter and the succeeding spring, until natural honey is available, are essential. Space for the bees to heat and care 
for in winter should be reduced to a minimum. Remember that a temperature of $57^{\circ} \mathrm{F}$., requires work on the part of the bees to prevent a lower temperature in their cluster. The more of this work they do, the more the colony loses in numbers and in the vitality of its individuals. Have good hives, tight, waterproof covers, reduced entrances, and protection by fence or trees, against the prevailing winds of winter days. If your part of the South is where snow falls and temperatures drop low, your bees might profit by being packed. Send for the government's free bulletin on "Wintering Bees Outdoors."

\section{The Theory and Practice.}

The theories of successful beekeeping have been stated in the first paragraph of this chapter. Learn them well first. This will enable you to separate the chaff from the wheat in what you read, or what you are told by beekeepers who may not be as well posted as they believe. Given the mastered theory, the practice will not only become easy, but will prove the most interesting study you ever attempted, if you are destined to be a beekeeper. If you are not, give up beekeeping right now. There are already too many men and women masquerading under the title "beekeeper.'

Subscribe for bee papers and get one or two of the better bee books, which give the results of practice, and not theory alone. Attend the short courses for beekeepers and witness demonstrations in handling bees made by the bee culture extension men. If there are no such meetings near you, take the initiative and arrange for some. Begin to put your theories into practice modestly, search your practices for a confession of fault as you go. Above all, remain open-minded about your beekeeping methods and you will be sure to succeed. In any event, invest modestly at first and make the bees keep you. 



\section{CHAPTER III}

\section{Apparatus of the South.}

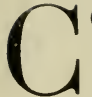

ONTRARY to what might be expected, the needs of the beekeeper in the South are quite similar to the needs of a beekeeper in the North. There is no style of hive which has proved better for all conditions in the South than the standard ten-frame hive sold by all manufacturers. If there is any pointed difference in the needs of the South so far as a hive is concerned, it is that the hive should not be too small. The author was rather surprised to find at first that the ten-frame hive was perhaps more widely distributed and used in the South than elsewhere in the country. Probably the reason for this is because extracted honey is almost universally produced throughout the South among commercial honey producers. This is probably due to the difference in intensity in the nectar flows, especially in the more tropical South, where longer, lighter secretions of nectar are common. However, there are many locations in the South where comb honey is produced and many where it ought to be produced, in view of the fact that comb honey always brings an average higher price in normal times, than extracted honey. Even for comb honey there is no necessity for reducing the size of the brood chamber for southern beekeeping.

Another factor which has probably tended to gradually increase the use of the large brood chamber in the South, is that in most cases more honey is consumed by a colony of bees during southern winters than would be the case, say in Illinois. This is not due to cold weather, but on the contrary, to the warmer winter, during a great part of which some brood rearing may be carried on and the stores thus be rapidly depleted. There are many locations in the South where the honey contained in one ten-frame brood chamber in the fall will seldom sustain a colony until the next year's surplus nectar flows. This is true of the 
author's apiaries in the vicinity of Dallas, Texas, and in parts of Florida, where even two ten-frame bodies for winter at times fail to supply sufficient honey. On the Appalachicola river in Florida, for instance, it is often necessary to store honey for brood use the next year. Many southern beekeepers prefer to store away the sealed combs of honey rather than to leave too much honey on the hive. If left where the bees have access to it, they seem to get that "Millions at Our House" feeling described by G. M. Doolittle, and proceed to turn it into brood out of season. This is inadvisable in most parts of Dixie, since the sustaining honey flows often come many weeks after the beginning of brood rearing is possible. Consequently the bees might frequently starve if left to their own 1esources.

\section{A Southern Hive.}

There have been numerous attempts to invent a hive which would exactly fulfill southern needs. One might expect to find the long idea hives of Poppleton throughout central Florida where he lived in late years, and the Danzenbaker hive popular throughout the vicinity of Richmond, Virginia, for a similar reason. This is not true. The opinion of good beckeepers, like the choice of the majority in American political life, is one of the safest guides to value. No man has succeeded in making up a strictly "southern" hive.

The tendency throughout the South, whether the beekeeper runs his bees for comb or extracted honey, has most certainly been toward a deeper hive. With the standard size hive taking Hoffman frames popular throughout Dixie, this deepening has often been accomplished by the addition of another brood chamber, or by the use of a shallow extracting brood super above or below the brood chamber. Although this nears the idea intended in the use of the once popular sectional hive in parts of Texas, the author saw but comparatively few of the sectional hives there. The tendency, as elsewhere, was to add another full brood chamber. Whether or not a deeper frame, such as used by Dadant, to combine this increased brood room all in one body will be popular in the South or elsewhere, is problematical. It is the 
opinion of the author that this style of hive will be adopted in the North long before the South accepts it, because of the winter stores problem. The need of greater brood room later in the spring is mentioned by J. J. Wilder of Waycross, Georgia, in the "Dixie Beekeeper," page twenty-two, April, 1919. He advocates the use of a nine-frame hive and the addition of a shallow extracting super later in spring. Mr. Wilder's bees in the south of Georgia are run both for comb and extracted honey.

\section{The Box Hive.}

While census figures show that there are more colonies of bees in the South than in the North and West, this number is appreciably increased by the number of box hives which are found

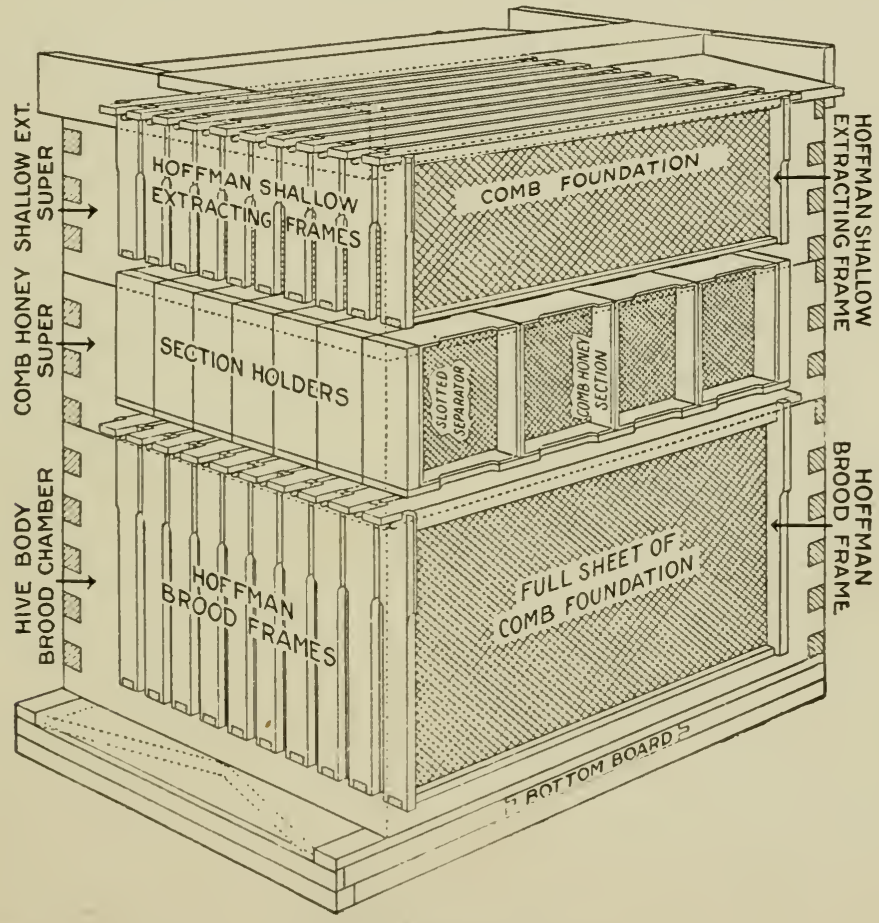

Fig. 5. A modern hive. 
throughout Dixieland. It has been the privilege of the writer to travel in the Middle West, and it is known that there are many box hives in that region too. However, in the many portions of the various southern states where there are practically no commercial honey producers, the box hives far exceed the number of standard hives. However, this is probably the case in any locality where commercial honey producers are less in number. In most parts of the South, box hives containing bees are valued as highly for purposes of sale, as are hives of modern style. This is due to the fact that there may seldom have been anyone locally who has personally advocated the real advantages of the modern hive whose recommendation was valued. Southern beekeepers are just as progressive as any other beekeepers, where opportunity is shown them to make a change for the better. The work of the federal and state extension service has offered the best medium of spreading this information up to date. It will probably always continue to bear a strong relation to the progress of beekeeping in the South.

\section{Making a Start.}

To the beginner in beekeeping anywhere in the South, there is little to be taken into consideration in choosing a hive, other than there is elsewhere in the country. Probably a safe choice for the South as a whole is the ten-frame "standard" hive, whether for the production of comb or extracted honey. It is necessary to have one hive for each colony of bees you wish to keep. The bees may be gotten by purchasing swarms, transferring bees from box hives, or log gums, or may be bought as pound packages of bees or nuclei from reliable breeders in the South. Nuclei are one or more frames of brood, honey, and bees, with which comes a queen. One then has the nucleus of a colony, and this may be put into a hive, and under favorable circumstances, will soon increase in size to a full-fledged colony. Pound packages are one or more pounds of bees, net weight, without combs, which arrive accompanied by a queen bee, and which may be put into the hive which has been prepared for them. 
This book is not intended as a manual of beekeeping, but only to differentiate southern beckeeping conditions from those of the North. Every beginner of beekeeping should purchase one or more of the standard bee books, send for all the free bulletins issued by the United States Department of Agriculture on beekeeping, and discuss with local beekeepers the best methods of making a start. 



\section{CHAPTER IV}

\section{Making a Start.}

T T IS necessary before beginning to keep bees to become as familiar with the care and habits of the honey bee as is possible. The more one knows about bees, the more certain one is to succeed. In every line of work, it is the specialist, who is best acquainted with his business, who reaps a harvest where others may fail. This is particularly true of bee culture.

One may learn the essentials of bee culture from a study of bee books. One must grasp the theory before beginning to keep bees, since it is necessary to know why certain methods are used in the production of honey, if their application is to be successful. An excellent way to gain much first hand knowledge, is to visit the yard of a neighbor beekeeper, and put on a bee veil, and go with him through a day's work in the apiary. It is well, however, since not all beekeepers are good beekeepers, to make a study of the work by studying bee culture before undertaking such an expedition. If you know when the beekeeper is right and wrong in his speculations regarding what happens in the hive, in case he doesn't really know, you will be able to avoid absorbing a lot of bee lore which you may have to unlearn.

The beginner will learn much more from handling bees than any other way, and first hand information is easiest learned. It is not necessary to learn a great mass of statistical and rule of thumb plans, to be a successful beekeeper. Practical beekeeping requires a simple knowledge of a few fundamental reasoris as to why bees increase and protect themselves against their natural situations. When this is known, practical beekeeping becomes applied bee behavior, or learning how to shape the work of the bees naturally toward your own ends. When you have fully grasped these fundamentals, you will know more real beekeeping than many beekeepers. 


\section{Start in Spring.}

The best time to start with bees is in the Spring of the year. Then the bees have the full season to build up in, to prepare themselves against the rigors of cold weather, and to return to you something for the labors of caring for them.

It is impossible to fully guide the beginner in these columns, as the space is limited. Secure from the United States Bee Culture Laboratory, Department of Agriculture, Washington, D. C., one of their free bulletins on bees and learn to recognize the different parts of a hive and the hive inmates. Study the diagram at the beginning of this chapter. If one wishes to invest in a bee book, all right. The trouble with many bee books is that they give too many different plans for the same work and go into such varied details that the beginner is lost in the maze and knows not where to start. The government bulletins make excellent text books, since they treat of but one topic at a time. By all means one should subscribe to one or more of the bee journals, since this tends to keep one flush with bee lore, and abreast of the times on beekeeping topics and methods. Never make the mistake of buying a lot of bees before you have learned the essentials of beekeeping. Failure is as certain as death in that case.

\section{Beginner's Needs Are Simple.}

The needs of a beginner are rather simple, depending largely on the scale which marks the beginning. No beginner should attempt to handle bees without a bee veil, which protects the face from stings. The more timid may also buy bee gloves to protect the hands. A smoker is an absolute necessity in every apiary, be you professional or beginner. Bees are smoked before handling, by driving a puff or two of smoke from rags or waste, into the hive entrance. When the cover is removed, a few more puffs to the tops of the frames follow. This makes the bees rush to fill themselves with honey and to forget the intruder, when they may be handled without stings, if care is used. Every beekeeper gets stung sometimes. Careful beekeepers seldom get 


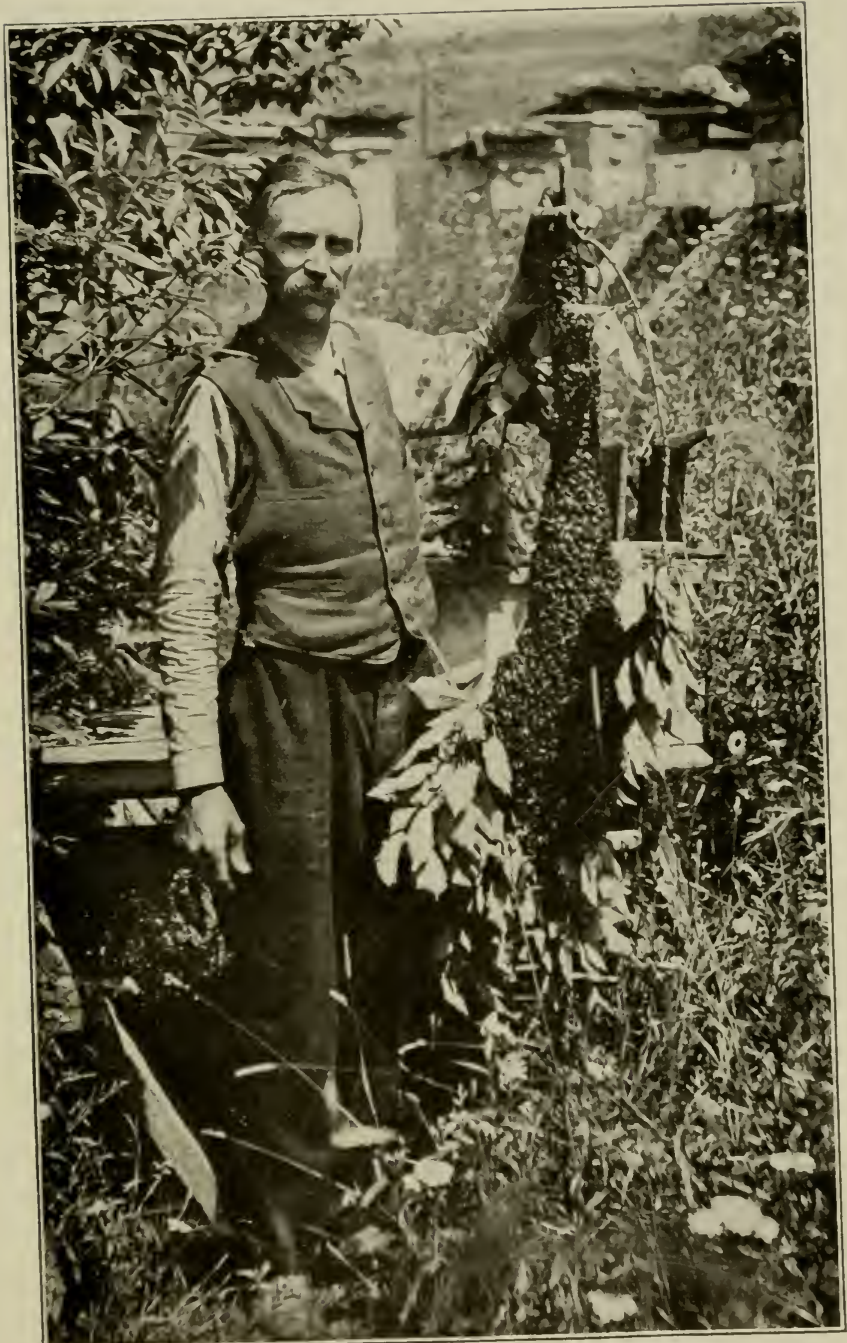

Fig, б. A Virginia swarm. 
stung. Your gentleness and actions with the bees largely determine their treatment of you. A bee brush, hive tool and other articles are useful. Get a supply catalog and study its pages. There is a wealth of information in the pages of a good supply dealer's catalog. You will find there why the various appliances are used, and much of the "how" of their application.

If swarms, nuclei, or packages of bees are bought, the hives must first be purchased, set up, and made ready for the bees. Delays of shipment make it imperative that the supplies be ordered long before they are needed for the bees. Waiting for hives with the bees on hand means their certain loss to you. In choosing hives, it is well to avoid fads. The ten-frame so-called "standard" hive is the standard of the bee world of today. This hive is a good one to choose. Do not choose more than one style or size of hive. Inability to interchange parts of hives is a nuisance in the apiary. The value of well made goods cannot be overestimated, and it is well worth while to pay a price which will bring you materials to last a lifetime, rather than flimsy, shoddy goods at a lower price.

\section{Comb or Extracted Honey?}

Every beginner is confronted with the problem of whether or not to begin with comb honey or extracted ("strained") honey production. Here are some simple rules for guidance. What does your grocer sell best? He is most willing to buy that. Find out. Then learn what your principal nectar secreting plants are, and whether or not they yield in short, intense flows, or give nectar over long, slow periods. Short, sharp flows of light colored nectar are excellent for section honey. Slower flows, and dark colored nectar, are best for extracted honey. The adoption of either should be governed also by what you can sell best in your locality. Pick out your hive supers to correspond. Most beginners in the past have begun with comb honey, because the initial expense was less. Comb honey usually sells for more on the market than other styles of honey packages. However, it requires a better beekeeper to produce comb honey than 
extracted, and the choice should be largely your own. By choosing supers for your hive which are made to take either comb or extracted honey appliances, the cost is less for a later change which may appear advisable.

\section{Choosing Paraphernalia.}

After a good hive has been found, the beginner should insist on Italian or yellow bees, if it is possible to get them. They have proved in the hands of American beekeepers, to be the best from all points. They are gentler, more resistant to the bee disease European foul brood, active against the inroads of wax moths and are good workers. No beginner should fail to use full sheets of bee comb foundation in the lower part of the hives, where the bees live and rear their brood. Foundation should also be used in the surplus boxes, but the use of full sheets is not so necessary there. A study of catalogs and bulletirs will

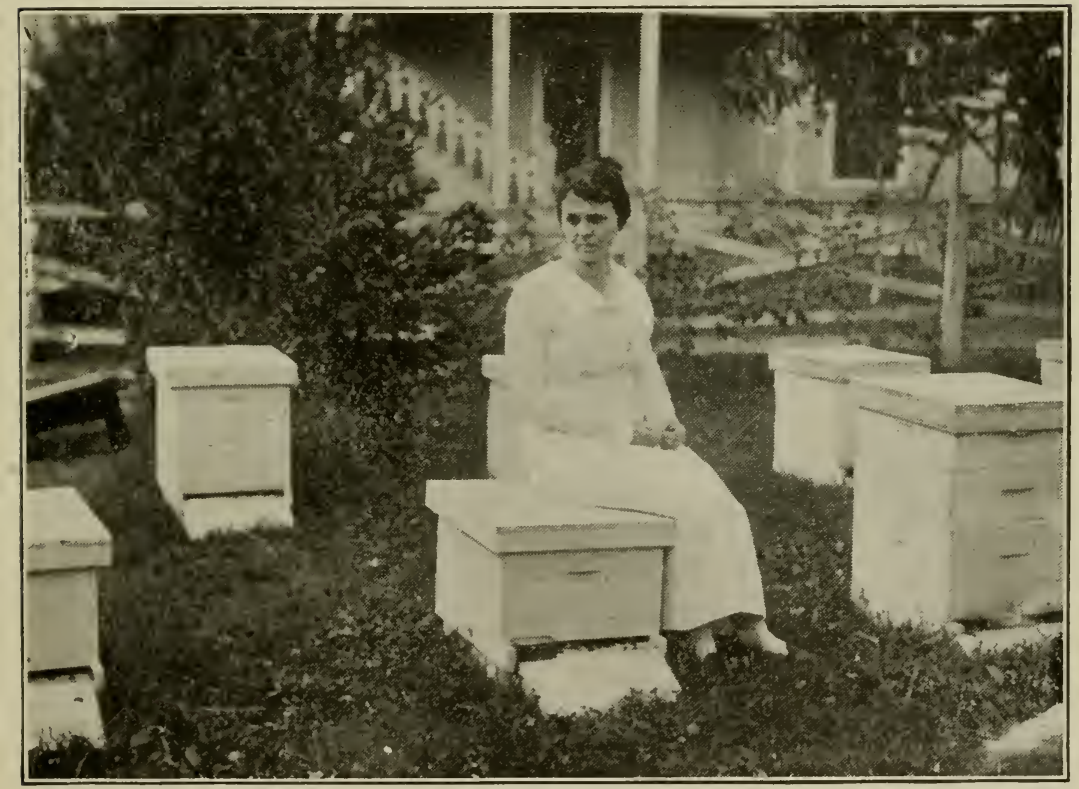

Fig. 7. Mrs. Grace Allen's backlot bees, Nashville, Tenn. 
convince you of the value of using comb foundation, even though it costs more at first.

The location of the bee yard may be determined after a study of the bulletins as to why partly shaded places, facing away from the prevailing winds and toward the sunlight, are best. The style of covers, hive stands, and other minor details are more a matter of individual choice. In every move you make toward becoming a beekeeper, find out first why you do everything, and then you will make fewer mistakes. When bees refuse to do what we think they should do under given circumstances, usually it is the beekeeper who is at fault, be he beginner or expert.

\section{A Means of Study.}

Many of the colleges of agriculture in the several states are annually giving short courses in bee culture. The federal and state departments of agriculture have several men in the field teaching beekeeping. Find out about these and take advantage of them. They are usually men who know what they are talking about, and their guidance will be valuable to you as a beginner.

If study, communion with good beekeepers, careful examination of bee behavior and applied beekeeping do not interest you, don't start beekeeping under any circumstances. You are destined to fail without them. The beekeeper who doesn't care, and who will not learn is already a curse of beekeeping, keeping down honey prices, spreading bee diseases by carelessness and ignorance. It seldom pays to do anything unless you will do it well. If you do not intend to be a good beekeeper, do not venture into the field at all. That is only justice toward those you may hurt unintentionally, not to speak of your own financial loss and the eventual loss of your own self-esteem. 


\section{CHAPTER V}

\section{The Seasons in the South.}

$\mathrm{P}$

RACTICAL bee culture everywhere is largely an organized system of beekeeping manipulations. It should be also the study of bee behavior. Since the condition of the bees influences largely what the beekeeper must do at the time, bee culture in the South differs only slightly from the same science in other parts of the country. Any difference in bee culture in the South, from the same science elsewhere, is only because of the difference in the exact time when most of the common manipulations of bee culture must be attended to. The more carefully one studies bee culture methods in vogue among

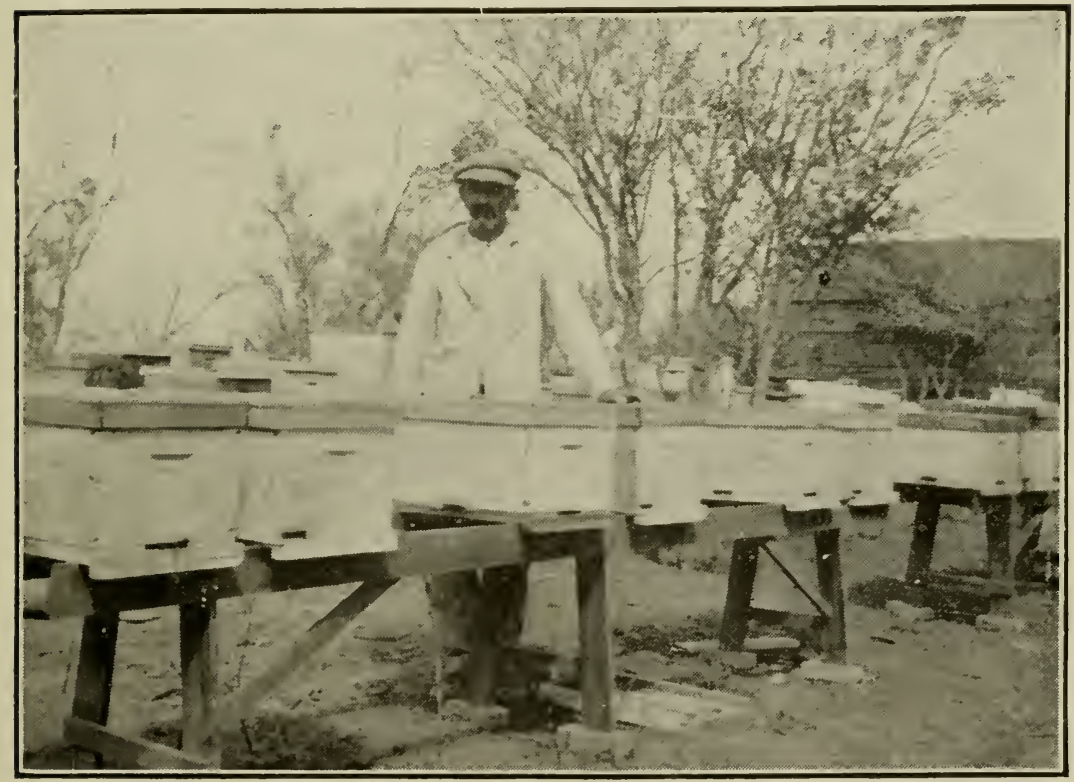

Fig. 8. It is necessary to guard against high water in many desirable locations 
better beekeepers in Dixie, the more one is impressed with the fact that methods practiced there are common in their fundamentals. There appears to be no such entirely different system of bee culture in the South, as beekeepers in other parts of the country might suppose. The prime differences, as they appear to the author, result from the prolonged seasons when manipulations common at certain times only in the North, may be common several times during the season in the South. If you are a good beekeeper in the North, you can be a good beckeeper in the South, providing you pay attention to the difference in honey sources, and the influence of these upon the bees.

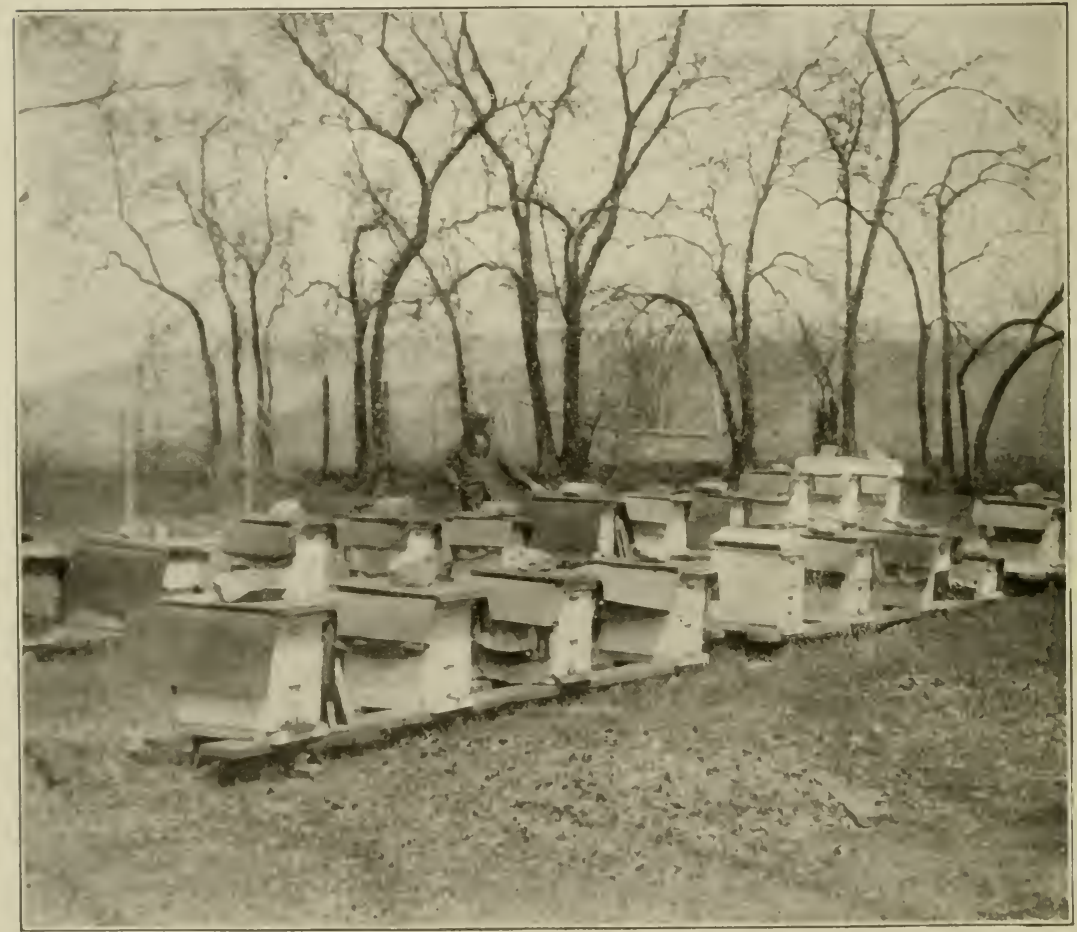

Fig. 9. Apiary of P. J. Thullen in Alabama. 


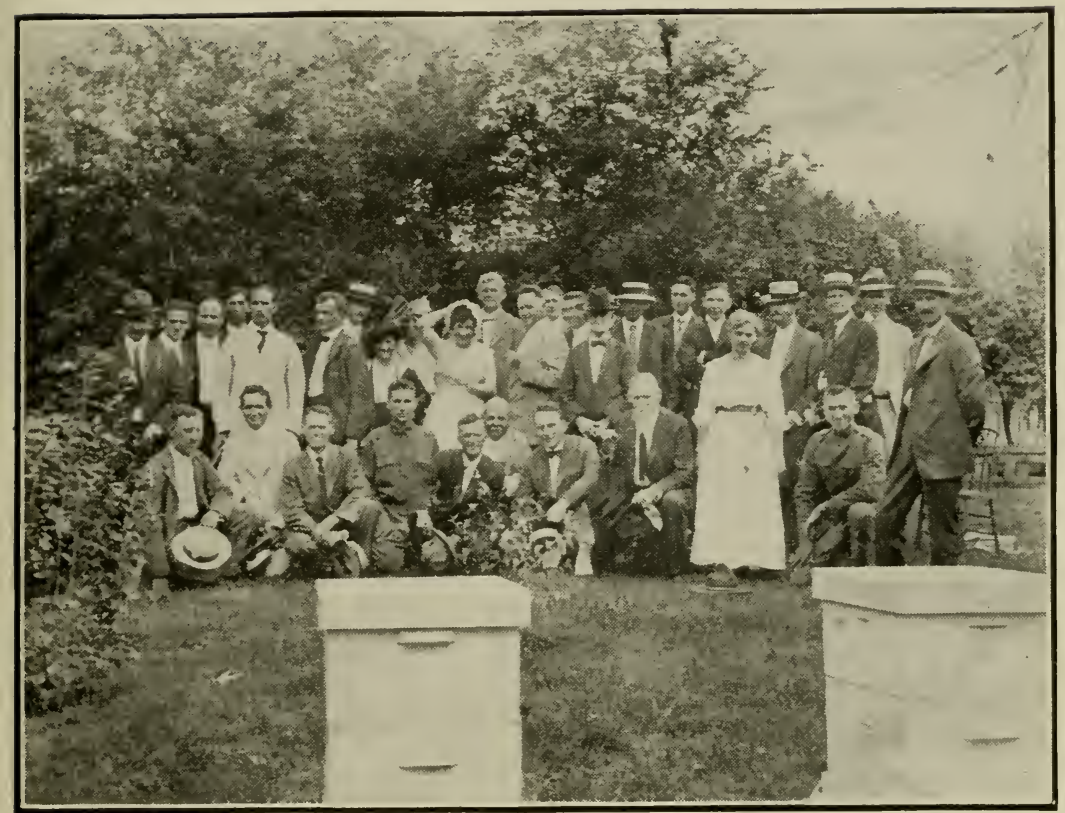

Fig. 10. A summer meeting of Tennessee beekeepers.

\section{A Primary Difference.}

In the North the beekeeping calendar may be readily divided into two parts, the season of preparation, and the season of honey flow. In the South, speaking of the South as a whole, this is not quite so feasible. A primary difference is in the much shorter season of inactivity and the much longer season during which bees rear brood. An additional important point in connection with the season during which bees may rear brood follows: Bees in parts of the South often begin rearing brood weeks before the main honey flow. They may swarm, become impoverished for lack of stores and bring about unusual conditions at several seasons of the year, which the beekeeper of the North is seldom accustomed to meet but once during the season. 
Many beekeepers have been forced to cope with such a situation as a honey dearth for a week or more between two honey flows. This situation may face a beckeeper in certain parts of the South, half a dozen times in a season. Then there are some few locations in the. South where there is seldom ever a honey flow in spring, sufficient to more than sustain the bees. Naturally the bees are slow to build up in spring and may often face starvation unexpectedly, with the speedy use of their honey for brood. There is one offset to these situations. Honey flows in the South are usually longer than in the clover, buckwheat or alfalfa regions of this country. Otherwise bees might seldom get in shape in time for a honey flow in some of these southern localities. To anyone who has tried to build up weak colonies, with sugar stores alone when all colonies in the yard were weak, and when but little natural pollen was available, - that person knows what the beekeeper faces in such "late" locations of the South. However, in many sections the reverse is true. The problems become, in most cases, to find plans to prevont too rapid building up and to prevent excessive swarming. That remains largely a problem, except for the shippers of combless packages or the man who wants increase.

\section{The "High" Spots.}

Such a type of honey flows, which might be dubbed "languid" is not without exception. There are a few locations in the South where the entire surplus honey crop of the locality is harvested in a few days. The Appalachicola River region in Florida is one of these. Here titi furnishes some stimulation. Black and white tupelo follow immeriately in February and March and furnish the total surplus crop, blooming only a few weeks altogether. To see bees working tupelo in this region is an inspiration. They go "honcy crazy." So great is the secretion of nectar that but little attention has been paid to overstocking any tupelo location while the flow is on. Rather the beekeepers there have tried to estimate how much of the nectar goes to waste. 
Then there are other locations where there are one or more short, sharp flows and one or more longer, slower flows of nectar, during the several months of the season. In some of these, comb honey is produced during the heavy flows, and extracted honey during the lighter flows. The partridge pea region of south Georgia and north Florida is one of these locations. Together with gallberry, tupelo, and some other nectar sources, the beekeeper is enabled to run for both comb and extracted honey. This practice has proved quite sensible when the usual price of comb honey is considered.

\section{A Changing Prospect.}

There are so many different kinds of soils, honey plants, climates, and peculiar conditions found in the South as a whole,

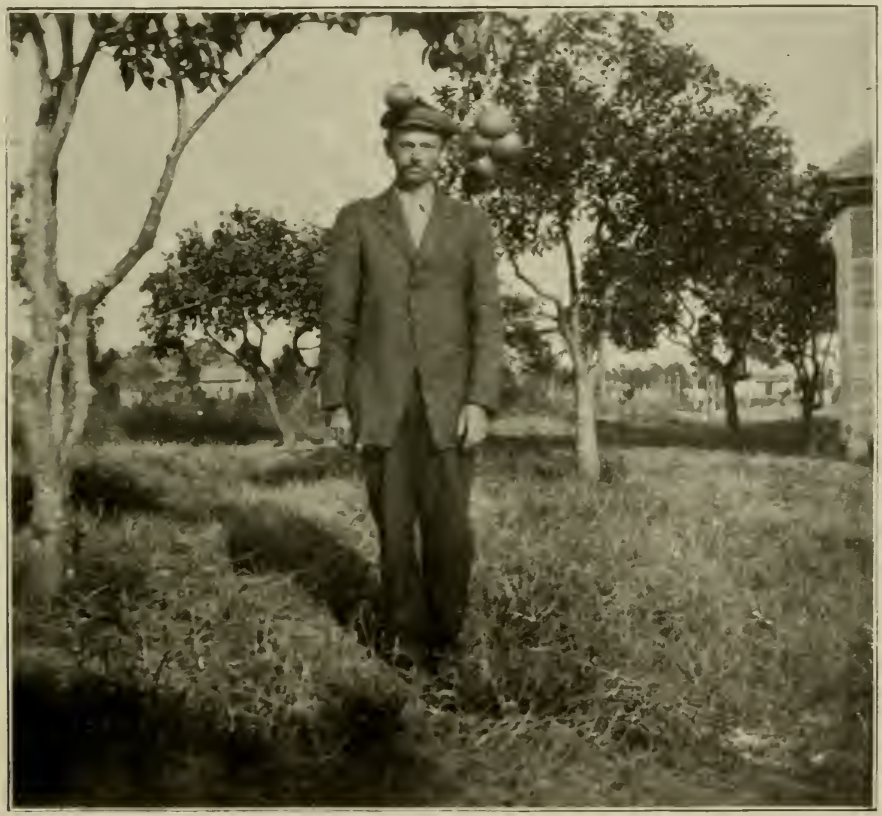

Fig. 11. J. J. Wilder of "Dixie Beekeeper." 
that it impossible to write accurately of conditions that will apply widely. These conditions necessitate different periods for the application of the common manipulations of bee culture, bring up the old explanation of "locality." But the best prac. tices do not have to vary materially. Rather their time of application varies.

Of this situation, J. J. Wilder says: "Starting at the highest point of our country, along the Blue Ridge Mountains, and gradually sloping off down to sea level out along the great coast region, we have all kinds of climate from the most rigid to the most mild. We may have some winter problems in the most rigid sections but none elsewhere."

The statement concerning the winter problem, except as it applies from Florida to Mexico, along the gulf coast only, is open to debate. This is a question upon which but few southern beckeepers agree. There certainly can be room for improvement in the practices of wintering common in many parts of the South (see chapter on "Wintering"). The author has never been convinced that there was not some better beekeeping practice

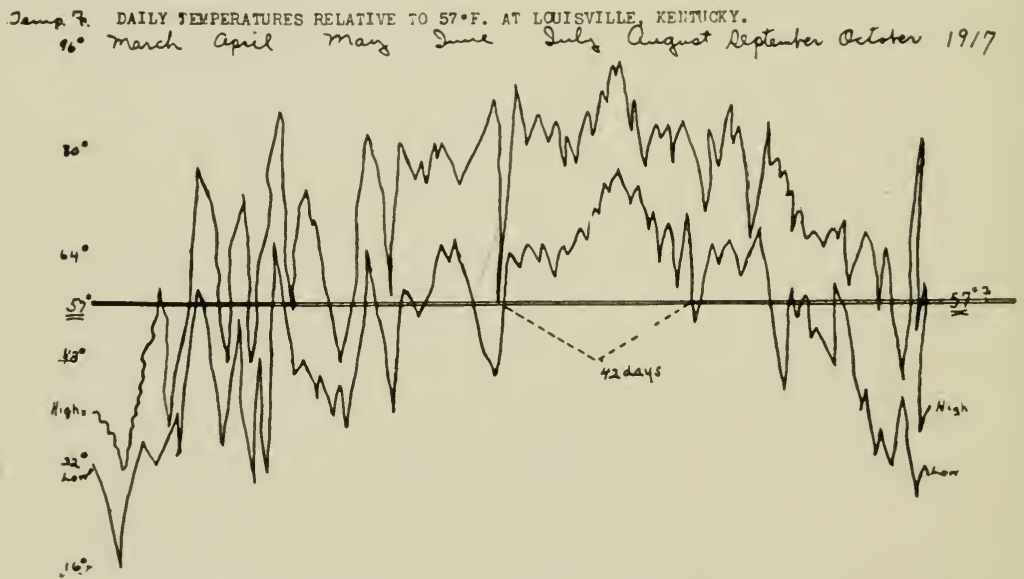

Only 43 days durlng the ent1re esaeon when at some t1me the temperature did not fall below $57 \cdot F$. Based on U.S. Neather Bureau rooorde, Courteey R.P.Diotzman, Lou1svillo.

Lowet tomperature nover above $57 \cdot \mathrm{F}$. in Jan.Feb. Nov. Doo.

Fig. 12. Daily Temperatures at Louisville, Kentucky. 


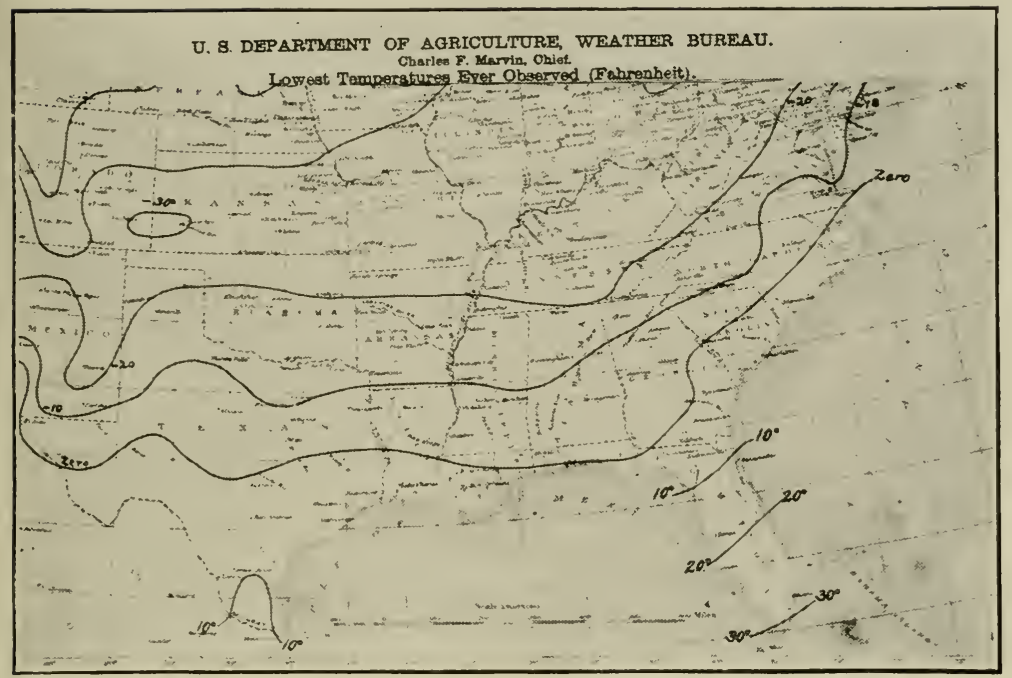

Fig. 13. Chart showing lowest temperatures.

which could be worked out in parts of the South, than to winter bees outdoors without protection and often with one or more supers on, where the snow may often be six inches deep for a week or two in winter. There is no frostless winter in the South until one goes very far south. There are few winters in the South when snow does not fall throughout West Virginia, Virginia, Kentucky, Tennessee, Arkansas and Oklahoma. The writer has seen snow near Pensacola, Florida, Shreveport, Louisiana, and in Dallas, Texas. The best beekeeping practice is the one which cares for all eventualities. Certainly there may be a wintering system worked out for the South, which will'protect in extremes, and which can be turned to additional advantage in the means. No beekeeper who is a thinker will deny that.

\section{Honey for Winter.}

There have been very few of the many localities visited by the author, where it is often necessary to feed bees in fall to provide sufficient winter stores. It is our opinion that this is one 
of the dominant differences between many bee ranges in the North and in the South. In many beekeeping localities in the South, there are good fall flows of nectar, which tend to put bees in good shape for the coming season of inactivity. Of more import, it tends to put them in good condition for the longer season of spring activity, when there may be little nectar available, even in quantities to care for brood rearing.

\section{Migration.}

In a number of localities in the South, migration is practiced with some success. However, the great migration from South to North has never proved out for southerners, any more than it has for beckeepers of the North.

One of these localities may be on any of the navigable rivers in the far South, where a good sized launch may go well up into a different type of country than that which may be found on the coast. Gus Hensler, who lives at Wewahitchka, Florida, told the author he could take bees up the Appalachicola River from his tupelo locations and locate them in the regions of southern

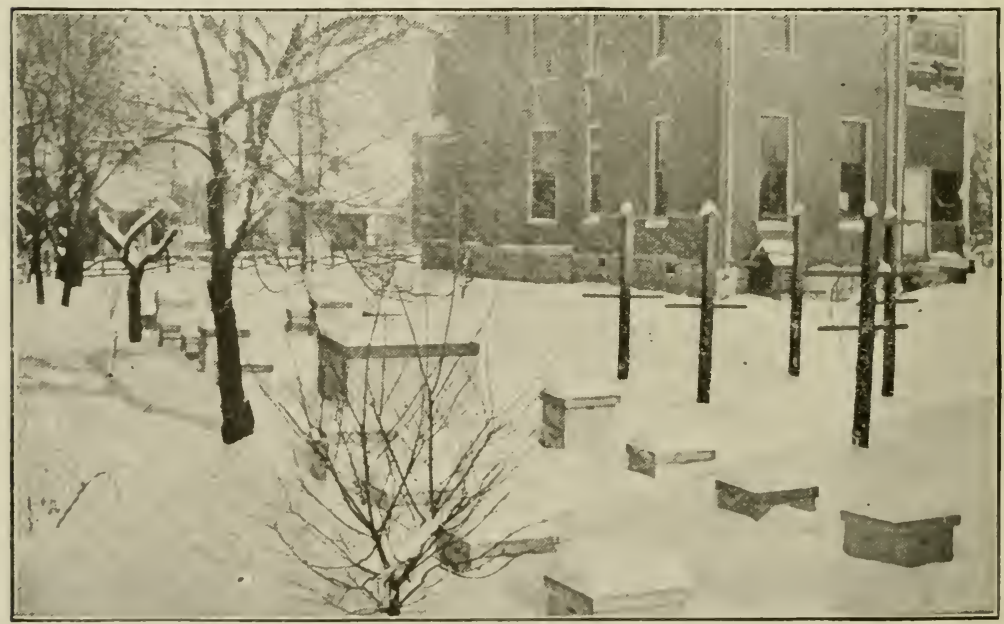

Fig. 14. A Winter Snow in Tennessee. (Photo by Grace Allen) 
Georgia and Alabama to a great advantage. By moving up there along in early fall, he could get sufficient honcy in many years, to draw out one or two sets of foundation into combs and to frequently get twenty or thirty pounds of surplus honey to the colony. The value of combs never appears so pre-eminent to the beekeeper as in such a location as on the Appalachicola River where the principal feature of getting a tupelo honey crop is to supply enough ready built combs.

Further south in Florida, on the east coast, at Miami, the author met several men who said they made a success of moving their bees down among the Keys off the coast, where they could take advantage of valuable nectar sources, such as black magrove. This also proved to be the case on the west coast in the vicinity of Ft. Myers. However, no one was met who had made a great success of moving bces on the Mississippi, the Red, the Missouri, or any of the other main water arteries of the South. Bees can undoubtedly be moved to advantage in the swamp regions in many cases. There is probably no nicer means of moving bees than on a quiet, steady launch. But it's all off when the "blows" come up suddenly. One beekeeper at Pensacola, Florida, recently lost a launch, bees, and a good share of his season's honey crop in a squall of wind which caught him unawares in Pensacola Bay. 



\section{CHAPTER VI}

\section{Wintering Bees in the South.}

7 HE wintering of bees in the South is easiest to understand. if viewed from three standpoints: namely, from 1 the standpoint of the beekeepers who live in the tropics, in the alluvial region and in the mountain sections. Viewed in this way, the problem is as different in the three belts named as it possibly could be.

For the sake of convenience in considering the winter problem of the southern beekeeper, let us divide the territory into the three belts named above, which practically coincide with the divisions cited in the chapter on honey sources. This will give us a narrow belt along the gulf coast, touching Georgia, Alabama, Mississippi and Louisiana, and widening out at either end to take in most of Florida and the great region of south Texas. In that territory the problem is not one of low temperatures, but of working out feasible methods to solve the problems of insect pests, winter stores and increase, during the very short period of inactivity on the part of the queen, which nevertheless depletes the numerical strength of the colonies. The problem there is altogether one of combating pests and supplying stores, rather than one of combating the effect of low temperatures.

Many beekeepers have complained to the writer that they had great difficulty in keeping moths out of empty combs during this period, even when these combs are left with the bees. In parts of Florida the writer has seen frames of foundation or empty combs in hives of bees taken possession of during winter months by ants and mud wasps, until in some cases the combs were ruined. In some cases this has been obviated by setting hive stands in troughs filled with oil or water, but where the mud wasps are considered, the problem is still largely to be solved. Small entrances do not always completely do away with such conditions. Frames of foundation seem to be particularly desired by 
the wasps. So far as is known to the writer, these conditions do not apply much to southwest Texas, except that in certain localities, the problem of combating the ants often necessitates tracing them to their nests and the use of the spade, fire and carbon disulphide to eradicate them. Even with these agencies, this remains a hard problem.

The problem of winter stores is pertinent at many times, both in Florida and west Texas, perhaps more so in the latter region, because of the frequent drouths, when no material natural sources of nectar may be available for months. In south Florida there is usually some source of nectar at every season, and fresh nectar may often be found in the brood combs in varying quantities at every month of the year. In Texas the problem becomes one of storing or feeding back honey, if early sources of nectar such as huajilla, catclaw, cactus and similar flowers fail. The food supply problem is not so hard to solve, however, unless the beekeeper goes through a period of drouth extending over many months, such as was the case of Texas in 1916-17.

\section{The Alluvial Regions.}

Extending north of this tropical belt well up into the foothills of the mountains in north Georgia, Alabama, Mississippi, Arkansas and Oklahoma, is a region of early activity on the part of the bees, frequently accompanied by only light flows of nectar, until several months after brood rearing may begin. Some beekeepers in this region are fortunate enough to have early surplus flows, as is usually the case in northern Louisiana, for instance. Otherwise the colonies often reach swarming strength several weeks before a source of surplus nectar may be available. Holding the numerical strength of the colony intact where no increase is desired, is then a problem indeed. Similarly the excessive use of stores to rear this brood when nectar is scarce often makes the food supply an equally important problem. Most beekeepers in this region are against any sort of winter protection as it is understood by northern beekeepers. With no means of using the bees, which would be raised here out of season in in- 
creased numbers, under northern winter protection, who shall say that they are not right?

The winter problem has been long considered from the temperature standpoint only. In this case the rule of temperature alone does not apply always. Gauged only by temperatures, the packing of bees in winter cases would be proper in most parts of this belt. Note that the U. S. Weather Bureau reports that a temperature of zero has been recorded as far south as Raleigh, North Carolina, Flomaton, Alabama, Natchez, Mississippi, Natchitoches, Louisiana, Waco and El Paso, Texas.

However, the average beekeeper in this region, when heavy protection is given against his normal winter temperatures, finds his colonies at swarming strength several weeks before they would be otherwise, and too strong a number of weeks before he has available a surplus source of nectar. Consequently, heavy winter protection for this belt is a mooted question.

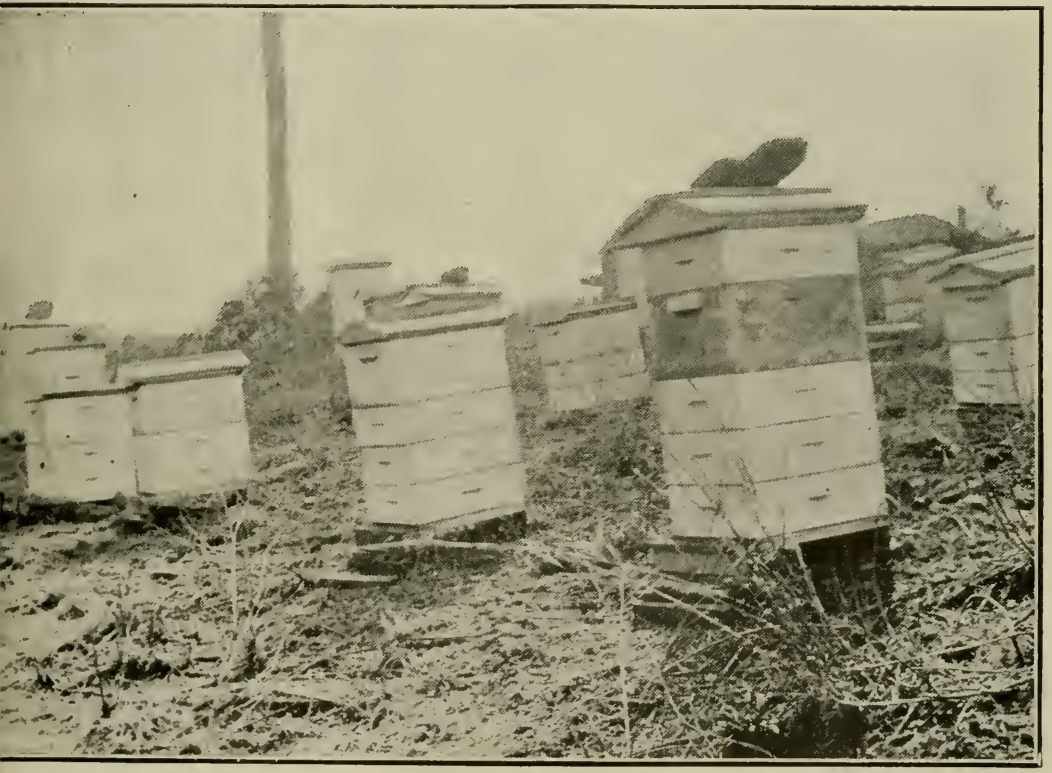

ig. 15. It is a common practice to winter the bees with supers on the hives to guard against moths. 


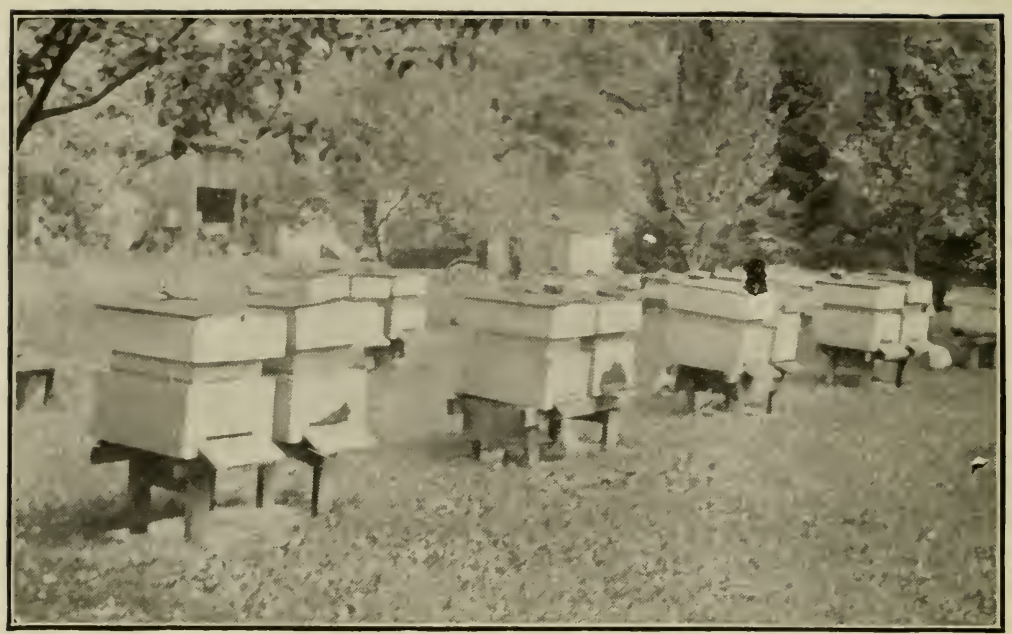

Fig. 16. A West Virginia apiary in double walled hives.

\section{The Mountain Region.}

North of this alluvial country begin the mountains of the South, and in most parts of Maryland, West Virginia, Virginia, North Carolina, Tennessee, Kentucky, Arkansas, and Oklahoma, the proposition of heavier winter protection deserves the serious attention of the beekeepers. It has been customary for beekeepers of Kentucky, Tennessee, and Oklahoma to assert that such a practice was wholly unnecessary. The truth of the proposition will never be known until the practice has been tried out on many colonies for a period of years and the results in honey production compared with colonies not so protected. Such an experiment is now being carried on in a small way by Mrs. Armstrong (Grace) Allen at Nash ville, Tennessee, with results so far not particularly favorable to heavy packing. However the test is far from complete, and the best feature of Mrs. Allen's work is her openmindedness on the proposition. The winters and the honey plants in much of this section approximate in source, temperatures and seasons, the white clover belt of the North, so that it would seem that some packing might pay. It is certain from the 
census, from reports of extension men and from other reliable sources, that winter losses of this region are frequently appalling. In the portion of this region embraced in the Appalachian mountains, spring losses are frequently enormous, due to European foulbrood ravages. However, this disease should be considered as an effect and not a cause in this case, since we know weak colonies are more susceptible and less resistant to European foulbrood than strong colonies. With great losses in numerical strength certain among many of the colonies of this region which usually are not adequately protected, European foulbrood finds a ready and fertile area for its deadly work.

Temperatures here are good indicators of the need of protection, since swarming time and honey flows approximate those of the white clover belt. The beekeeper here has a different problem than in the alluvial regions, where late flows and early

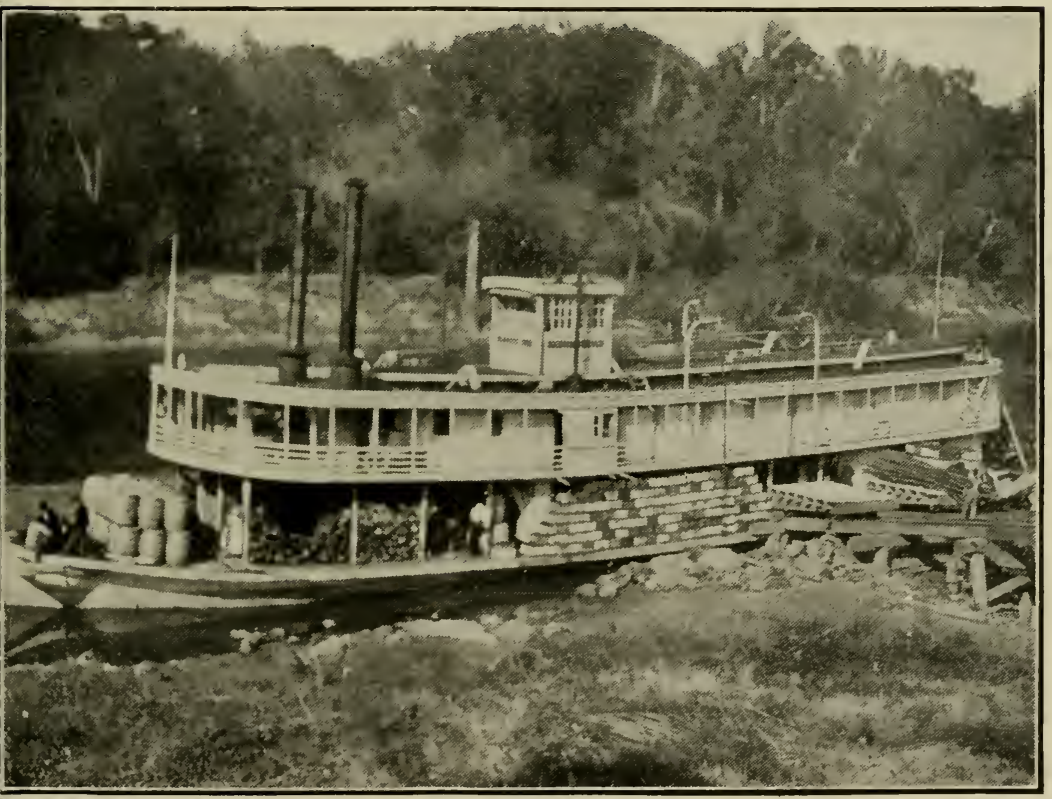

1 ig. 17. By rail and boat to Florida (F. IV. Sommerfield, Ohio). 
swarming are common. An instance of temperatures in the relation to $57^{\circ} \mathrm{F}$, the critical temperature at which bees have to begin clustering in the hive to continue heat and life, was brought out at a meeting of the Kentucky State Beekeepers Association at Lexington. The association president, Hon. Richard Priest Dietzman, showed a chart taken from the U. S. Weather Bureau records, for 1917 at Louisville. There were in 1917 but sixty-nine consecutive days during which the temperature did not at some time go below $57^{\circ} \mathrm{F}$. The value of adequate protection in such a locality is evident. (See Page 40.)

\section{What Is Protection?}

Adequate winter protection need not mean in all southern locations the use of heary packing. It always means first the several other necessities, which are too often considered to be minor. Of prime importance is a vigorous queen to insure many young bees in the hive in the fall. Next is the supply of honey, which should be adequate to keep the colony in seasonable condition from the end of the honey flow one year to the beginning of the honey flow the next, whether or not all of it is left on the hive in the fall.

Next is the hive. Too many leaky covers, loose bottom boards, hives set on the cold ground and similar faults are frequent among our fraternity. Too many supers should not be left on the hive, even in the South. Why heat the "spare rooms" when there are no "guests?" The location of the hives in winter in relation to moisture and wind protection is important, as is the use of a small entrance.

When all these things have first been supplied, the need of packing is not great, in parts of the South. Too many beekeepers do not supply them. Even packing will not remedy all mistakes on the part of the beakeeper. Constant attention to little details leads to beekeeping success.

\section{Sources of Winter Supplies.}

This feature of successful wintering in the North is not so pertinent a problem in the South. With a greater flow of honey 
dew and similar poor winter foods available for bees in many parts of the South, this is providentially offset by the fact that there are usually more frequent periods when the bees may fly during the winter. In parts of the South where cane grinding goes on, great quantities of cane juice are often appropriated by the bees, but without serious effects in most cases, because of the much shorter period of winter confinement in the hive.

In the regions of Kentucky, West Virginia, Virginia and Maryland, there are areas where asters are found flowering in the fall, in vast beds on the hillsides. There is as yet but little evidence that the winter losses of this territory may be attributed solely to aster honey for winter stores. It is probable that aster honey makes an excellent winter food for bees in most parts of the country from the clover belt south. No trouble was ever experienced with this winter food in Illinois, Texas, or Florida, by bees owned by the writer and it is possible that the humble aster has been blamed for a lot of winter troubles really due to other causes.

\section{Successful Methods.}

To winter bees successfully in the South, especially where lower temperatures are recorded, one must know well the normal seasons and honey flows. The question of more protection than is now given bees in the South during winter is one for experiment, and this must be done in the South. Open minded beekeepers there can do a great service for beekeeping. Narrow minded beekeepers never do any good anywhere.

\section{Tests Are Best.}

E. R. Root is quoted as saying of good winter protection: "We believe this advice is as valuable for beemen of the South, even in Florida, as it is further north, especially so in November, December, January and February. In the latter two months, bees need it for the sake of early breeding, the two former for the sake of the life of the bees and the conservation of honey."

The writer does not mean to unreservedly recommend heavy winter packing for the South. But he does wish to emphasize 
the need of more winter protection in many parts of this region. The best test for the beekeeper is for him to ask himself if he is really satisfied with his present yields of honey. If not, and his methods of beekeeping practice are sound during the rest of the season, look to wintering and springing for a remedy. Experience should furnish the best means to judge. Be open minded and try out better methods of wintering. 


\section{CHAPTER VII}

\section{Combless Packages.}

$\mathrm{O}$ $\mathrm{NE}$ of the most serious problems which faces the southern beekeeper is swarm prevention, whether or not the beesare kept in modern hives. While readers will say this is just as true of the beekeeping problems elsewhere, it is especially true in the South below Tennessee and east of the Mississippi River, since in many such localities even the Heddon method of after-swarm prevention is often a failure. So are most methods of swarm prevention, for many beekeepers of this region. Because of the long brood rearing season, when bees may begin to breed up sometimes four months before the main nectar flow, and be sustained by a continual light flow of nectar, swarm prevention becomes a problem indeed. In such localities bees frequently cast a swarm and after all, store about as much honey as those which do not happen to swarm. Imagine the northern beekeeper confronted with such a problem as that. Probably this excessive swarming is one of the reasons for the great number of colonies of bees in the southern states, compared to any other region of similar area in this country. Add to this the box hive and swarming seems at first the bane of southern beekeeping.

So far as is known to the author there is no method of swarm prevention which is widely used in the South, that differs from swarm prevention methods in the North. In the Carolinas, Kentucky, Tennessee, Virginia, Arkansas, Oklahoma and north Texas, swarm prevention methods used in the North are feasible and in use by all commercial honey producers of the region named. Adequate room seems to be a paramount requisite.

In much of the area of Florida, Georgia, Alabama, Mississippi, Louisiana and south Texas, all swarm prevention methods too often fail. The writer never met a beekeeper in this region who did not face the swarm problem every year and who was not of ten, in a good year, without remedy except to take bees away from the colonies. Increase is a simple method in most parts of 


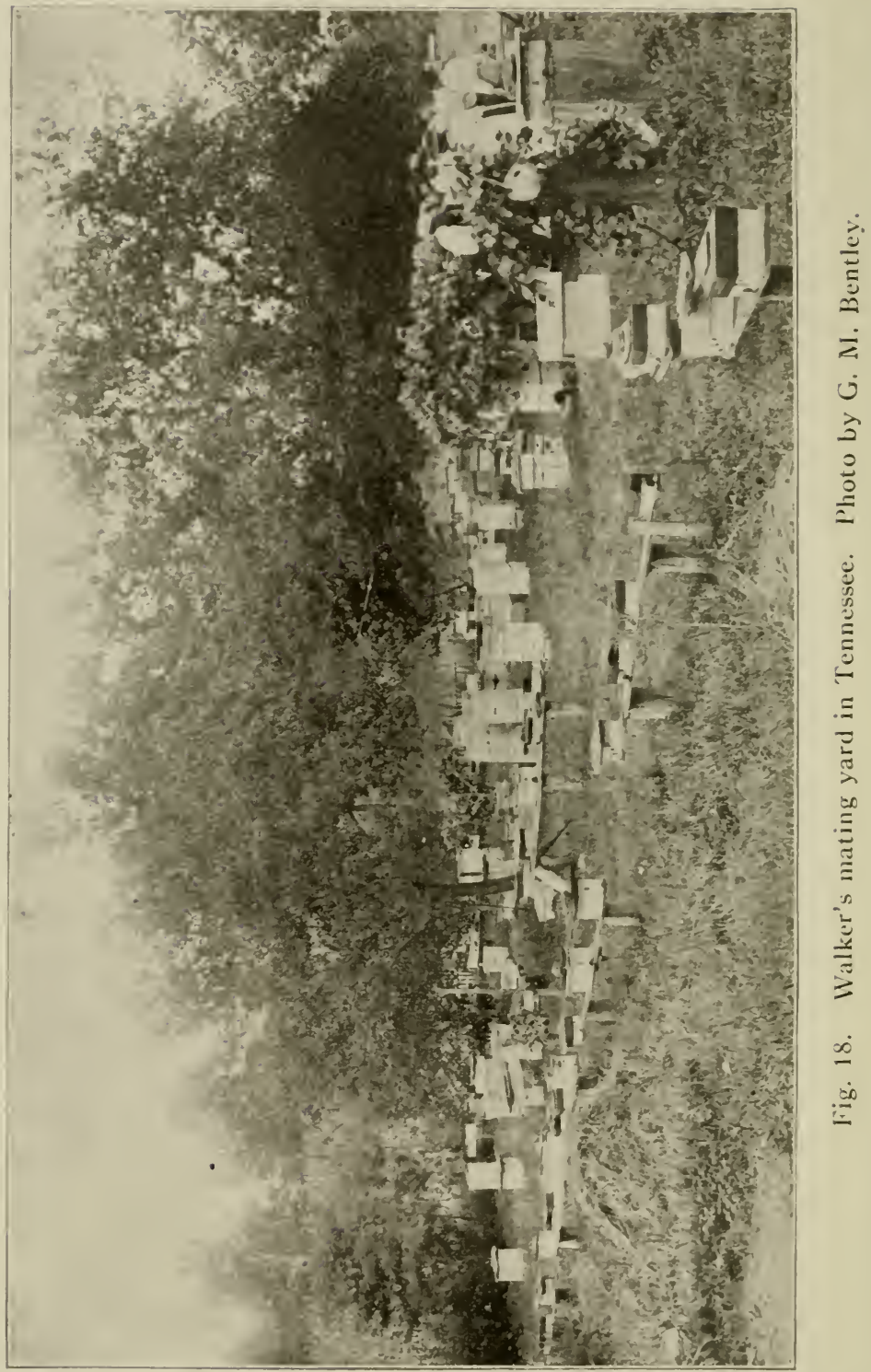


the South and the cxtent to which it could be successfully carried in the regions where the early summer honey flow is constant but light, is only to be conjectured. The direct relation of the swarm problem is probably the reason behind the popularity of bulk comb honey in Texas and probably explains the production of extracted and chunk honey rather than comb honey in much of the South. There are many regions where section honey could be successfully produced and some where comb honey is being produced extensively. A hindrance to comb honey production in this region, as seen by the author, is the large number of bees operated by most commercial honey producers. With an aggravated swarm problem, a change from extracted to comb honey in much of the South will probably await the discovery of more successful swarm prevention methods for outapiaries.

\section{Combless Packages.}

The combless package has proven a blessing to dozens of honey producers in the South. The early failures in package shipping caused many of the best known beekeepers of the North to put little faith in the future of the combless package business. First, the northerners did not know the value of taking bees from colonies in the South to prevent swarming; and second, they had little faith that shipments would ever be made successfully.

The shipping problem is rapidly being solved and has been found to be largely the fault of some who advocated the use of too small a shipping cage for combless packages, to insure reasonable success in shipping. There are dealers in the South now who ship hundreds of packages annually with little loss. T. W. Burleson, of Texas, told the author recently that he had shipped several hundred combless packages in a year without the loss of more than a dozen packages. Another fault was that some shippers in the South took orders, for bees, too far from them, to insure reasonable safety in shipping. Those who condemned combless packages when the industry first started either executcd a right about face as to their value, or have been left behind in bcekeeping progress. 


\section{Swarm Prevention by Packages.}

Southern beekeepers have always krown that in most years their bees bred up too fast and were so strong long before the main honey flow began, that to prevent swarming was an almost impossible task. This was particularly true of the region south of the Carolinas, Tennessee and Arkansas. Along came the combless package demand and behold, their problem was solved.

Such package shippers as M. C. Berry, Hayneville, and W. D. Achord, Fitzpatrick, Alabama, T. W. Burleson, Waxahatchie, Texas, as well as many Georgia, Florida, and Mississippi beekeepers, feel that combless packages have solved a problem for them, and at the same time offered a means of increasing the profit from their bee yards several fold. In the localities mentioned, bees frequently begin breeding up in January and February. The most important honey plants of south Alabama, Mississippi, Georgia, and north Florida come into bloom in these localities about May fifteenth on the average.

With breeding up well on the way by March first and two whole months ahead before surplus honey may often be expected, one can readily see the swarming problem which results. But since they are enabled to fill combless package orders for shipment to the North in latter April and May, their swarming prob-

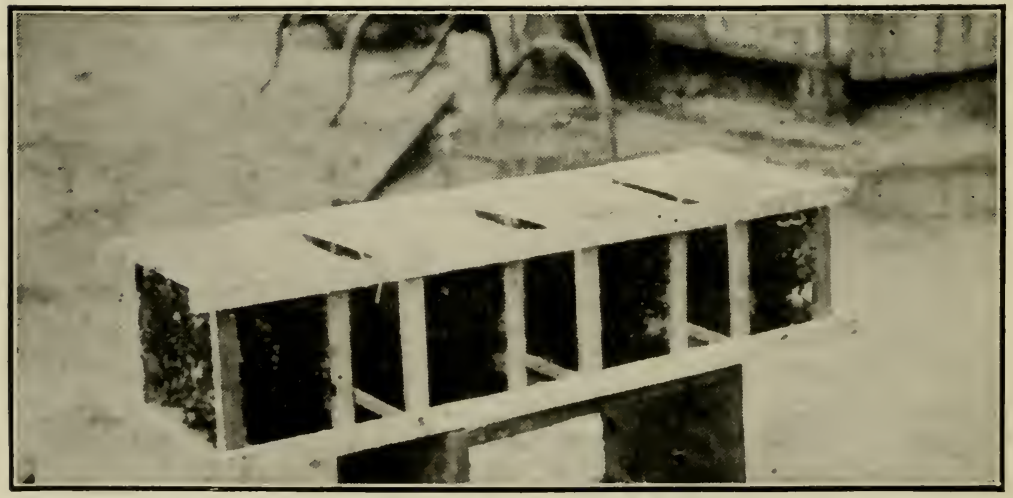

Fig. 19. Packages crated for shipment. 


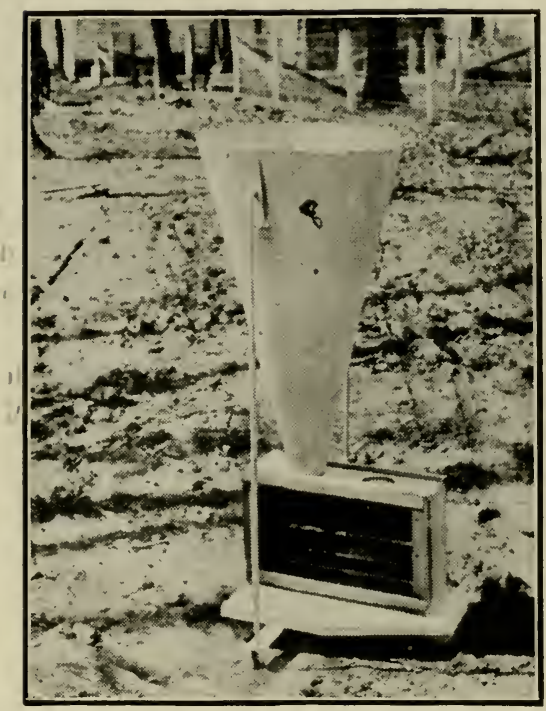

Fig. 20. A handy funnel for filling packages.

lem has disappeared. They are enabled to remove enough bees, often as many as five or more pounds from each of their strong colonies, and the hatching brood after this depletion will usually bring the colony to full field strength for the beginning of the main honey flow. By giving plenty of room at all times and watching the yards carefully, they experience little further trouble from swarming in average years. Thus, the combless package has a demand in the North and in the South, and solves a real problem at either end.

\section{Rearing Queen Bees.}

Another prominent feature of beekeeping in the South, in a belt of country wider than that from which combless packages may be shipped, is the early rearing of queen bees for the market. This belt extends up into Virginia, Kentucky, Tennessee and Arkansas, where the same long, slow nectar flow early in the year, common in many parts of the South, is ideal for the production of good queen cells and the rearing of vigorous queen bees. 


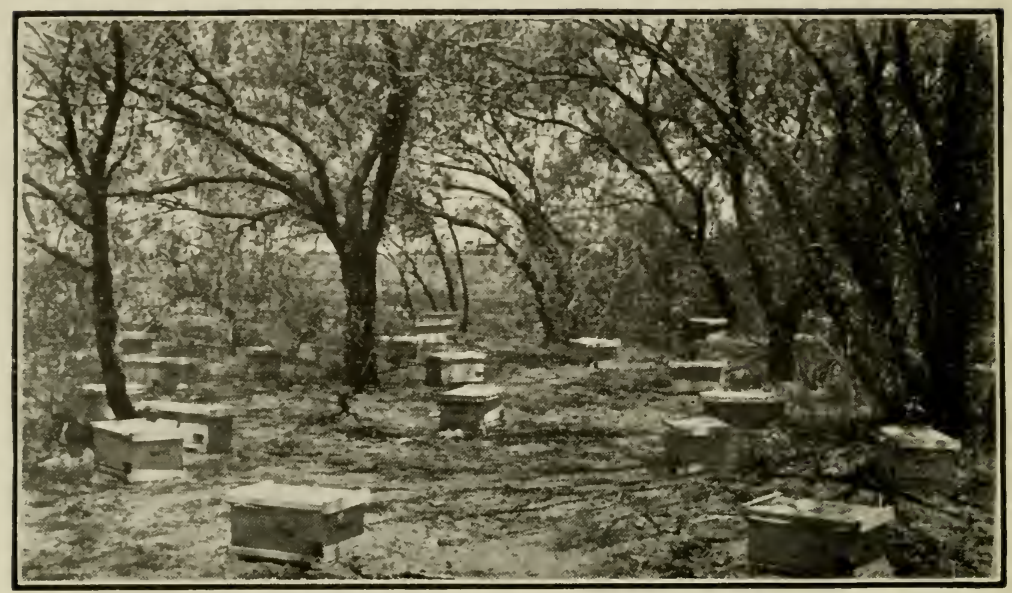

Fig. 21. Queen mating nuclei in Southwest Texas.

There are many beekeepers in this region, who devote much or all of their time to the production of queen bees, like Ben G. and John M. Davis, of Tennessee. With a large home apiary for a mating yard and several outyards from which to draw bees for mating nuclei, swarm prevention in the outyards loses its significance and an interesting and profitable business results. Probably one of the first ambitions of most beginners in beekeeping is to be a breeder of queen bees. That there are fewer beekeepers really fitted for this work than any other phase of beekeeping, is the opinion of the author. The production of good queen bees, reared in strong colonies and mated in nuclei strong enough to be worthy of the name, is a science by itself. Like the small combless package for shipping bees, one of the greatest hindrances to successful queen rearing has been the early advocacy of the "baby" nuclei. Every queen breeder whose business is growing in the South, and whose yards have been visited by the author, is leaning more strongly toward the use of larger queen mating nuclei each year. Some even have gone to the extreme of using four and five full Hoffman frame nuclei. Needless to say this trend has improved the quality of the queens. 


\section{Early Breeding Up.}

In Farmers Bulletin 975, on the Control of European Foulbrood, is written: "If it is certain that there will be no honeyflow until midsummer or later, it is not so necessary, from the standpoint of good beekeeping, to have all colonies strong so early in the year, but it is surely an exceptional locality where there is nothing for the bees to get in early summer." Applied to northern conditions this is eminently true. Applied to much of the South and the need of a use other than swarms for early hatched bees is plainly seen. At present, swarm prevention is being handled largely by shipping combless packages or in making queen mating nuclei. With others, unless they are careful beekeepers indeed, swarms are the result. Excessive swarming is probably the best reason for the average lower yield per colony of honey in the South, if the last federal census figures are to be credited.

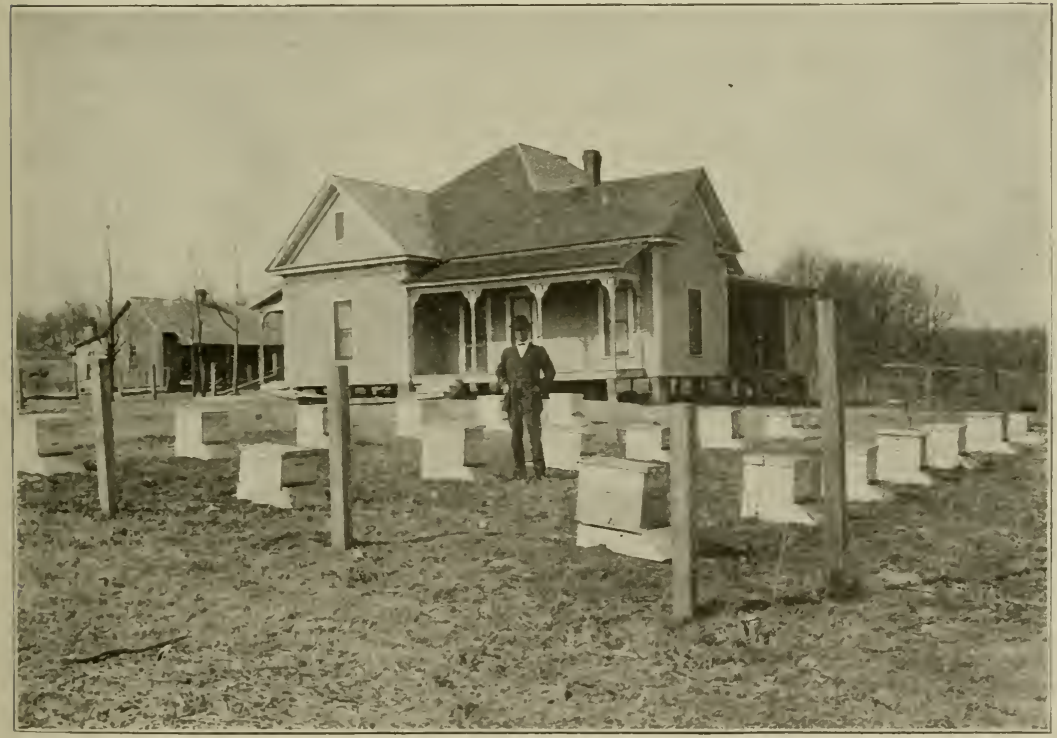

Fig. 22. Home and queen mating yard of J. L. Leath of Corinth, Mississippi. 


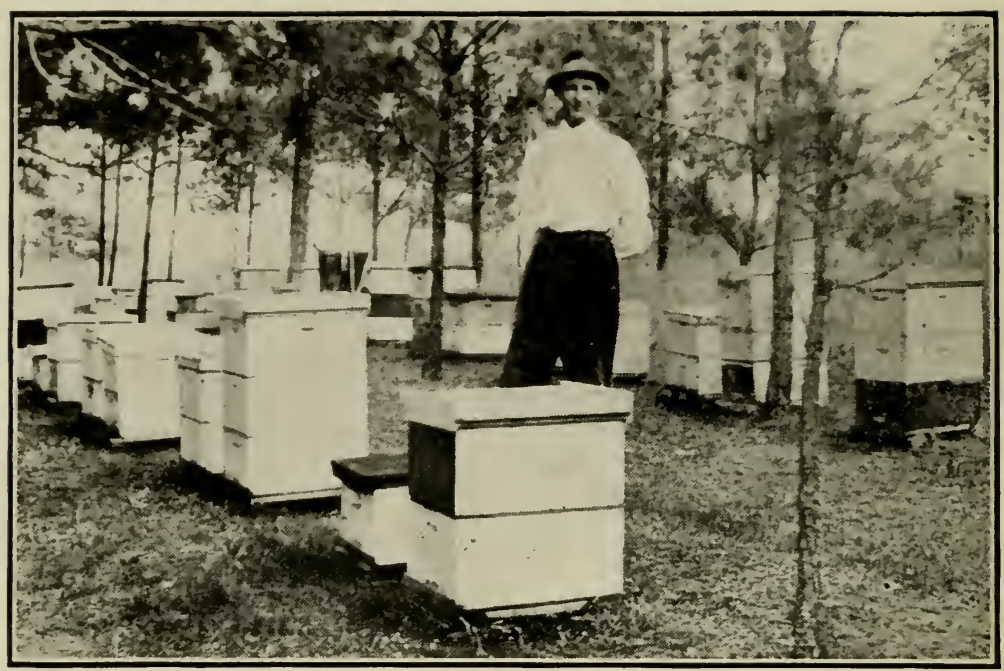

Fig. 23. One of M. C. Berry's yards for breeding package bees.

\section{A Drone Reservoir.}

The practice common among southern queen breeders to protect their supply of drones, when shortages of honey come between flows, is interesting in the application of a known bec instinct which it makes use of. Queenless bees welcome drones and seldom kill them off in any number. By keeping certain colonies in the yard permanently queenless at the approach of a dearth of honey or fall weather, drones will congregate there and be available for queen mating purposes long after they might otherwise be driven out. This is called by some beekeepers, a "drone reservoir." 


\section{CHAPTER VIII}

\section{The Tropical South.}

$7 \mathrm{HE}$ area which may be called tropical really occupies a small part of Florida, Alabama, Mississippi, Louisiana, and south Texas. It differs from other parts of the South, so far as beekecping is concerned, in many ways. Primary among these is the average higher temperatures and relative freedom from frost. The honey plants are also quite different and are in turn influenced in their nectar secretion by both the excessive rainfall and the dry weather common to that part of the "Great American Desert" which lies in southern Texas. There are regions along the coast of Alabama, Mississippi, and Louisiana, where tropical temperatures are approximated in most years. However, the chances of frost in this latter area are greater than further south. Because of the higher temperatures which prevail throughout the year in this tropical area, there is a much shorter period of inactivity and a much longer one when bees are active, than in other parts of the country. The climate of southern California approximates it.

One of the primary differences in this area, when compared to others, is the soil. The effect of soils on the secretion of nectar by honey plants has not been studied to any great extent, but it is known that soils have a considerable effect on honey plants. Throughout much of this region the type of soil is somewhat sandy. Much of tropical Florida is sandy, with occasional patches of black, loamy land, while most of southwest Texas is sandy and rocky. The fact that this land is sandy does not mean in all cases that it is infertile. The opposite is true of many parts of Florida and Texas alike, where a sufficient water supply is available for commercial plant life. Honey plants, fortunately, are not necessarily of commercial importance to other lines of agriculture, and the beekeeper here benefits thereby.

In Florida the rainfall is fairly constant and many parts of the state where tropical temperatures prevail are so near sea 


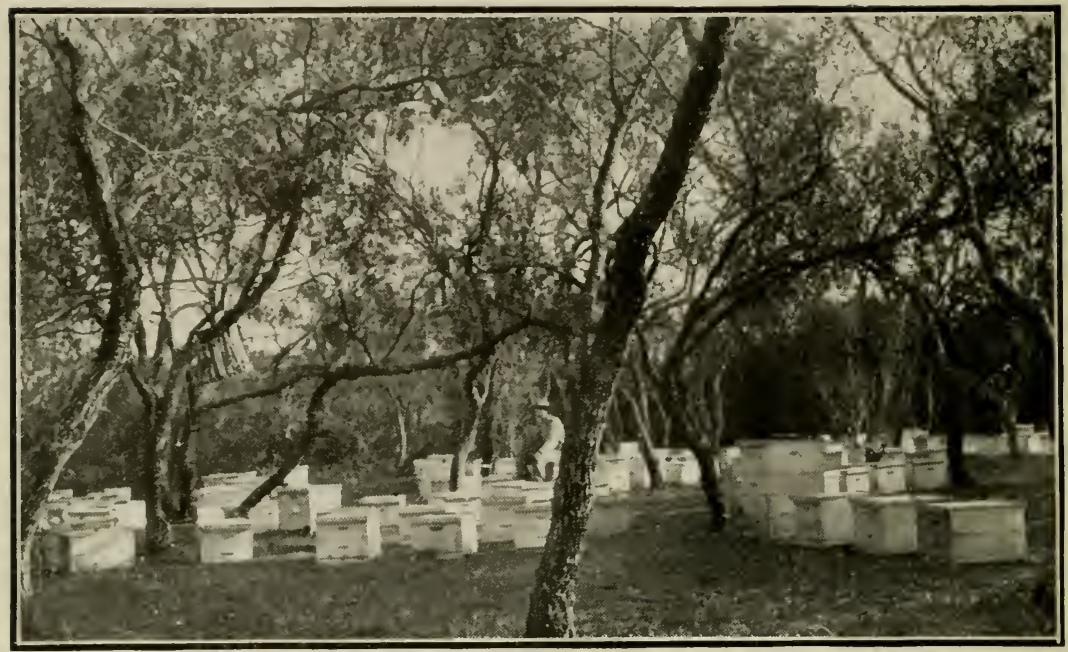

Fig. 24. Apiary of B. M. Carraway, Mathis, Texas.

level, that the moisture problem is nil so far as the beekeeper is concerned. Drouths do not figure largely in beekeeping in Florida, although several of the most important honey plants of the state are greatly affected, as to yield of nectar, by the temperatures. Cabbage palmetto bloom, for instance, will stand neither extremes of heat or cold. Rainy, cool weather seems to stunt its bloom, while very hot weather seems to "burn" the blossoms. It yields best in even, moderately warm temperatures. Black mangrove has a similar tendency and frequently yields at certain hours of the day, or ceases nectar secretion altogether, like buckwheat in New York state.

\section{Migratory Beekeeping.}

This tropical country, particularly Florida, was the original home of migratory beekeeping. O. O. Poppleton, who lived for a time at Stuart, and whose locality was visited by the writer, was perhaps the first exponent of migratory beekeeping, but gave up the practice in later years. The Marchants, of Georgia and Florida, have practiced migratory beekeeping with some success. 
as have many other beekeepers of the Appalachicola section. Beekeepers have been visited at Miami, who place their bees on lighters and tow them further down the east coast to the mangrove locations on the Keys. On the west coast, this plan has not been so thoroughly tried, but is proving feasible. However, migratory beekeeping, either in Florida, or from other states to Florida, has been largely given up. Success has not usually attended the efforts to make it pay. Most of the beekeepers of this area have permanent locations for most of their bee yards.

\section{Queens and Packages.}

One feature of tropical locations, both in south Florida and southwest Texas, is the value of such locations to raise queen

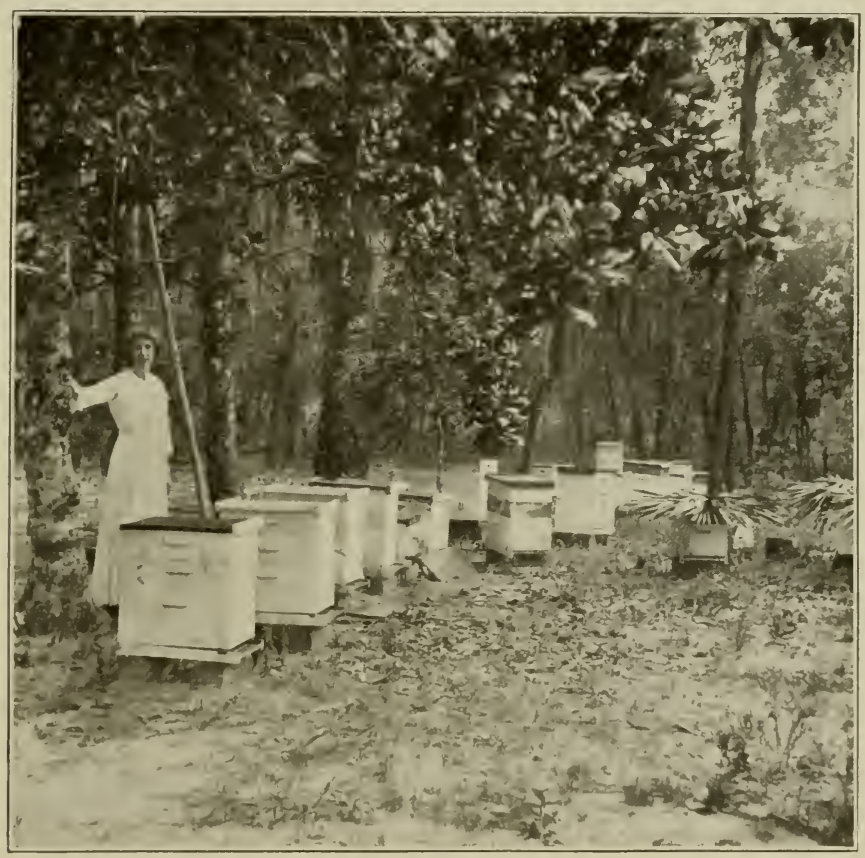

Fig. 25. Harry Hewitt's apiary at Lake Apopka in Tropical Florida. 
bees and for the early shipment of pound packages of bees. Many bees in such locations are run for packages alone, as the surplus season frequently closes early. In locations like Texas, where mesquite, a principal source of surplus honey, may bloom two or three times in a season, it is possible to get honey in addition to bees. The shipment of queens and packages ceases earlier in the tropical locations, than a little further north, because of the higher temperatures of summer and because of the later demand for bces from more northern points.

One of the hardest problems of the man who ships packages of bees, from any of the locations north of the tropics, is to furnish the necessary queen bees at the time the packages are shipped. In many cases the package shipper is not a queen breeder. The demand for packages without queens is comparatively light. Breeders of the far South have solved this problem. With their bees at swarming pitch by the time the package man makes ready to ship, the queens to accompany the packages are often reared a few hundred miles further south, as by B. M. Caraway for T. W. Burleson, both of Texas.

\section{Bee Pests.}

There is no locality in the tropics where insect pests and even animal pests do not have to be figurcd on. This is more especially true of Florida than Texas. "Bee hawks," a common name for large dragon flies, have often proved to be preventatives of successful rearing queen bees in the swampy tropics, at certain seasons of the ycar. Queen becs prove casy prey to the dragon flies, and many missing queens is frequently the lot of the breeder in such localitics.

Mud wasps have proved to be another source of frequent annoyance in portions of sou:th Florida where they often take possession of empty combs and sheets of foundation, while bees may be in possession of other parts of the hive. In Florida the writer visited a number of beekeepers who showed him combs with patches of brood chewed out nearly as large as the hand, which was blamed to tree-toads. The beekeepers reported having 
caught the animals in the act. Predatory animals also figure as pests, in Texas, as well as Florida.

Probably the most common insect pest is the ant, both in Texas and Florida. In many places in the latter state, the bees are kept on raised platforms, with the legs of the stands resting in troughs, which are kept full of water. In the case of outyards, it frequently becomes necessary to keep the surface of such water covered with oil, in order to decrease evaporation. In Texas, the ant pest is probably the most serious one and with J. W. Reid near Uvalde it is often necessary to hunt out ant nests and by the use of scalding water, the spade, carbon bisulphide and fire, attempt to destroy the nests of the maurauders.

In both these states the bee moth is a serious menace where combs are left without the bees to cover them, but this pest never proves to be serious in the hands of the careful beekeeper.

\section{Wax Production.}

In many tropical countries where there is usually much dark honey produced, beekeepers frequently make a practice of producing all the wax possible. Wax production alone was not found in any locality visited by the writer in either Florida or Texas. In Texas at the apiary of J. W. Reid, Uvalde, the writer saw 3,547 pounds of beeswax in one pile. In southwest Texas where mostly extracted honey is produced, wax is one of the principal sources of income of the beekeeper. Quantities of wax are also shipped from Florida, where the custom of using eight frames in a ten frame super for extracted honey adds to the crop of wax in uncapping.

\section{Variety of Honey Plants.}

One is impressed in visiting any good location in tropical Florida, Alabama and Mississippi, near lowlands, with the variety of plants available as nectar sources for bees. At DeLand, the home of Prof. E. G. Baldwin, the writer was shown a list of about 120 plants on which bees had been seen working at some time. One is impressed by the fact that fewer of the surplus nectar sources are small plants and more are shrubs or trees, in the trop- 


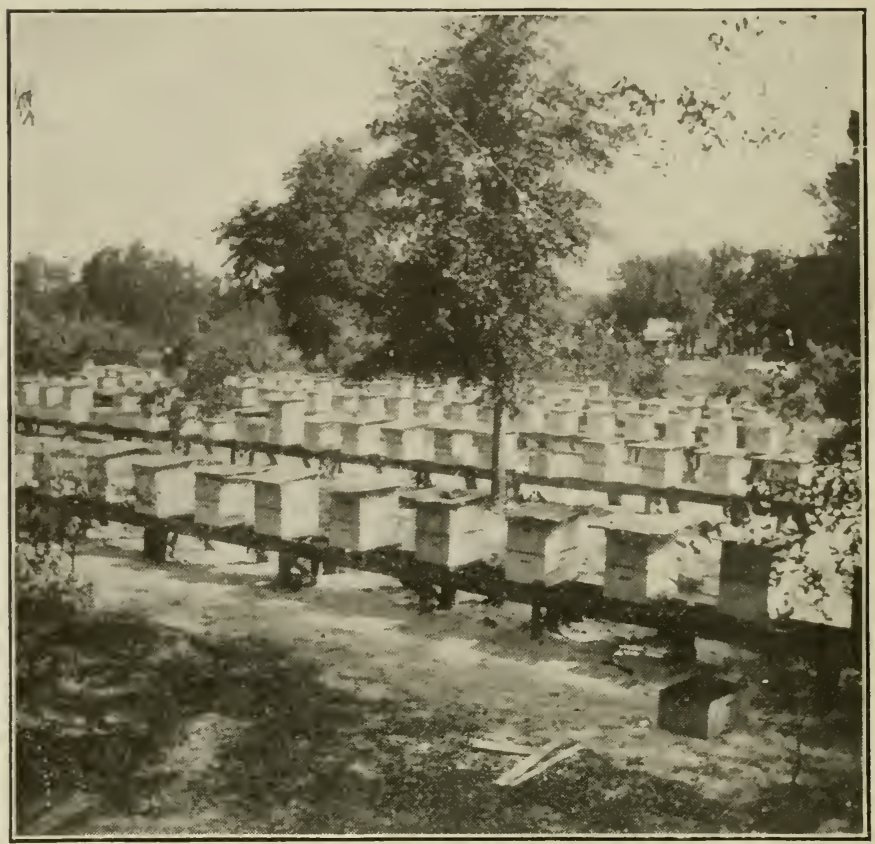

Fig. 26. Apiary of 300 colonies belonging to J. K. Isbell on the Apalachicola River, Florida.

ics. In Texas they are typically desert trees and shrubs, protected by thorns in nearly every case. This is seldom true in Floricla, where the trees which yield nectar are simply featured by the rank growth which is typical of the lowland tropics. In Texas, the variety is not so great as in Florida, probably due to the greater available water supply in Florida. R. B. Willson reports an enormous variety of honey plants, as yet largely unclassified, growing along the Gulf in southern Mississippi.

\section{Nectar Sources.}

There are probably four or five plants or trees in Floricla which would be considered the important nectar sources of the state. Primary among these is the saw or scrub palmetto, which grows practically throughout the state, and which is a very dependable 
parts of the state frequently yields surplus honey, where colonies are in shape to gather it beginning early in the year.

Texas tropical honey plants are fewer. Mesquite is probably the most important and is a tree varying in size up to fifteen feet in height, which may bloom as many as three times a year. Catclaw and huajilla are other important nectar sources coming early in the year. Further west alfalfa is becoming quite important, where a greater water supply is available. (See Chapter on Honey Plants.) 


\section{CHAPTER IX}

\section{The Alluvial Regions.}

B

ETWEEN the tropics of the South and the mountain regions toward the North lies a vast alluvial region of rolling claysand hills, interspersed here and there with patches of rich, black land. This belt extends across South Carolina, Georgia, Alabama, Mississippi, Louisiana, Texas and up into parts of Tennessee, Oklahoma and Arkansas, between the mountain ranges there. We are concerned principally with the region east of the Mississippi, where beekeeping conditions differ radically from the tropics and from the mountain regions and where beekeeping conditions more rearly approximate the Northern "white clover belt." It is this vast alluvial region which forms what most of us are accustomed to think of as the "South."

On the line next the tropics, the seasons approximate tropical beekeeping conditions, as with J. E. Marchant of Columbus, Georgia, while as one goes north toward the ciistant mountains of Tennessee and the Carolinas, the season shortens and the winters become more severe. In the centre of this belt from north to south, conditions are not unlike those of the Middle West, except for shorter, lighter winters and longer summers. One of the cardinal points, which has impressed the writer, is that most of the honey sources of the alluvial section are plants and shrubs and few of them are trees. In both the tropics and the mountainous section of the South, many of the most important honey plants are found among the trees. While there are a great variety of honey plants in this alluvial section, the territory may be roughly divided in to belts, as to the most important honey plants.

Another influence on the secretion of nectar in honey plants is the soil and climate. Neither of these features has been studied much as yet. However, it is quite interesting to notice that the alluvial region differs in soil types from both the mountain 


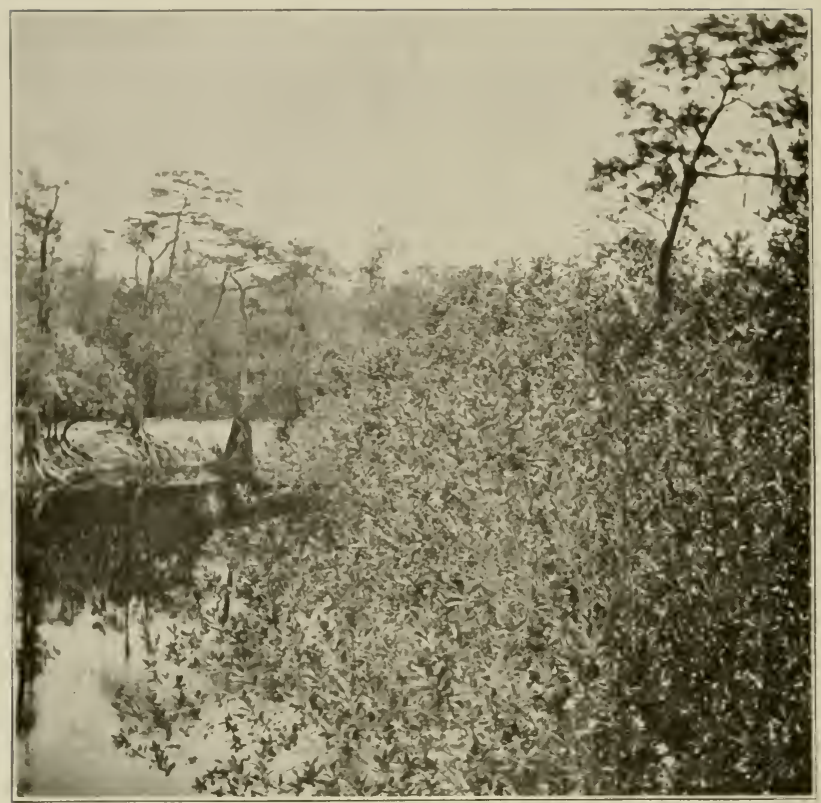

Fig. 28. The rich flora of a Georgia swamp.

and tropical parts of the South. In the tropics, sand predominates, while in the alluvial section, it is scarce, the red and blue clay types being in the majority. There are many sections, as in Alabama and Mississippi, where the soil is well supplied with limestone and where sweet clover abounds. Along the Mississippi River in Louisiana, Mississippi, and Arkansas, the swamp flora of the tropics is somewhat duplicated and we find again trees largely dominating as honey plants. Just back from the Mississippi River, the soil is usually of the black type, and the shrubs and smaller honey plants are largely in the majority, according to F. M. Morgan, J. F. Archdekin, and Frank Pease of Louisiana. On the Atlantic coast of Georgia, North Carolina, South Carolina and north Florida extends the famous gallberry region, where this plant alone is often sufficient to give an entire crop of honey. In all these lowlands, vines 
figure also largely in the list of honey plants, as for instance the rattan in west Louisiana and east Texas.

\section{Queens and Packages.}

In this alluvial section queen rearing and pound packages of bees figure as an important source of income for the beekeeper. The season when nectar may be found by the bees is long enough to permit queen rearing to continue through most of the season that queens are needed in other part s of the country. In the tropics, however, the honey flows often cut off when very hot weather comes. Then, too, the alluvial section honey flows, except in a few localities, are long and steady, or at least are not so intensive as the beekeeper in the white clover belt is accustomed to. For the most part extracted honey is produced, although there are many parts of this vast region where some comb honey is produced and many more where it would pay well for the beekeeper who has not too many bees, to handle the problems of

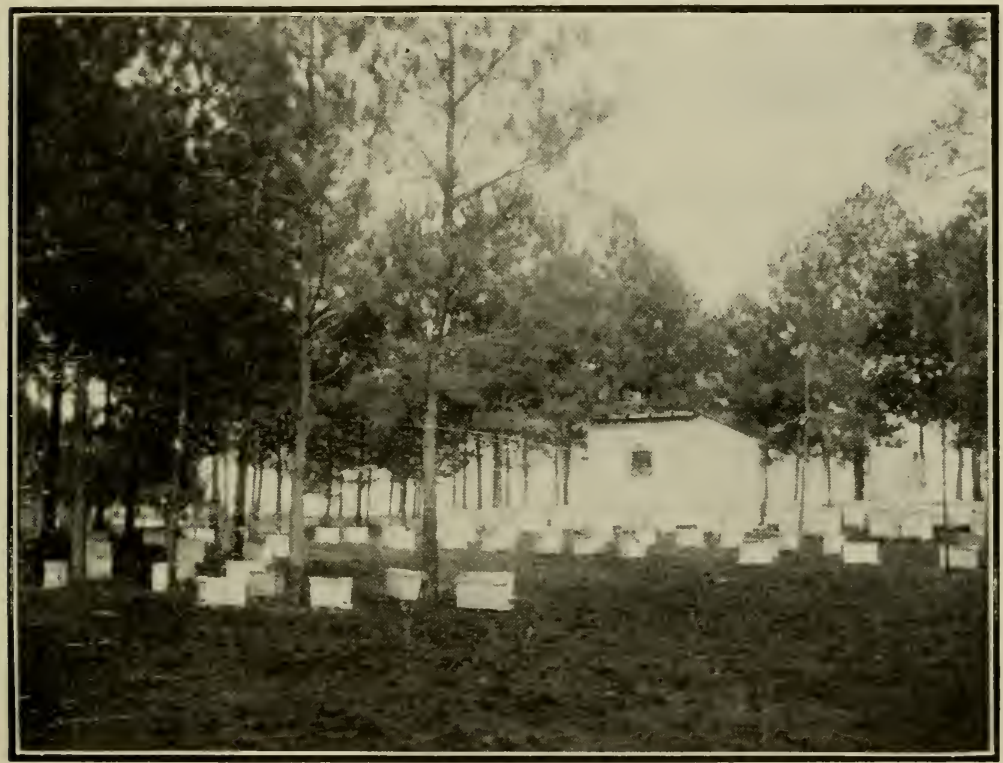

Fig. 29. An up-to-date apiary in the pine woods of Alabama. 


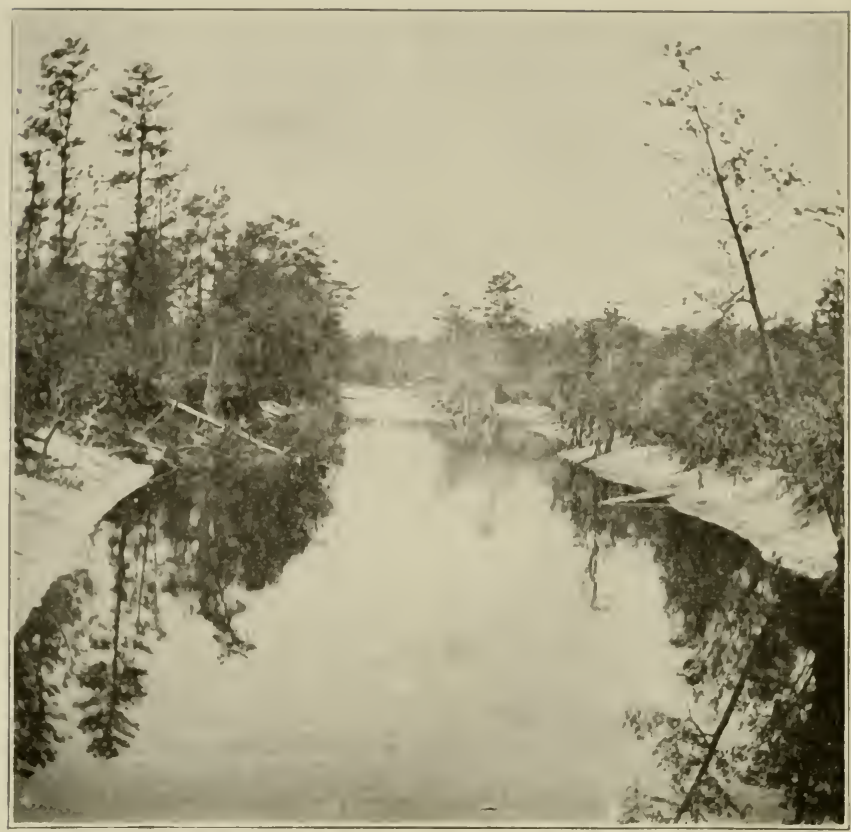

Fig. 30. There are many good locations along the streams in Ceorgia.

the comb honey producer. The writer would estimate the commercial production of extracted honey to comb honey in the alluvial section as about 80 to 20 in 1919 . It is probable that lowering prices for extracted honcy following the peace treaty may increase the production of comb honey again, since prices on comb honey in the past have been more stable.

Much of this region is covered with pine woods and in such locations but few of the big beckepers of the South are found. However, much of the woods is being cut and when cultivation of this region has gotten well under way in all parts of the South, it is probable that the pasture for bees from such cultivated crops as field peas, soy leans, cow peas, cotton and alfalfa may increase. Some very good alfalfa honey is reported in parts of Mississippi along the "river" where the soil types seem to differ radically from the bulk of the soils of this region. This is 
one of the first instances of this plant's yielding surplus honey east of the Mississippi River which has come to the attention of the author.

\section{The Melilotus Area.}

Northern beekeepers who are accustomed to seeing ficlds of cultivated sweet clover grow, should visit the sweet clover or "black land" belt of Mississippi and Alabama, where thousand of acres of this plant grow wild. The land is of a limestone type and the plant makes a thriving growth. This makes a veritabl paradise for bees, and as sweet clover wherever found makes a dependable honey plant in spite of drouth or flood, the value of this region as a honey producer can easily be seen. However, much of this land in Alabama, near W. D. Achord, is being bought up for pasturing and is being fenced, where blooded stock is being introduced. This may mark the end of honey plants in much of this region at a not far distant time.

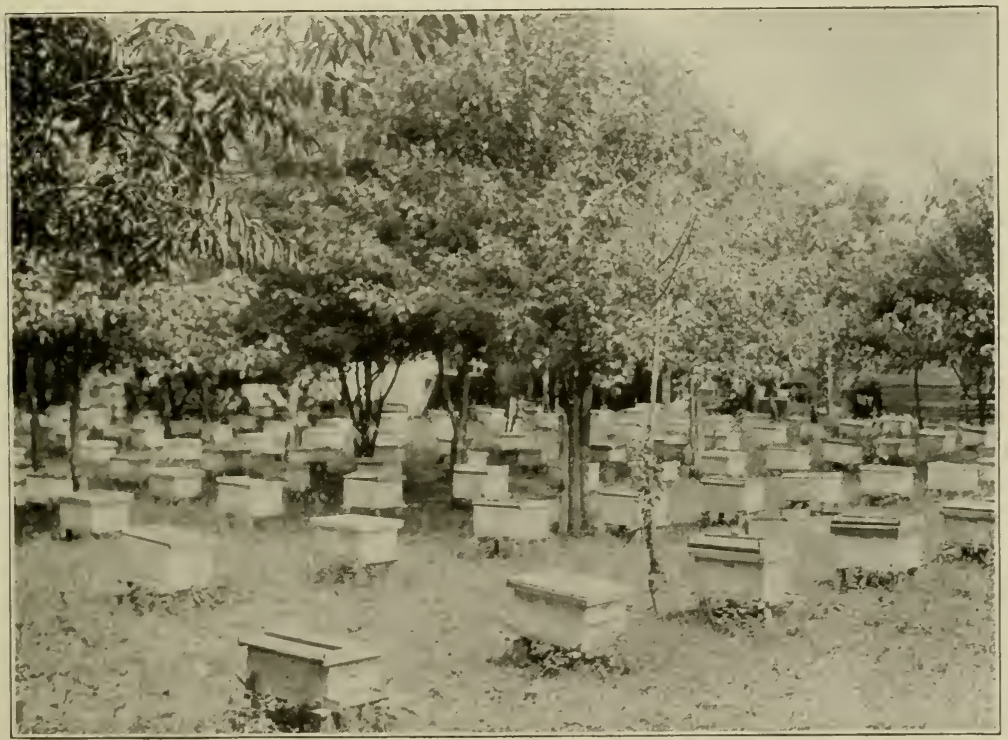

Fig. 31. Where Tennessee Bees hum. Apiary of J. M. Davis at Spring Hill. 


\section{Pound Packages.}

In this territory the pound package business has assumed proportions only equaled in parts of Texas. Thousands of pounds of bees in combless packages go north each year to Canada and the northern states, and add to the income of the southern beekeeper. In this vast sweet clover belt, where melilotus is the principal source of surplus honey, but where a stimulative nectar flow may begin weeks before sweet clover blooms, the package trade has become the salvation of the beekeeper. The apiarist of this region is enabled to take from one to ten pounds of bees from his colonies at the time they may approach the swarming strength, but when it is yet several weeks until the sweet clover may bloom. This enables him to handle the swarming problem at an advantage to himself, both financially and from a standpoint of beekeeping practice. With the package shipping season over, the colonies easily regain surplus strength for the sweet clover flow, and a crop of honey follows the crop of bees. We often wonder what in the world the beekeepers of this region did before the advent of the package business. Answers to this query from some of the extensive beekeepers in Alabama indicate that there was often nothing to do but let the bees swarm, even where no more increase was wanted and the honey flow was yet several weeks distant. This may account for the hundreds of colonies of "wild" bees found in the woods of this region.

\section{Much Honey Produced.}

By far the greater portion of the honey produced in the South is secured in this alluvial region and one of the weakest points of beekeeping here is the absence of any marketing organization. This has made it impossible in the past for some of the beekeepers to secure an equitable return on their investment. Most of the honey of this belt is light in color, being of light amber or lighter. There is no more beautiful honey in the comb than the partridge pea honey of Georgia and the gallberry regions of the costal lands produce a product worthy of greater attention than it has received in the past from the connoisseur of honey. 


\section{Winter Losses.}

While winter losses in this region are frequently heavy, when an unusual winter occurs, it is doubtful if beekeepers of this region will ever adopt northern methods of winter protection. This is because of the discrepancy in the time between the peak of strength of the colonies of bees and the beginning of the main honey flow through most of this belt. In the North there is every reason for packing bees, so as to reach the peak of brood rearing before the main honey flow is in progress. There is as yet but little reason for using methods of wintering which will increase the number of bees in a colony in parts of the South, at the season when there is no immediate need for bees and no way to use them. Low winter temperatures are not unusual here and snow often falls in winter in much of this entire region. However, it seldom remains on the ground for long and there is seldom a stretch of many days when bees may not fly, accord-

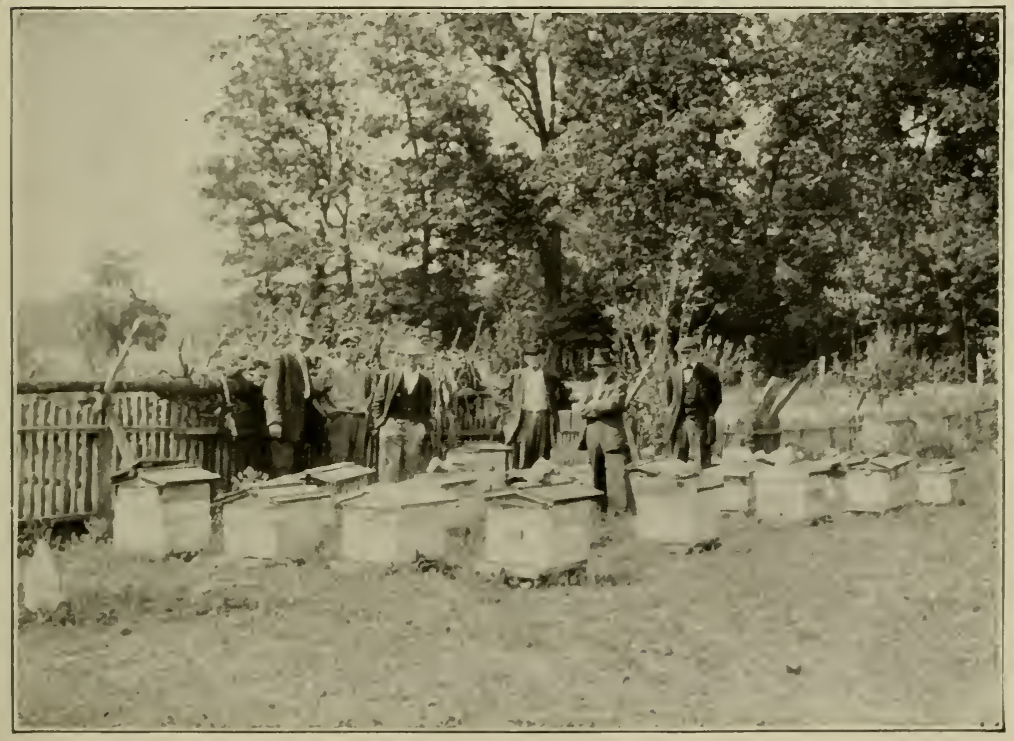

Fig. 32. A Virginia clover location. 
ing to George H. Hummer of Prairie Point, Mississippi. If the beekeeper in many parts of this belt can bring his colonies through alive, even though weak, he can build them in time for the crop. The excellent wintering, so necessary to a honey crop further north, is not so necessary here. A temperature as low as $10^{\circ} \mathrm{F}$. below zero has been recorded near Atlanta, Georgia, Birmingham, Alabama, and Greenville, Mississippi, according to the U.S. Weather Bureau. However, this is the exception.

\section{Deeper Brood Chambers.}

One item of progress which is to be noticed here is the gradual placing of the eight-frame hive and all hives of small brood chamber size, into the discard. The standard ten-frame dovetailed hive is found in use by most of the beekeepers in the western section of this region. In Georgia and South Carolina, where smaller hives have been used in the past, sentiment is also changing toward a bigger body. In Georgia and northern Florida many beekeepers have in the past used an eight-frame body and a shallow extracting super in addition, for the brood chamber. This is continued to some extent and is also serviceable where it is not feasible to leave all the "winter" honey in the brood chamber in the fall. Bees wintered with the brood chamber filled with honey may then be given the shallow super of honey in the spring when a dearth may threaten, or a few weeks before the main honey flow. However in much of this alluvial territory, the entire supply of honey is left on the hive. But the need of a larger brood chamber than is afforded by the eight-frame hive and in some cases by the ten-frame hive, is noticeable. Many beekeepers of this section run the year through with two full tenframe bodies for the brood chamber. It is our opinion that this custom increases as one goes west from the Atlantic coast, across the South. In all parts of this territory, excessive swarming is a real problem. Some of the largest apiaries in the world are located in the centre of this belt and with them are found some of the best beekeepers in the country.

\section{Cotton as a Honey Plant.}

One of the distinct features of the honey plants of the alluvial 
region is the frequent failure of cotton to yield much nectar in all parts of this belt. There are some locations in Alabama and Mississippi where cotton is scheduled as a nectar producer, but for the most part throughout the entire alluvial region, cotton does not rank as an important plant for the beckeeper. This is a peculiar fact, and is possibly due to the difference in soil types, since in northeast Texas, cotton is the principal honey plant and there of ten yields enormous quantities of nectar. However, in this portion of Texas the soil is a deep, black, waxy loam, while in some of the Alabama and Mississippi cotton belt red and blue clays often predominate. It is the opinion of the writer that where cotton yields in the alluvial section, the soil types more nearly approximate the black land of Texas, than elsewhere in this region. This is an interesting topic for research by southern beekeepers.

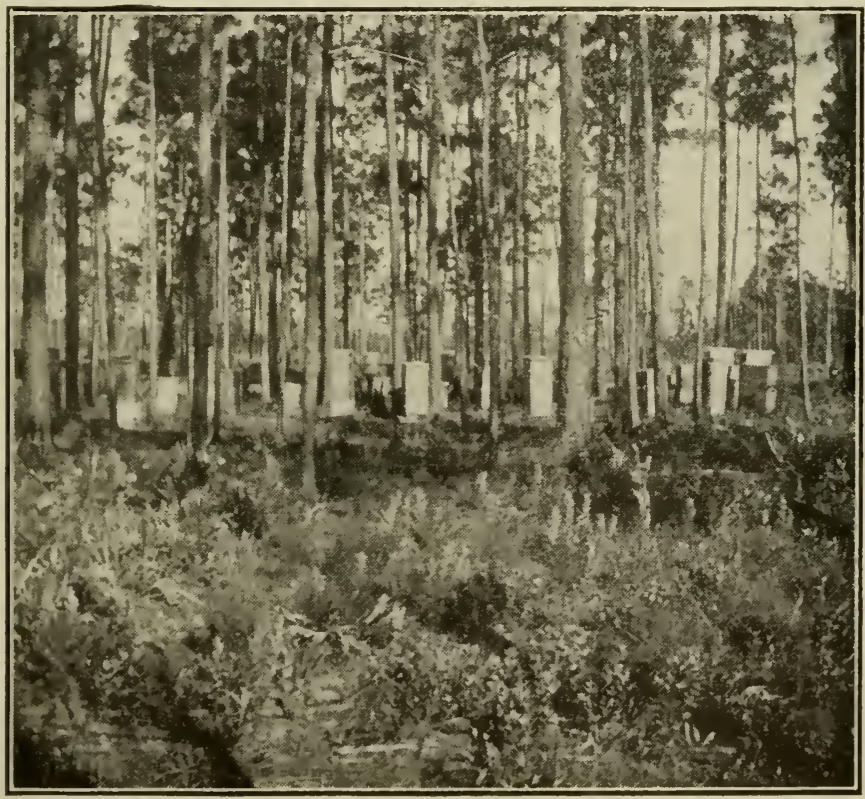

Fig. 33. One of J. J. Wilder's apiaries in South Georgia. 



\section{CHAP'TER $\mathrm{X}$ \\ Mountain Beekeeping.}

1 CROSS the northern tier of states usually classed as part of tude of most of the country and transforming much of the season and many of the types of honey plants. It is this region with which we will deal in this chapter, principally to differentiate the seasons and honey plants, rather than to show a different type of bee culture or bee appliances. These latter are much the same as in other parts of the South.

East of the Mississippi River, some of this mountain bee territory is included by flora, in what is commonly known as the "white clover region." Indeed, it is the white clover region, for no beekeeper ever tasted fincr white clover horcy than that produced by such men as Porter C. Ward, in the rolling hills of Kentucky. This plant is also an important source of nectar in some parts of West Virginia, Virginia, Maryland and Tennessee. West of the Mississippi River in this same hilly region, through the Ozarks of Arkansas and their continuation into eastern Oklahoma, white clover is seldom mentioned as a source of honey and nectar comes from other sources too numerous to name.

With the arrival of the beekeeper in the mountains of Tennessee and Kentucky, particularly along the lines of the Louisville \& Nashville and Queen \& Crescent Railroads, the type of soil found throughout the alluvial region is absent. Nearing the famous bluegrass regions, one finds a soil not unlike that of Illinois and Indiana in some places, but the presence of the mountains brings about an entire change of flora from that of the alluvial region.

\section{Trees Predominate.}

As in the tropics, many of the most important sources of honey are again trees. Prominent among them rank the tulip poplar, basswood and sourwood, as well as locust, sumac, and lesser 


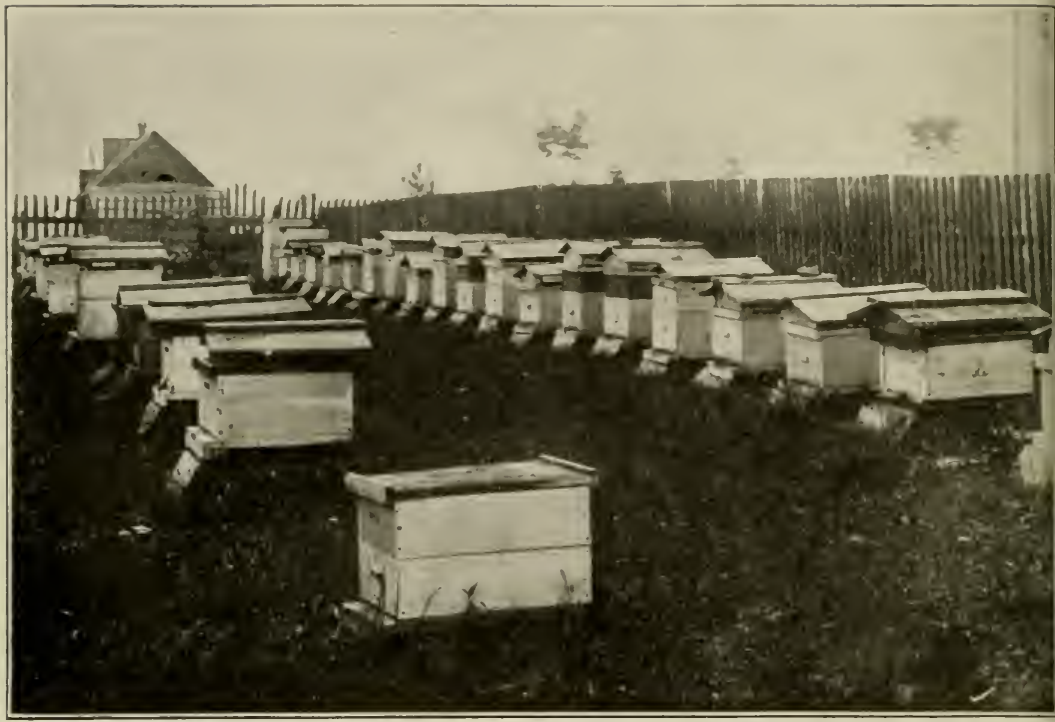

Fig. 34. Apiary in Blue Ridge Mountains of Virginia.

trees, according to G. M. Bentley, of Knoxville, Tennessee. Basswood yields in greater quantity as one approaches the mountain country where temperature conditions of climate, during its period of bloom, are similar to those of Wisconsin. Tulip poplar also varies in yield according to its elevation and the type of soil in which it is growing. The reasons for this are as yet a mystery and offer a fertile field for investigation.

In Maryland, for instance, according to G. H. Cale, of College Park, there are regions where tulip poplar grows in abundance and where, with identical trees within a few dozen feet of each other, some fail to yield nectar, while others do. It has been noticed that the tulip, growing on an clevation, apparently yields nectar abundantly. Trees growing further down the slope, in exactly similar weather conditions throughout the year, often fail to yield nectar appreciably. It is believed that the tyre of soil, which is known to vary in such cases, has much to do with this variation in value of tulip poplar as a nectar producing plant. 
Basswood also shows a difference, in the type of wood, since basswood from trees in Tennessee, for instance, has never given satisfaction when used for section making by manufacturers of bee supplies. This is particularly true of those which grow on lower land in the South and Southeast.

\section{Mountain Climate.}

The climate in the higher altitudes in this region is almost identical with that in many parts of the North, in the so-called "White Clover Belt." In West Virginia, in altitudes in the vicinity of Webster Springs, the winters ard summers approximate in length and intensity, those of Wisconsin. This also applies to much territory in eastern Tennessee, eastern Kentucky and western Virginia, where heary snowfall, heary rainfall, quite low winter temperatures and shorter hot summers are common. This makes it almost needless to say that bee culture in such localities in the South requires almost identical bee behavior operations as in the North.

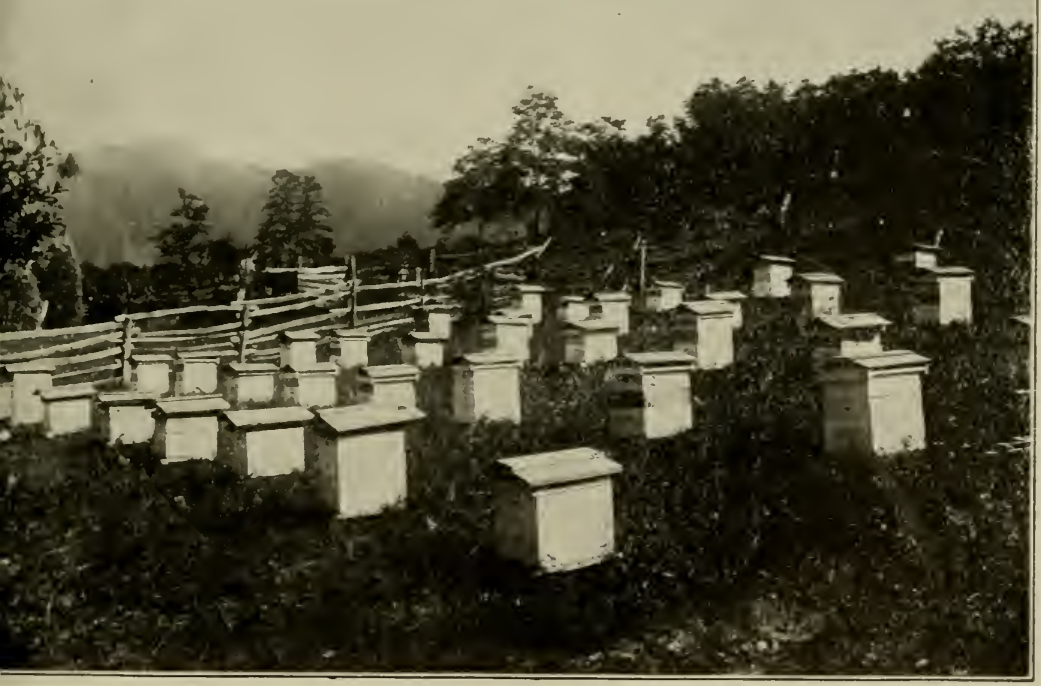

Fig. 35. An attractive hillside location in Virginia. 


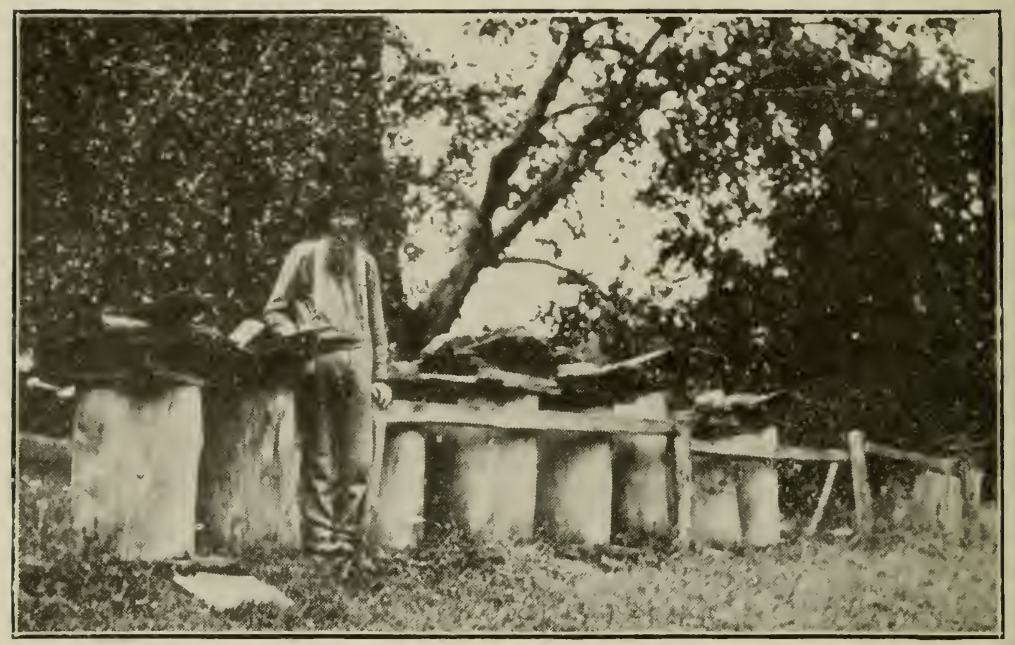

Fig. 36. A typical apiary in gums.

Throughout a great part of this mountain region, however, the altitudes are not nearly so high, and while the winters frequently approximate those of central Illinois, they are usually milder. However, in practically all cases, the summers are longer, frosts disappearing in early spring, returning only late in the fall, often after Thanksgiving. This, of course, results in a different type of bee culture, necessitating the application of white clover region bee behavior operations earlier and later in the season.

\section{Box Hive Common.}

The box hive is well distributed over this territory, usually exceeding in number many times, the modern hive, in the higher regions of the mountains. It is probable that there are ten box hives to every one modern hive in many parts of mountainous West Virginia, Virginia, Kentucky and Tennessee. However, these regions are often so rich in honey producing flora that it is difficult to induce beekeepers unacquainted with modern methods, to adopt them. They often get a fair return in chunk honey from box hives, in spite of poor beekeeping, and 
are skeptical of the initial expense incident to the adoption of better methods. However, the success of one influential beekeeper in their vicinity, using more modern methods, usually turns the scale in favor of modern beekeeping. This does not mean that there are no good beekeepers in this mountain region. But they are somewhat the exception and are usually found in scattered localities, where the success of some modern pioneer has attracted others.

\section{Winter Losses Heavy.}

Winter losses among the uninitiated of these mountain bee keepers are often enormous. H. L. McMurray, formerly of Kentucky, C. A. Reese, of West Virginia, and C. E. Bartholomew, formerly of Tennessee, as extension workers in bee culture, have frequently reported very heary winter losses in their respective sections. The writer is inclined to believe this is due primarily

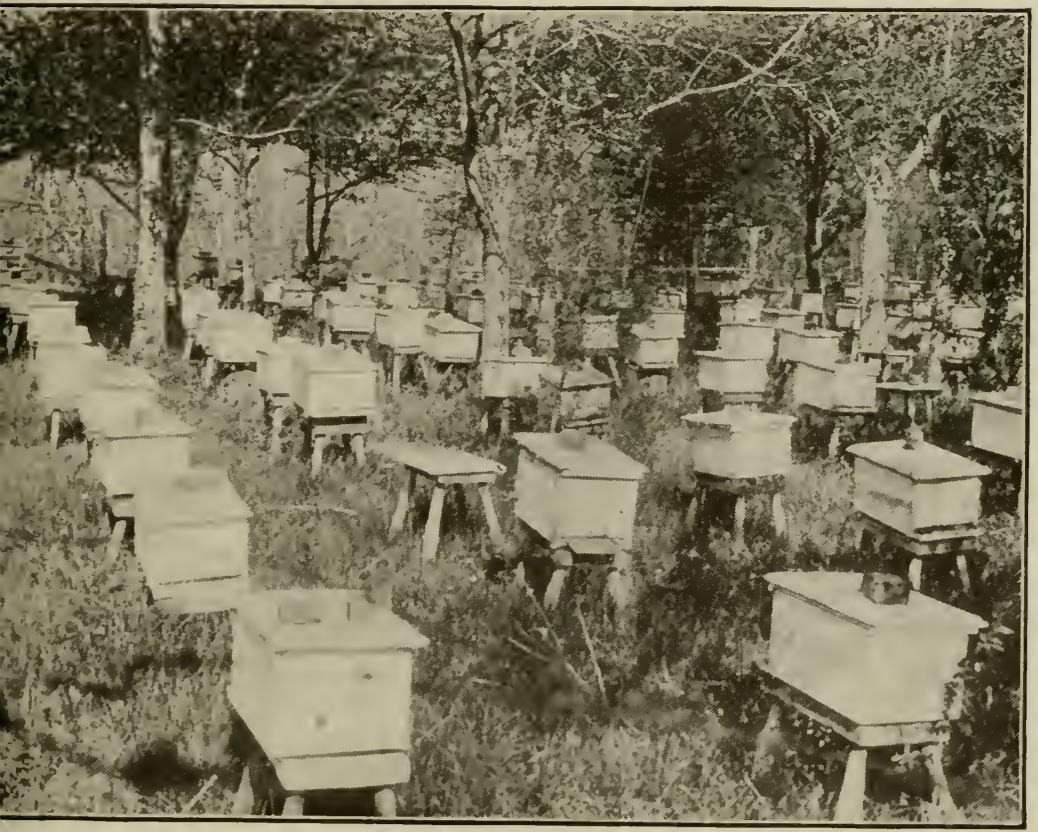

Fig. 37. A Mississippi River bottom location in Arkansas. 


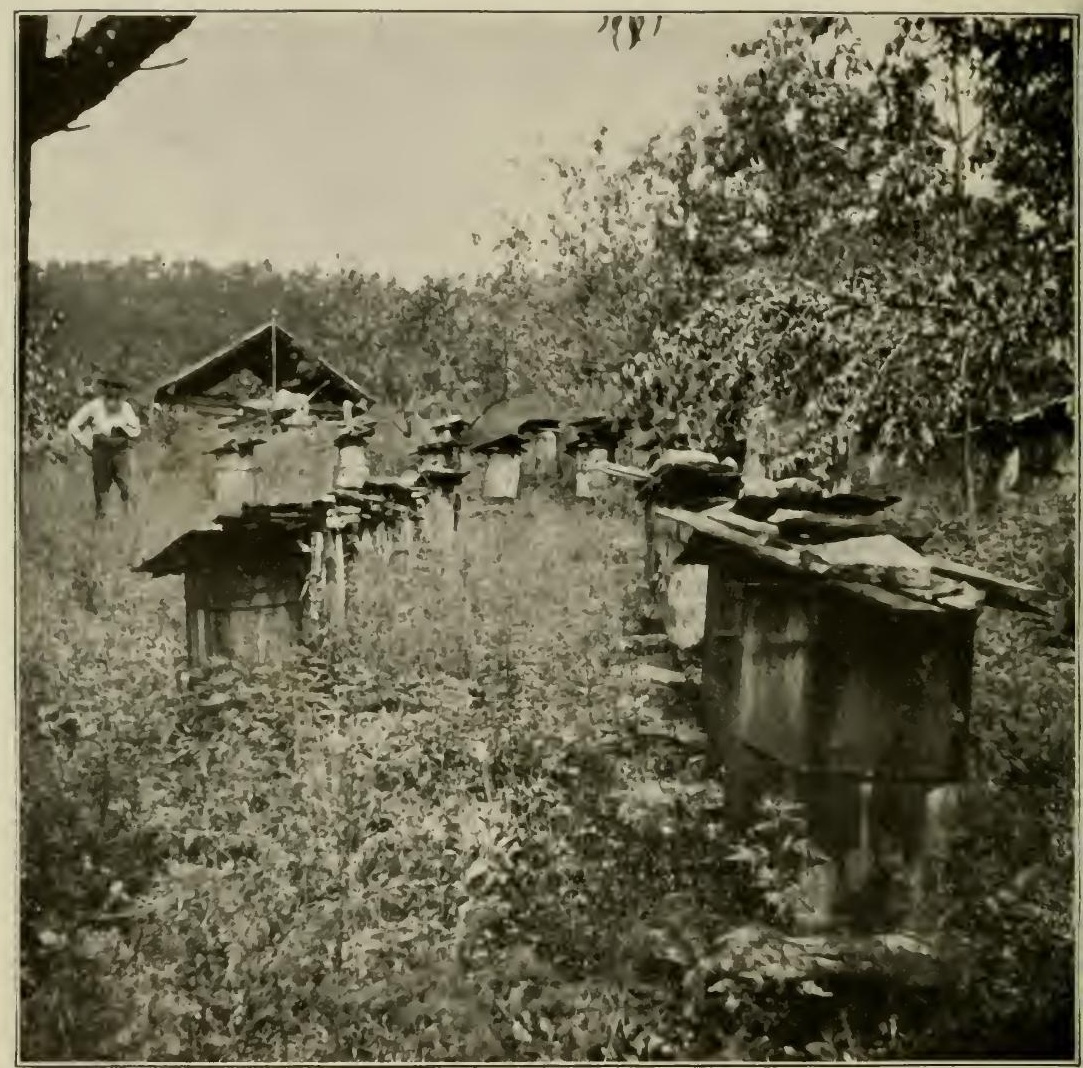

Fig. 38. Box hive apiary of a typical mountaineer.

to excessive swarming. After-swarms even to the number of five or six are not infrequent from a single "gum." These later swarms are always smaller, build up slowly for winter and are often hived so late that it is impossible to suppose they can gather enough honey to winter on. The fact that excessive swarming is allowed may account for the great number of bees in these localities, as the census map of bee culture shows. The application of modern methods of uniting late swarms and the prevention of excessive swarming works wonders in this fertile country. It is hard to convince beckeepers in these regions that they can 
of ten get ten times the amount of their average annual yield by modern methods, when their average annual yield is frequently less than twenty pounds to the colony. Custom plays an important part with some of these mountain people, too, for excessive swarming is undoubtedly due, among other causes, to the habit in some localities of "robbing" the bees but once in a season.

\section{Diseases Are Endemic.}

Happily American foulbrood has not yet found its way into many of the localities mentioned, in the mountains of the South. European foulbrood is endemic to this territory and epidemics of the disease frequently devastate large areas. A glance at the census figures for 1910, shows a depreciation in the number of colonies, from the previous year. It has come to light that hundreds of colonies were lost that year from European foulbrood. Among these box hive beekeepers European foulbrood is seldom recognized and never treated. Yet it exists throughout their territory. The writer remembers one Spring trip through Virginia, where not a single county of the two dozen or more visited failed to show evidence of European foul-

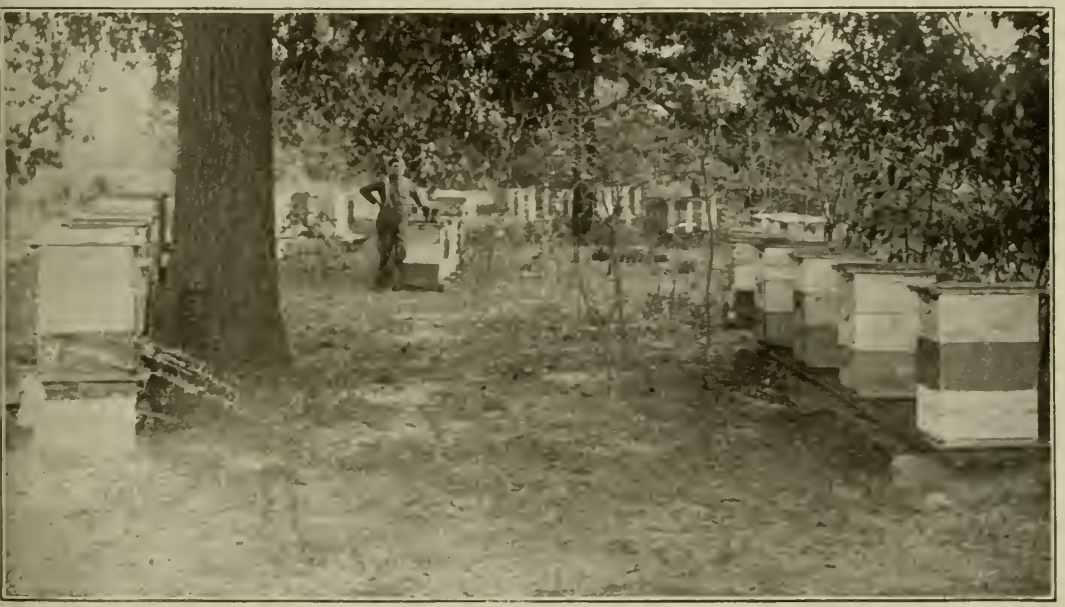

Fig. 39. Apiary of a Genrgia farmer who is an up-to-date beekeeper. 
brood. Similar conditions have been reported in Tennessee and Kentucky, in the mountains. No up-to-date beekeeper has much to fear from European foulbrood in this territory, for the adoption of good strains of Italians usually results in its eradication. Most of the bees kept in this territory are blacks. Occasionally one runs across a colony of beautifully marked Italians which the mountain beekeeper has caught as a swarm in the woods. This brings up speculation as to how far these bees traveled before they were hived and became "mountain" bees.

\section{Fall Flows Dependable.}

Fall flows are usual in all of the mountain regions of the states mentioned. There is no more beautiful sight in the South than a West Virginia or Virginia mountain side covered for acres with masses of aster and goldenrod in the fall, on which the bees make an excellent harvest. This probably accounts for the fact that bees in this region survive the poor methods of beekeeping, since excessive swarming and poor wintering go hand in hand. The winters are often severe and, in the higher regions, good protection pays well. Bees in the lower foothills of Tennessee are seldom protected, and successful beekeepers there make the adoption of heavy winter packing in their territory doubtful.

The territory west of the Mississippi River is similar to that of the region previously discussed. Honey sources are different and but few of the common plants of the eastern belt of the mountains are known across the "Father of Waters." The writer is not so familiar with honey sources in that locality, where the Ozarks of Arkansas and Oklahoma give lower altitudes than the mountains of Kentucky, Tennessee, and the Virginias. There are fewer commercial beekeepers located there and not as many colonies of bees. However, there are some fertile fields in both states, which are as yet but partly dereloped and which offer a field for extension work and modern bee culture. The climate in this region is somewhat mild in both winter and summer and the honey sources in good localities are equally varied, according to C. E. Sanborn, of Oklahoma, and Frank Horsefal, of Arkansas. 


\section{CHAPTER XI}

\section{The Lone Star State.}

$\mathbf{T}^{\mathrm{T}}$ is only just to readers and to Texas beekeepers, to treat of conditions in that state, even in the meagre way possible in this short chapter, in a separate classification. Until "Four Minute Men" of the late war told millions that Texas alone had more acreage than the whole of Germany, few Americans realized the vast extent of the state. Until writers point out the vast differences in beekeeping which necessarily obtain in so vast a region as Texas, beekeepers elsewhere may never get a proper conception of the variations in methods, climate, flora and honey sources which are peculiar to the state.

Following the lead of Louis Scholl in his bulletin on "Texas Beekeeping," published by the Texas State Department of Agriculture, 1912, the writer prefers to divide Texas apiculturally into six divisions, in comparing bee culture there. The Scholl divisions are: "North, Central, East, South, West and Southwest."

\section{North Texas.}

Imagine a line drawn through from east to west, which would cut off the northern tier of counties of the state, to include the famous Panhandle district. Here the winters are frequently severe and the summers usually hot and dry, and often not best suited to bees. Mesquite is found in some portions of this area and in certain sections, such as the black land portion north and east of Dallas, some of the finest cotton honey in the world is produced. Sweet clover is entering the state here in a wild growth, according to E. W. Cothran, of Roxton. Some horsemint, a famous honey plant of the state, is found on the southern edges of this district. Nearing the Oklahoma line, beekeeping is rather lax. Near the Arkansas line better practices are in vogue and in the vicinity of Texarkana, are some of the best 


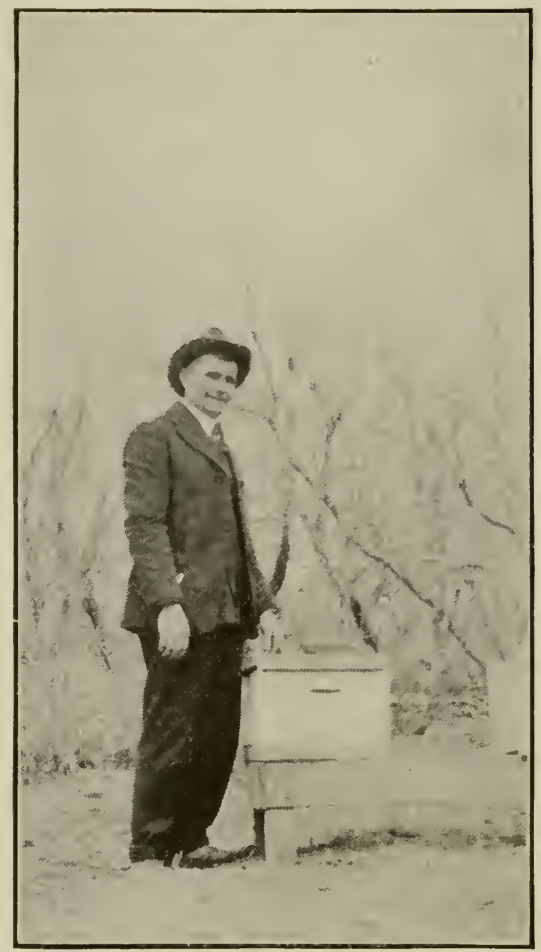

Fig. 40. E. G. LeStourgeon, the genial manager of the Texas Honey Producers Association.

beekeepers of the state. In some localities the lack of early honey sources prevents rapid building up in spring and probably not enough attention to scientific wintering is given.

\section{East Texas.}

East Texas abounds in minor honey plants, especially along the river bottoms, and in some sections fruit growing is adding materially to the stimulative and surplus sources for the beekeeper. Near the Louisiana line and farther south large growths of basswood are found. It is unlikely that basswood in this section ever yields as it has been known to yield in Ohio, Wisconsin and Michigan. Neither is the timber suitable for honey sections, 
as is the northern linden. However, there are some reliable reports of heavy flows from this source. Holly and chinquapin are mentioned as important honey plants and innumerable vines figure in honey production, giving a large share of the product a light or light amber color, according to T. A. Bowden of Palestine.

\section{Central Texas.}

In this region are tne main black land fields of Texas and here the famous horsemint flourishes in all its glory. However, this famous plant is gradually decreasing in acreage before cultivation, like the famous blue thistle of Virginia. In the southern belt of this region, mesquite is common and is an important source of honey. Sumac is named as important here and in some sec-

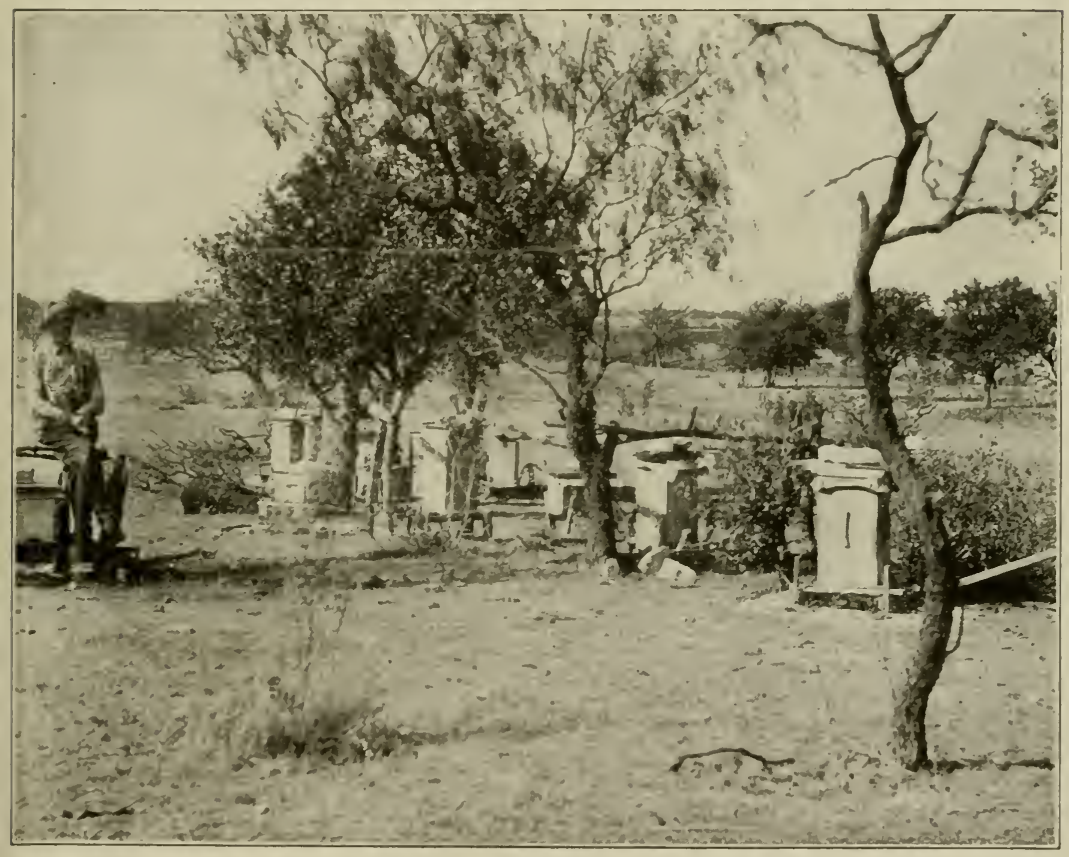

Fig. 41. Box hives like these are rapidly being replaced with good equipment. 


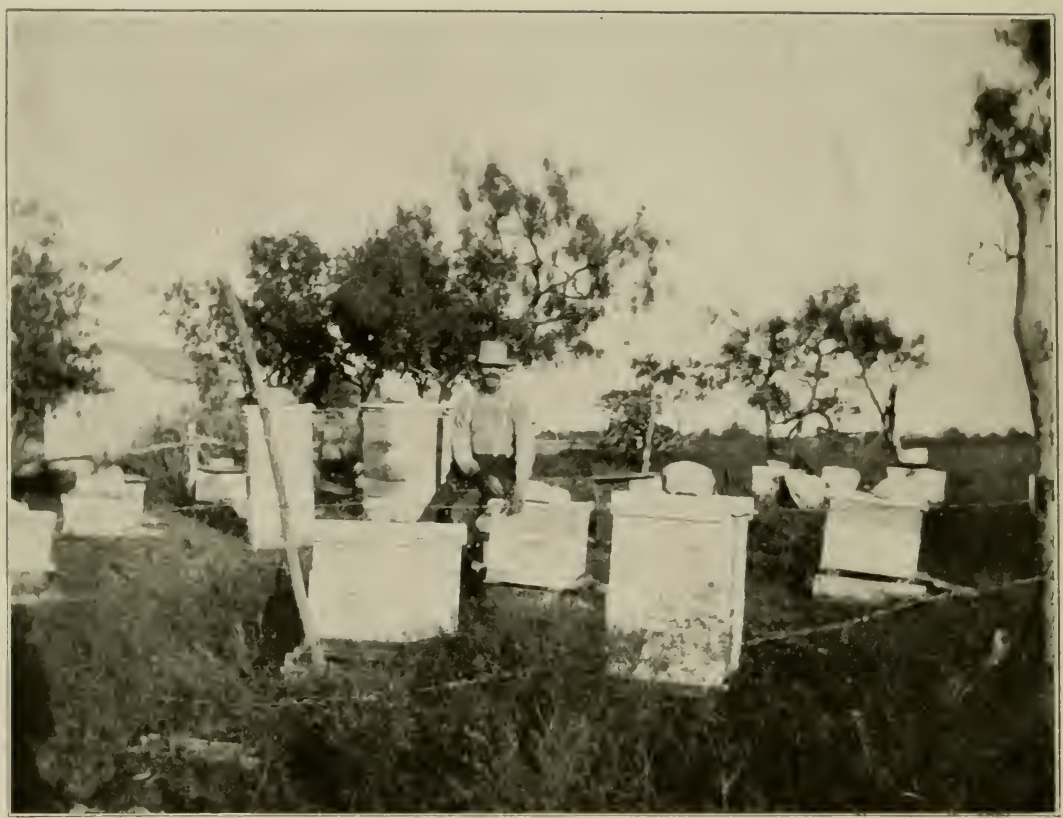

Fig. 42. The apiary shown in Fig. 41 after it had been transferred to good hives. tions broomweed, sometimes called summer farewell, is an important source.

\section{South Texas.}

The famous rattan vine of which one hears wherever he goes in the eastern portion of this belt, is an important yielder. In much of this country beekeeping is not profitable and a share of the honey produced here is of dark color. Reports have reached the author which indicate that frequent heavy winds from the Gulf interfere with the bees' flight in many localities in this region.

\section{West Texas.}

Much of this section is unsuitable for bee culture because of protracted drouths and soil conditions. In some of the valleys alfalfa is mentioned as an important honey plant and in some 


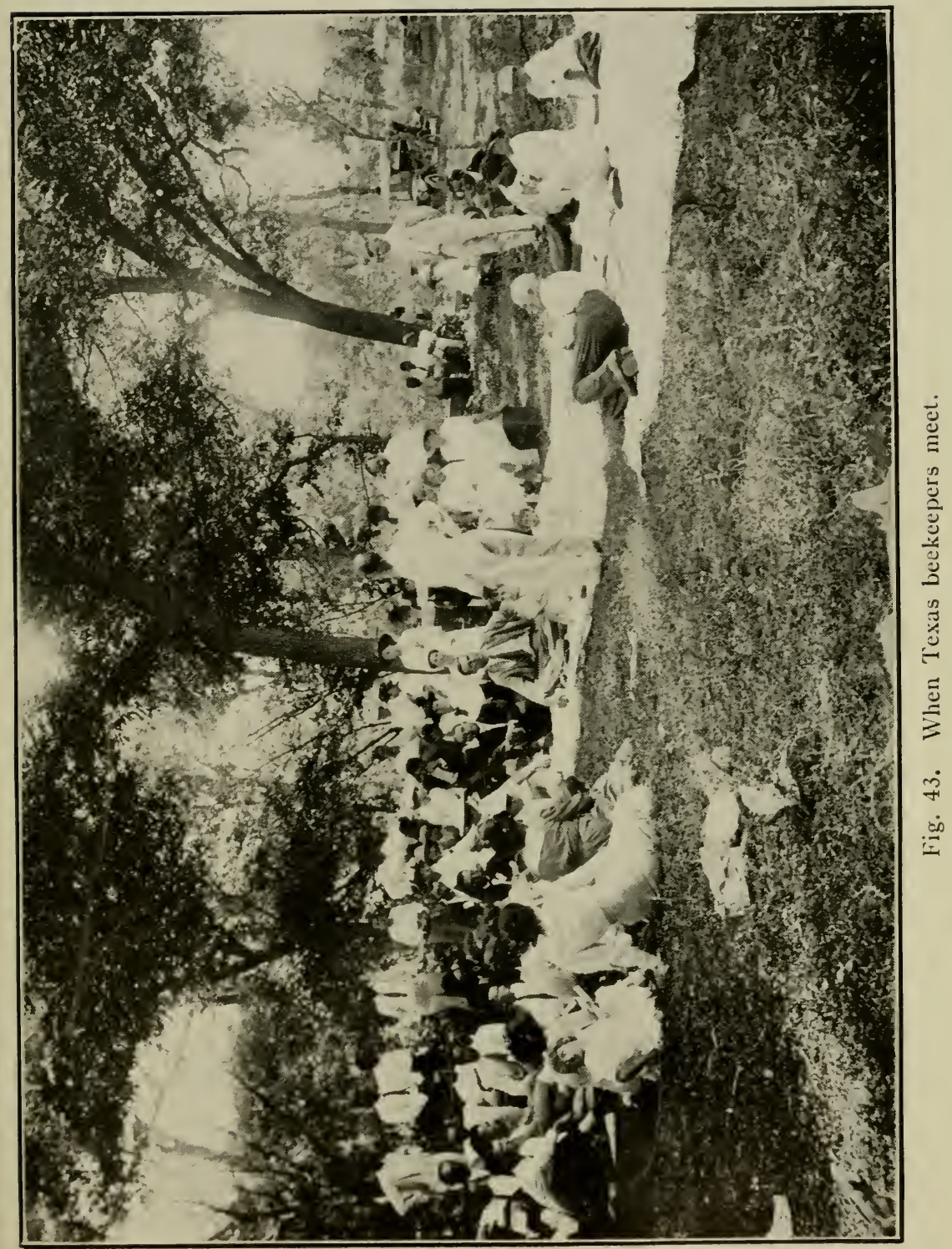




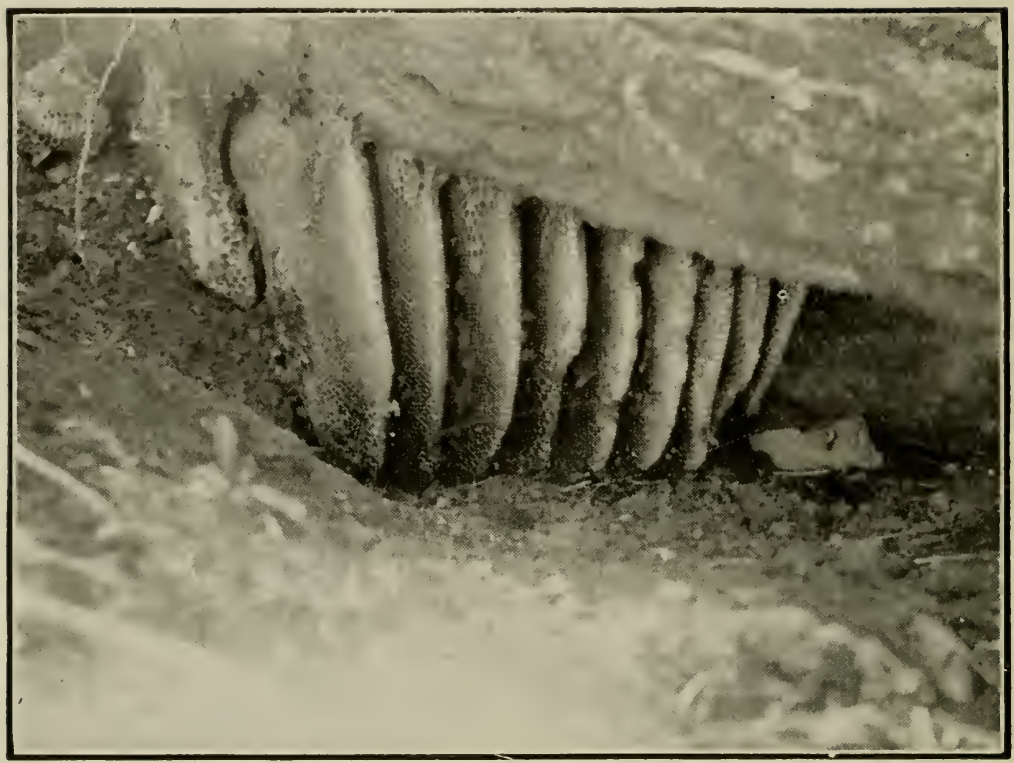

Fig. 44. Combs built by wild bees in the rocks of Texas.

seasons heavy yields are secured from mesquite, which is found generally over this belt. There are many lesser honey plants here, such as catsclaw, which figure in the total yield of the apiary.

\section{Southwest Texas.}

In some years this region is one of the most important honey producing areas in the world. In others, such as during 1917 and 1918, drouths devastate the country and necessitate the abandonment of portions of it. Mesquite is probably the most important honey producing plant and in some years, three blooms to a season have been known from this source, the first occurring usually in April. This honey is very light colored, of a fine flavor and forms the principal source in the famous "Uvalde" region. Other honey plants are huajilla, catsclaw and innumerable flowers of the desert regions of much of this territory. Huaijilla honey is rated by many, among them Scholl, as 
one of the finest honeys of the state. There are sources in this region which are available most of the year, but the main surplus flows usually come early in the season and are frequently of short duration. However, the flows are usually very heavy and big yields frequently result.

\section{Methods in Use.}

Not long since, bulk comb honey production was one of the principal methods used in this state, in which honey produced in shallow extracting supers was cut out and sold in pails or other receptacles, being first covered with extracted honey. This style of production is still quite popular in Texas. Extracted honey is probably the favorite method followed in this state at present, and because of the intensity of flows and their short duration in many portions, is likely to long remain popular. Commercial beekeeping in the state is mainly modern and the extension service of the state and disease eradication work,

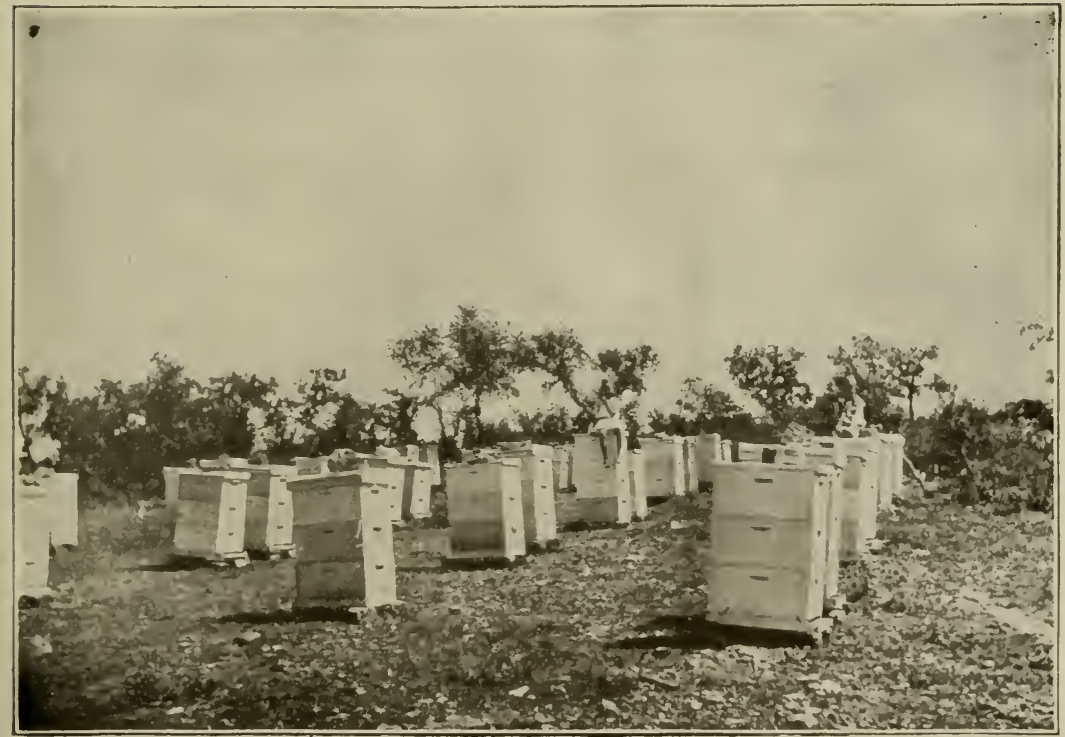

Fig. 45. L. B. Smith's modern apiary at Llano, Texas. 


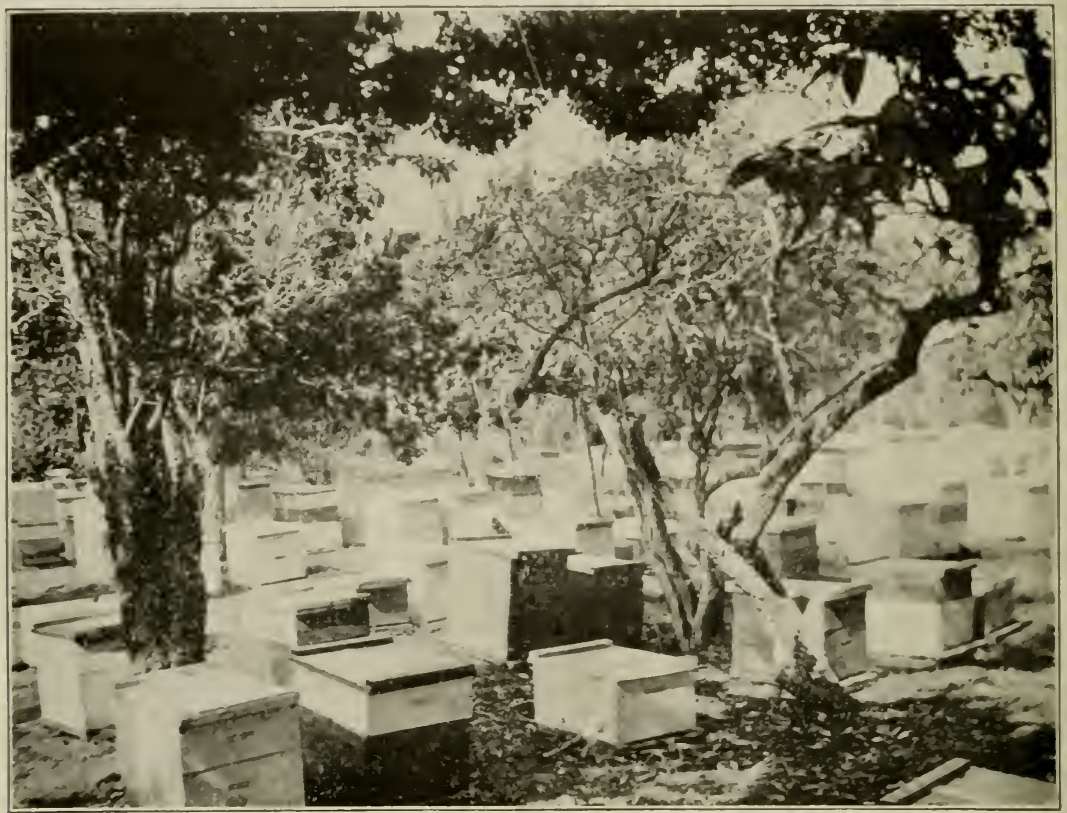

Fig. 46. A Texas apiary in the Rio Grande Valley that produced 20,000 pounds of honey from 90 colonies.

under the direction of F. B. Paddock, College Station, (now of Iowa) is probably second to that of no other state in the union. Many of the better sections of the state for honey production are well taken up, but there are still others where more bees could be kept profitably.

\section{Soils and Climate.}

Texas varies radically in soil 1ypes, from the black loam of northeast Texas to the desert of the southwest and the sands of northwest. Many plants are found in the state which do not yield as they do in other localities. Dandelion is found abundantly in north Texas, but H. D. Murry reports: "I do not mean to say that bees do not work on dandelion here. I have caught them in the act, but you wou!d never know it by looking in the 
hives." This seems indeed peculiar to the beekeeper of the North where dandelion is a mainstay of spring.

Climate varies here as one might expect, who knows the vast stretches of territory included in the state. In the north, in the vicinity of Fort Worth and Dallas, snows are not infrequent in winter and quite low temperatures are common at that season. However, throughout the state high summer temperatures are common and in the southwest, temperatures of the desert are well known. All this naturally tends to have a vital influence on the seasons when honey plants will yield and more as to the intensity of the honey flows. There is no prettier sight than the prairies of the state colored with flowers as far as the eye can see. In some such sections a bee is seldom seen on these flowers.

\section{Commercial Production.}

Excepting California, there are probably more commercial

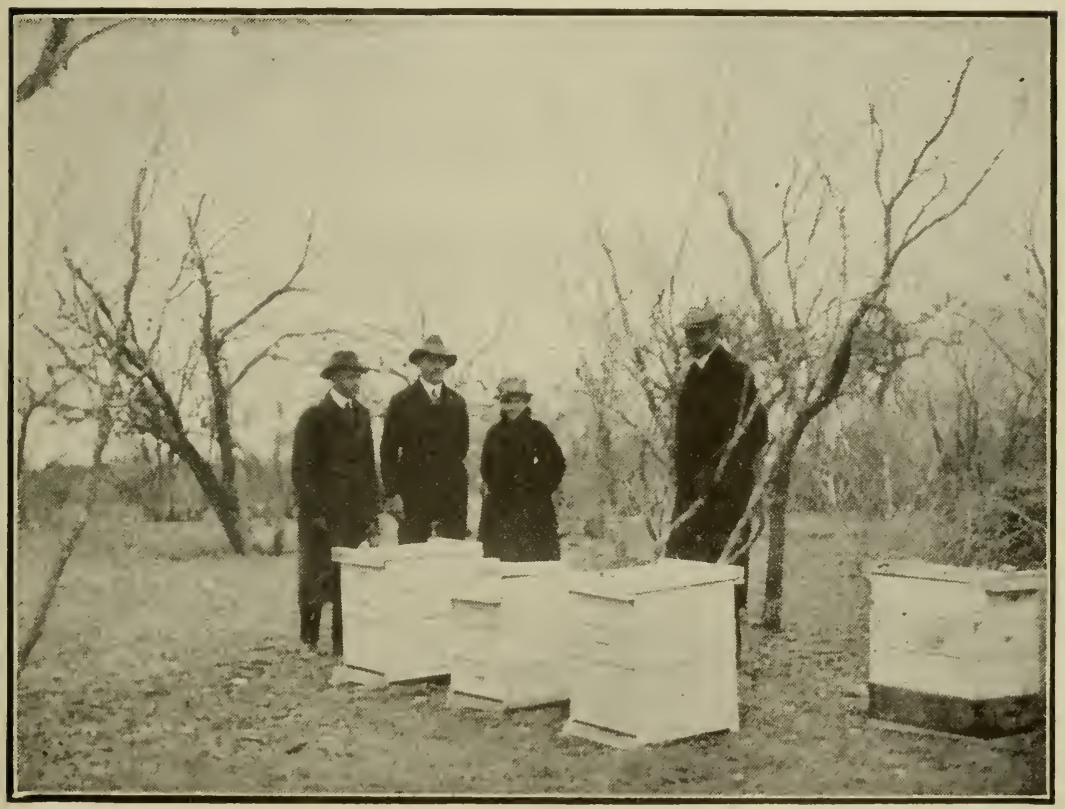

Fig. 47. Scholl arranges his hives in groups of five in partial shade. 
honey producers in Texas than in any other state. One is impressed in visiting the state by the number of beekeepers who do things in a big way, operating hundreds of colonies and marketing their honey in carlots. In the southern part of the state, much of the common labor in the Scholl apiaries has been managed by the use of Mexicans, and it is in this part of the state that the most honey is produced and marketed. In spite of the enormous quantities of honey produced in Texas, one is impressed by the similar quantity of honey which is sold within the state and consumed there, according to E. G. Le Stourgeon.

The breeding of queen bees and shipment of combless packages forms an important source of revenue for dozens of Texas bee men. The value of this work was evidenced during the European war, when Texas beekeepers shipped thousands of pounds of their surplus bees to western states, where heary winter losses had threatened the production of honey. The shipment of combless packages in Texas is somewhat different than in other parts of the South, since not all of the package shippers are confronted with colonics at swarming strength long before the honey flows. Many of the flows come nearer the natural peak of strength than in Alabama and Mississippi.

Texas beekeeping has already taken advantage of most of the good locations, with the exception of a few counties in the northern and eastern parts. These, for the most part, are not the counties where one would be most successful. However, there are many localities occupied too much by box hive men, as in all other states, which would be the better for settlement by bee men of modern tendencies. 


\section{CHAPTER XII}

\section{Bee Diseases.}

LTHOUGH bee diseases are quite prevalent throughout
the southern states, fortunately but a small percentage of
the total infections have been found to be American foulbrood. Consequently the losses to commercial beekeepers who use Italian stocks are slight. On the other hand, in the Appalachian mountains, where the hundreds of "beekeepers" have 90 per cent black bees, European foulbrood is endemic and frequently epidemic, causing the losses of thousands of colonies at least once in a decade. This was noticeably true in the year 1909, when the regions mentioned were visited by a European foulbrood epidemic. Most of the South is as yet unorganized to fight bee diseases, and if American foulbrood had ever gained a substantial foothold in this section, the bees would probably have been lost in a short time. In one case the writer visited in a southeastern state for one month in 1916 and found actual evidence of European foulbrood in every one of forty-two counties visited. In this state there was no inspection or extension service for bee culture and consequently but few rcal commercial beekeepers. Such conditions do not obtain in most of the South, however, and fortunately the writer does not remember of having seen but one or two cases of American foulbrood in seventeen months spent in this territory, investigating such conditions for the U.S. government.

\section{A Prospect.}

Since European foulbrood is considered to be primarily a spring disease and to of ten cure itself when settled warm weather comes, one might think its ravages in the South might be nil. Such, however, is not the case, as it is the opinion of the writer that more losses, winter and summer, are due to European foul- 
brood than any other cause, except excessive swarming. Probably the infection is a sequence of excessive swarming, since the disease is known to readily affect weak colonies. Again, the consequences are fatal in so large a percentage of cases because of the prevalence of black bees in most of the apiaries conducted by non-commercial beekeepers and novices. The writer has visited hundreds of bee yards in spring, where the beekeepers were discouraged with the outlook and believed the cutting of timber had ruined the territory for bee pasture. Examination of combs showed in many cases that the death of colonies was often due to European foulbrood, which disease may at least be retarded by the introduction of pure Italian queens. For this reason, it is the opinion of the writer and many of the beekeepers of this region, that extension work in bee culture is more vital to the immediate future of beekeeping, than is inspection work. When American foulbrood shall have made some inroads into the territory, inspection work will be necessary and probably more successful, for the preceding educational work which may have been done by the extension men and women.

\section{American Foulbrood.}

Practically speaking, widespread infections from this bee disease in the South are rare. Fortunately too, the few states where American foulbrood continually crops out in a minor fashion, have an adequate inspection service. This is true especially of Texas and it is the opinion of the writer, that so long as the present system of handling bee diseases in vogue in Texas is continued, beekeepers there will have nothing to fear from American foulbrood. The inspection work in Texas has been by areas, in counties where the beekeepers thought enough of their profession to organize. Some cases of the disease have been found in Tennessee and Kentucky and some in West Virginia. In Tennessee a good inspeztion service is maintained at this writing, in charge of J. M. Buchanan, Franklin. Charles A. Reese at Charleston was in charge of the work in West Virginia (now abandoned), and his work was entirely successful. Wilmon Newell and staff are doing good work in Florida. No other 


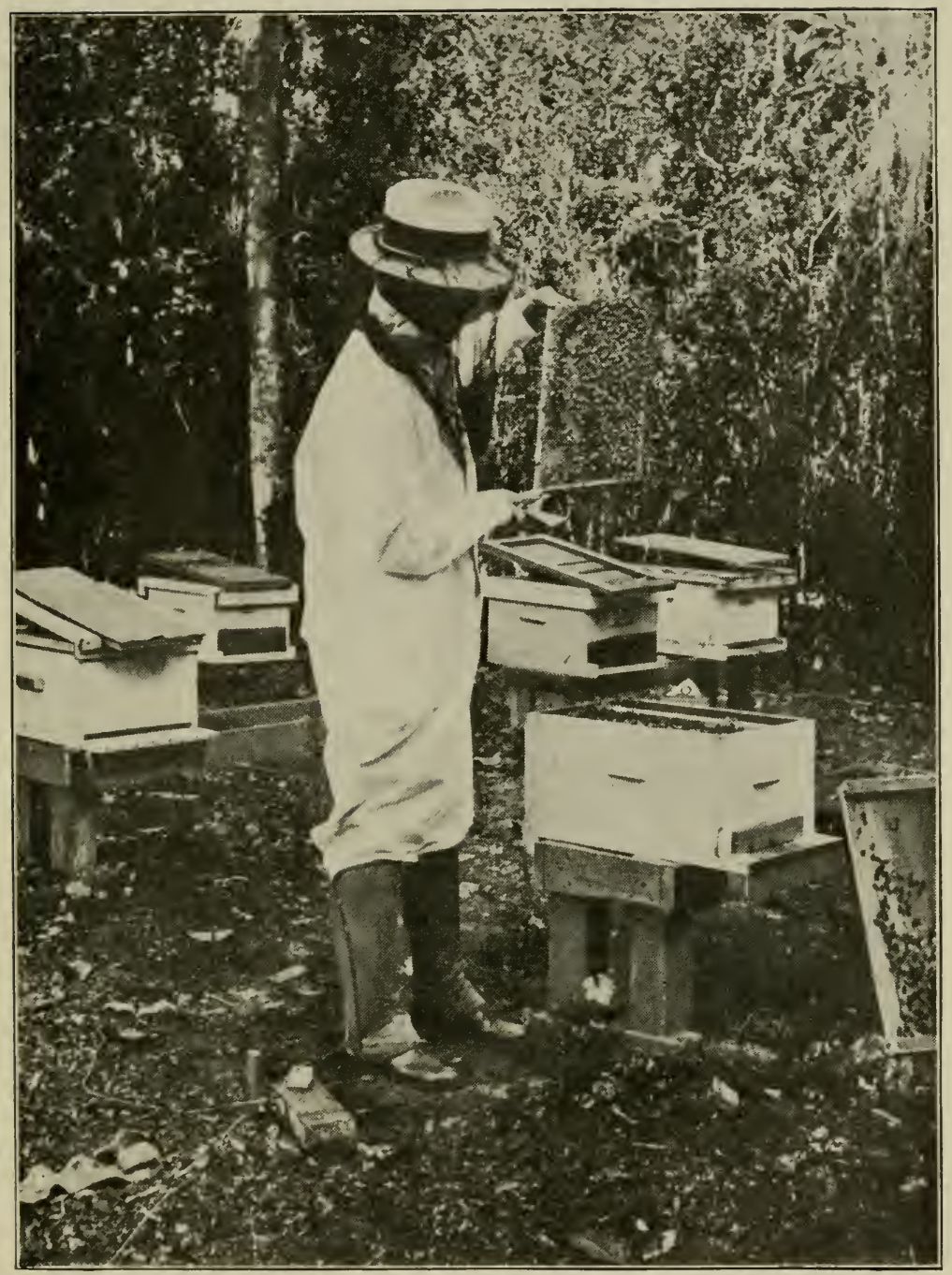

Fig. 48. Suit worn by a Florida Inspector. 


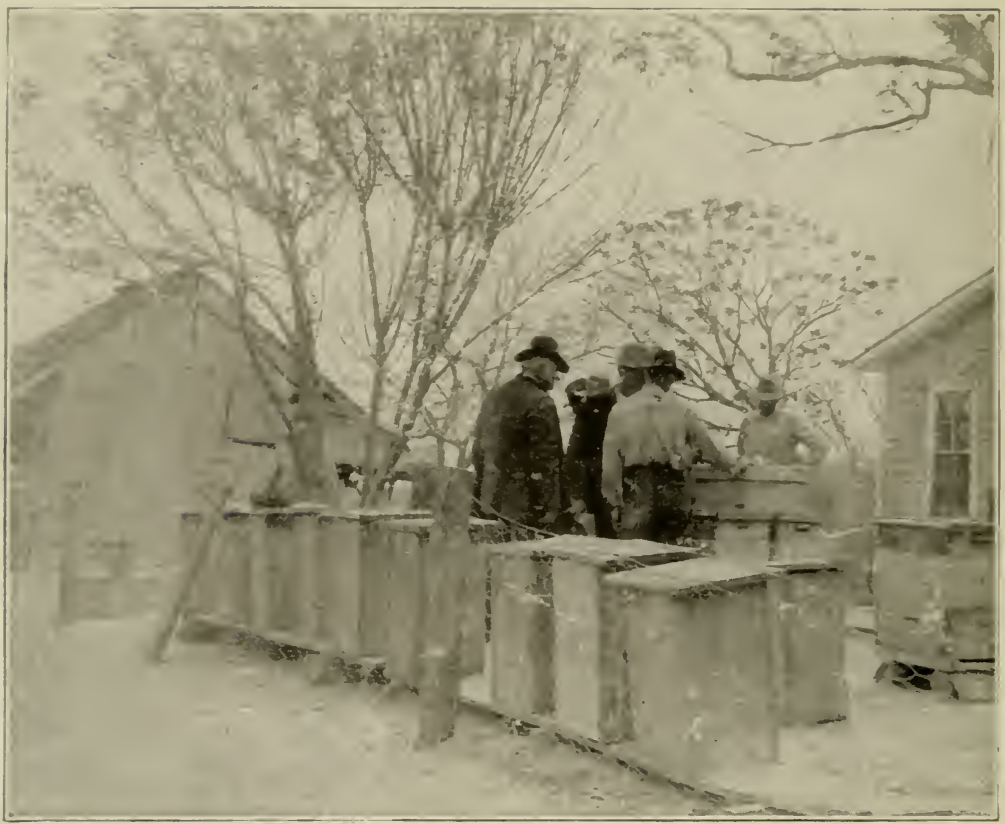

Fig. 49. Texas inspector giving a demonstration of transferring.

southern state is known to the writer to be maintaining an adequate inspection service at this time.

\section{Two Big Hindrances.}

In the eradication of bee diseases, there are two great hindrances: first, too many box hives, and second, too many noncommercial beekeepers. Both can be obviated by extension work. The box men can either be taught to adopt modern methods or be forced to get out of business. Modern beekeeping has no place for the man who keeps bees in other than a movable comb hive, whether it be manufactured or home made. The primary object is the ability of examination afforded by the movable comb hive.

The non-commercial beekeepers will be largely done away with when modern methods have been taught by the extension 
men. At present the South is not by any means overstocked with bees, even though 48 per cent of the total number of colonies of bees in the United States are said to be located in this territory. This means that more commercial beekeepers could be welcomed without overstocking either the pasture or the market. Even the fellow who keeps only a few bees for his own honey supply has no excuse for not using movable frame hives, since he can make them himself, if he does not wish to buy supplies. Every well posted beekeeper knows not only that it is impossible to eradicate bee diseases efficiently in non-movable frame hives, but he knows what is of more import: that disease cannot be recognized until much harm has already been done in the vicinity by its spread, where the bees are kept in logs and boxes.

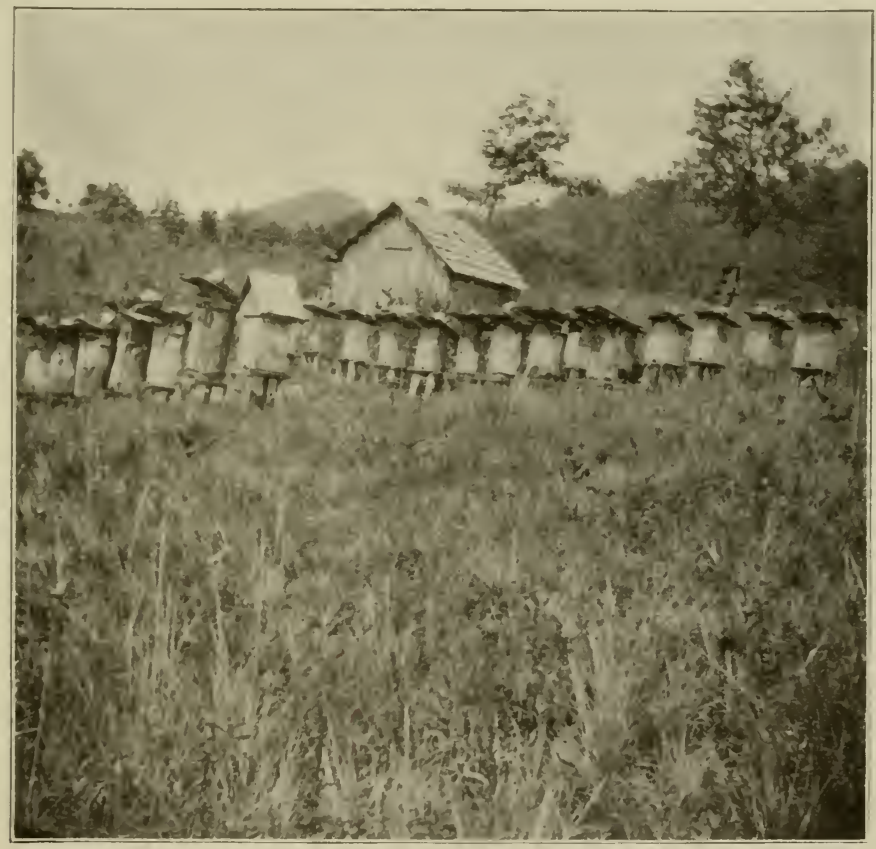

Fig. 50. Think of inspecting a yard like this. 


\section{Other Diseases.}

From some parts of the more tropical South come frequent reports of considerable trouble from bee paralysis. This disease is common to hot climates, but there have been few really serious losses from this disease, which unfortunately, does not vield to treatment in all cases. There have been reports of a "Disappearing Disease" but most of these have revealed nothing of import when investigated.

Just why the South with its great number of colonies of bees should be fairly immune from American foulbrood so far, is unknown. A conjecture which the writer believes a good one is this: There is little honey shipped into the region for human consumption and most of the shipping of bees is out of the South. While the facts are not known, it is reasonable to suspect that shipment of honey from apiaries where diseases exist is responsible for much disease spreading, through the robbing of used honey cans, etc. Whether or not much disease is usually shipped with bees is only to be conjectured. However, it is quite unlikely that much disease is ever transmitted by pound packages, and the shipment of nuclei is rapidly giving place to package shipments. Most men who buy bees in the South buy them from their own region and consequently run a smaller risk of buying disease than if purchased in the North, where disease is all 100 prevalent.

\section{Need of Education.}

The need of acquainting beckeepers with the symptoms of bee diseases is seen throughout the country as well as in the South. Beekeepers, as a rule, seldom harbor the disease when they know it is present. Taught to recognize the symptoms and to recognize the infections at sight, the end of serious disease losses would soon come. There is no more efficient method of accomplishing this than by extension work, either by purely extension or by inspectors who are authorized to give part time to educational work.

Not enough publicity is given the dangers of disease incident 


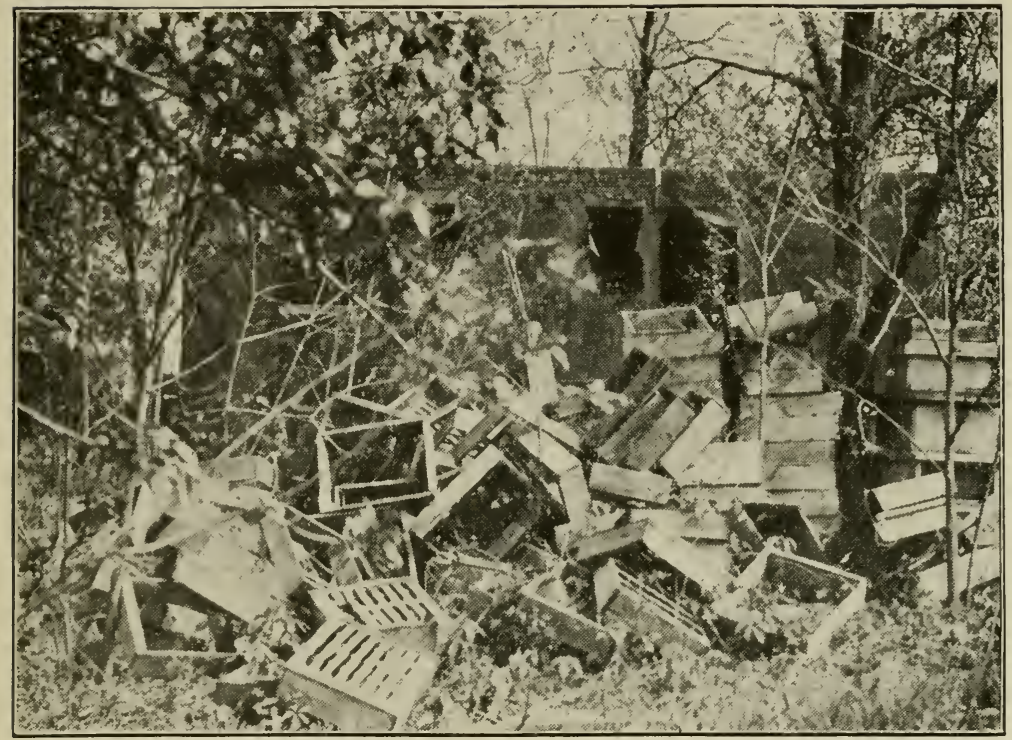

Fig. 51. The wreck that follows an epidemic of disease when left un treated.

to various phases of beekeeping. Too few of the beekeepers who must be eventually reached, take bee journals. The newspaper columns of most dailies are open to short articles on such subjects, when written by reliable men. This fact is being taken advantage of by some of the extension forces, in order to get the box hive beekeeper thinking and to reading free government bulletins, even when he will not buy bee journals and books. Of necessity the appeal must be to his greater chances of financial success by the change to modern methods and the eradication of diseases. Too much time has been given to patriotic appeals and attempts to reach his sympathy, which, except in war time, are largely preordained to failure.

No one can estimate the financial loss from epidemics of European foulbrood in the Appalachians, where most of the honey is consumed at home. The total would easily reach thousands of dollars. We are a wealthy people, too much given to belittling losses from waste. Every southern beekeeper should get behind 
the educational forces of his state and should see that the free government bulletins on bee diseases and bees receive far wider distribution among the little fellows, than they have ever had in the past. Dr. F. B. Paddock wrote of Texas extension and inspection work: "We have always felt that the inspection work in this state was most entirely a matter of education. While we have taken the stand that we could not legitimately, under the provisions of the law, engage actively in extensive extension work, we have nevertheless given the inspector every encouragement in this work. We are going farther and syggest that the inspectors put on demonstrations of transferring: and the treatment of clisease."

\section{The Value of Asepsis.}

Considerable interest among southern beekeepers is centering on the inspection work in Florida begun in 1919, where a large appropriation has been granted to fight bee diseases. The work is under the direction of Wilmon Newell.

Experience with the citrus canker in Florida, where success in the eradication of this plant disease has made Mr. Newell famous, has brought about extreme methods in asepsis among the inspectors. Very thorough methods are taken in disinfecting instruments used, and workers wear a regular suit, which is also disinfected, as are their shoes, before they leave the premises where bee disease may have been found. The success of this project will be watched with interest, as Florida has more to gain from preventive measures than from treatment of bee diseases, since the latter are happly rather scarce in that state. 


\section{CHAPTER XIII}

\section{Southern Marketing Problems.}

7 THERE is probably no region of this country in which the honey produced in any area is discriminated against as much as the honey produced in the South, east of the Mississippi River, when sold in northern markets. An obsolete and unfair classification of all honey produced in this region as "Southern" has been common. In this case the producer of light colored honey does not fare as well as he should, when his price for honey is compared with that of the producer of clark colored honey, who may also sell on the northern market. The present classification of honey based largely on color and not on food value and "foreign" content, no matter where produced, is obviously unfair, but it will take years of education to eliminate it. However, it will not take years to eliminate unfair discrimination against the fine honeys of the South. The best remedy is organization and honest grading.

Most of the emergency funds of the Bee Culture Laboratory during the war were spent in increasing honey production, some of it in the South. This was right. Nearly half the bees of the whole country are there and not much more honey than could be consumed locally has ever been produced in hundreds of southern localities, Texas excepted. Emergency funds could bring great results there where producers are anxious to increase their output and where their mental attitude was far more receptive to changes in their methods, than in much of the North and East. One of the good features of the work there was organization.

\section{Southern Honeys.}

For the most part, the honey produced in the South is light amber or amber in color. There are some regions where quite 


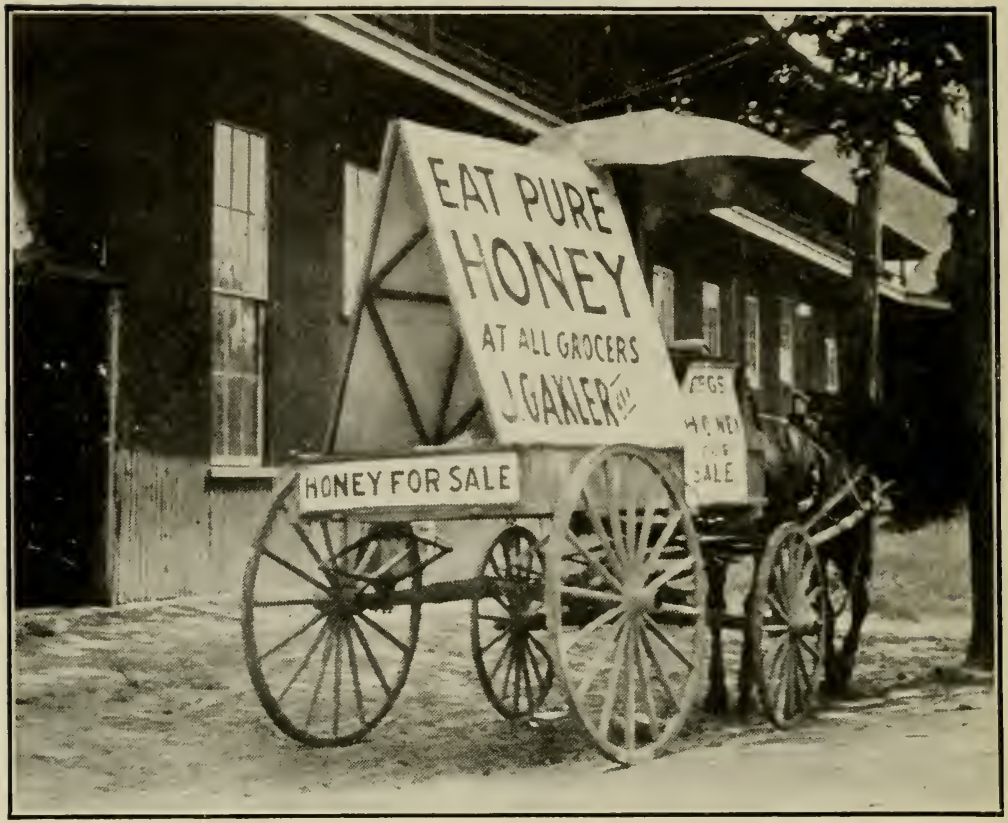

Fig. 52. Gakler's wagon was long a familiar sight on the streets of Memphis.

dark colored honey is produced, but these regions can not fairly bring upon the balance of the product, the unjust classification of "Southern." From some regions, namely Florida, where black and white tupelo honey is produced, there comes some of the finest honey which any man has ever eaten. Similarly in southwest Texas, huajilla yields a wonderfully fine grade of nicely flavored, white honey. For the consumer of the middle South: it is hard to better his purchases, than from the regions of Mississippi and Alabama, where wild sweet clover yields, or in south Georgia, where partridge pea abounds. Yet how many consumers of honey elsewhere in the country and how many beekeepers ever heard of these honers at bee conventions orin the market? The need is publicity and cooperative marketing. 


\section{Honey Prices.}

Not alone to justify the standing of the South as a honey producing region, is cooperative marketirg advisable. The unfair prices paid many southern producers by unscrupulous buyers of the North and South, give a more important reason for intelligent marketing. In one region, many barrels of honey were bought during the war at six cents per pound, and resold in New York City to a foreign government for seventeen and a half cents per pound. Surely this is not fair to the producer, whose honey, in this case, was one of the finest samples ever seen by the writer anywhere. It is quite likely that the average southern producer has received less for his honey than the producer of the other parts of this country, and in many cases, considering his product as graded by flavor, color, and body, he deserves a higher market price.

\section{Honey Exchanges.}

Organization is beginning in parts of the South, mainly through

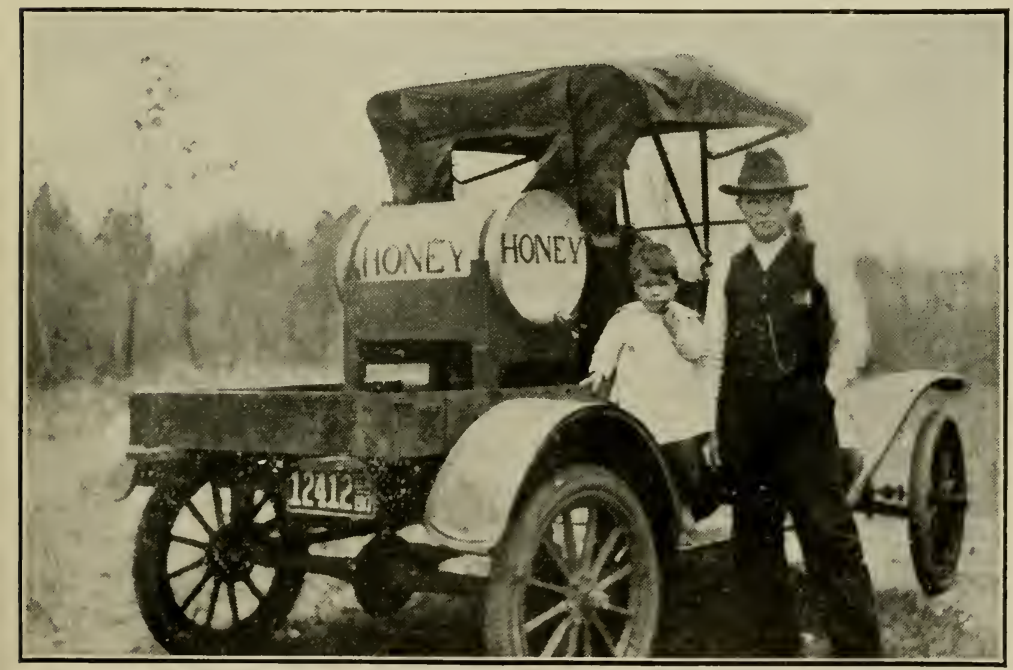

Fig. 53. This Georgia beekeeper has a honey route and serves his customers direct from the tank in the back of his car. 
the activity of agents of the U. S. Department of Agriculture. One of the best of these, the Tupelo Honey Exchange at Wewahitchka, Florida, was organized during a visit made there by the writer. There can be no doubt but that this was a move in the right direction, as the region served by this exchange has received but little of the benefits of war time prices. In Mississippi the writer has been informed by R. B. Willson that a number of the county agents, in localities where much honey is produced, have aided their beekeepers in marketing cooperatively. This is a movement which is bound to spread.

\section{The Texas Honey Producers.}

One of the most notable and most successful moves among beekeepers of the South for marketing their honey and receiving an adequate payment for their labor, is the case of the Texas Honey Producers Association of San Antonio, of which E. G. LeStourgeon is manager. This association handles the output of most of the large apiaries of Texas, has its own brand, enforces honest grading and safe packing, and has added several cents per pound, in many cases, to the total received by Texas beekeepers for their product. The association is also cooperative in buying supplies for the beckeeper and has served to put beckeeping of Texas on a more safe and sound basis. This is a system which could be adopted safely by many other sections and is a method of selling which must be adopted in some form, before the South as a whole is to receive her just deserts in the honey markets of the world.

\section{Southern Production.}

The total production of the South is low, when the total number of colonies of bees in the entire region is considered. Some whole counties have been gone over by the writer, with never a sight of a modern hive. The work of county agents, who have gone into such regions, with a modern hive strapped on the back of their buggies, where an auto could not go and the best means of travel was horseback, notably northern South Caro- 
methods of honey production, comparatively little has been done to better the marketing conditions. This is absolutely necessary if sales are to keep pace with production, and prices remain within reason for the producer. A few beekeepers like J. J. Wilder are pioneering in aiding others to sell their honey at a reasonable price, and still others are venturing into bottling and exploiting their own markets. The good effect of such ventures has already been felt in all such territories where the work is under way. Southern beekeepers, with their fingers on the pulse of sales and prices, should endeavor to keep up prices in comparison with increased production and to educate all markets to use southern honey. The classification "Southern" should soon become as famous as that of "Uvalde" or "Lone Star.' 


\section{CHAPTER XIV}

\section{Surplus Honey Plants of the South.}

7 COVER this topic in the space of one chapter is obviously impossible. However, no book about beekeeping would be complete without some reference to honey plants. The greatest difficulty in arranging the contents of this chapter has been to get reliable information. This does not mean that information which has been furnished the writer has been unreliable, but that the scientific name of individual honey plants was seldom known by the informants. That the task of

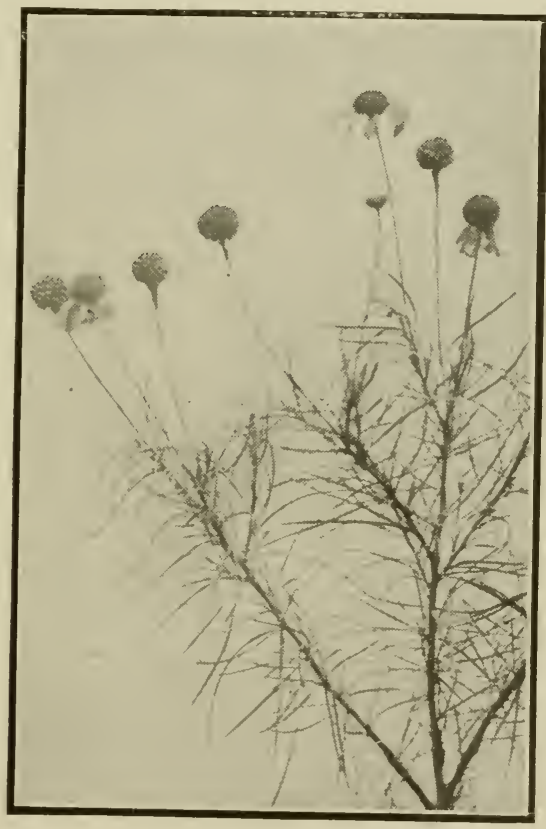

Fig. 55. Blossoms of bitterweed in Tennessee. 


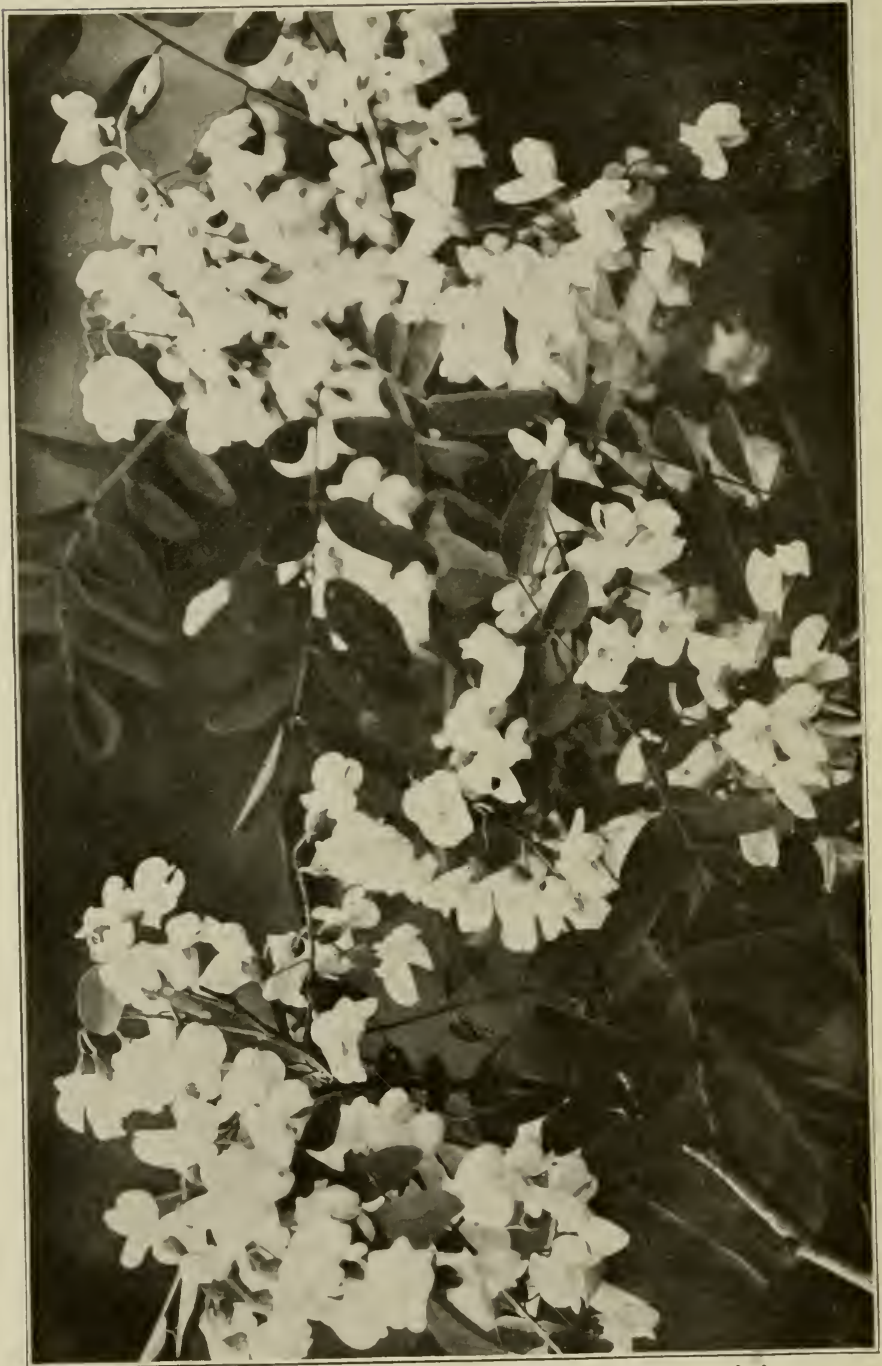

Fig. 56. Blossoms of black locust in Virginia. 
tracing these to a reliable source is too great to accomplish in a short time is certain.

Therefore the contents of this chapter will show only the ten or twelve plants in each state from which a sufficient portion of the surplus honey is secured, to make the plants of real apicultural importance. The scientific name of the plant has been determined by refererce of the case in question to the botany department of the several states in question, or to recognized scientific workers in the locality. The writer assumes no responsibility for the accuracy of other than the common names, although every effort has been taken to make this report worthy of credence.

\section{What Is a Surplus Honey Plant?}

Another feature which is seldom recognized by beekeepers is that frequently honey plants should be classed as surplus honey plants, when they are by custom placed in the stimulative or pollen-producing column. Too frequently beekeepers say this or that plant does not yield surplus. Many cases investigated have shown that the plant ordinarily yielded surplus honey, but that the bees owned by the man in question were seldom in shape to get surplus from the plant at the season of its bloom. Too frequently this is because of poor beekeeping, rather than because of the season or other conditions.

The mistakes of northern farmers who settle in the South, have frequently been pointed out to the virter, by government men in that territory. Attempts are made, unsuccessfully, to raise crops wholly unadapted to the South or by methods predestined to failure, merely because such crops or methods succeeded in the North. The Northern beekeeper settling in the South frequently makes the same mistakes. Many plant buckwheat or alfalfa, because they have come from portions of the United States where these were staple honey plants. Not enough attention has been given by beekeepers to the influence of temperature or soils on nectar secretion of horey plants. No attention can be given to these factors in this chapter, but they undoubtedly explain the failure of buckwheat or alfalfa to yield 


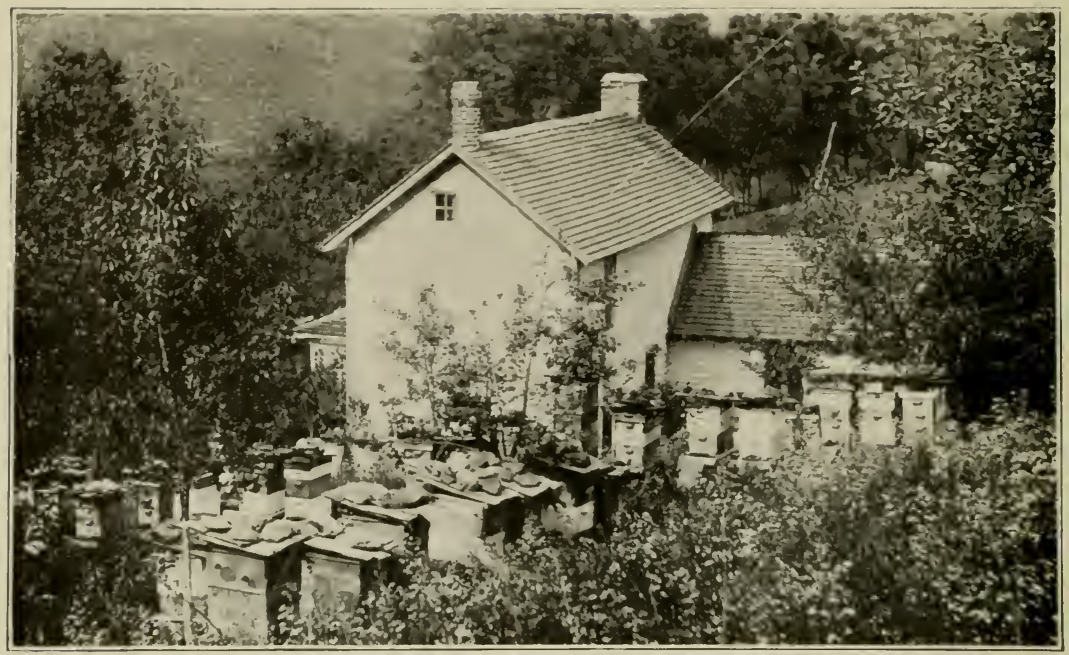

Fig. 57. Beehives a mong the wild asters in Virginia.

nectar in nearly every part of the southern states. Many plants have nectar secreting qualities attributed to them, when in reality such plants are seldom visited by bees. Doubtless many will criticize the lists given here. We leave their accuracy to the test of time. We enter a plea that beekeepers do more careful observing in their beekeeping practice. There are few industries in which less is known of the "why" of things than in beckeeping.

\section{Method of Listing.}

Plants are listed by states in the alphabetical order of their commonest local names. No attempt has been made to arrange the plants in the order of their importance. There are few surplus honey plants which are always important throughout one entire state. The scientific name follows the common name as nearly as it has been determined. The usual order of its bloom in a normal season, compared with others on the list, varies too greatly because of the elevation and latitude to list. Plants considered as surplus honey plants in this list are those credited by better beekeepers in the several states as being their principal sources of surplus honey, or those which the author knows to be 
important sources. All other plants, although worked hard at times by the bees, are omitted. The states chosen as southern states are those classed as such by the United States Department of Agriculture.

\section{Alabama.}

Aster-Aster Spp.

Clover (White)-Trifolium repens
Clover (Sweet) -Melilotus alba Cotton-Gossypium hirsutum Gallberry-Ilex Glabra

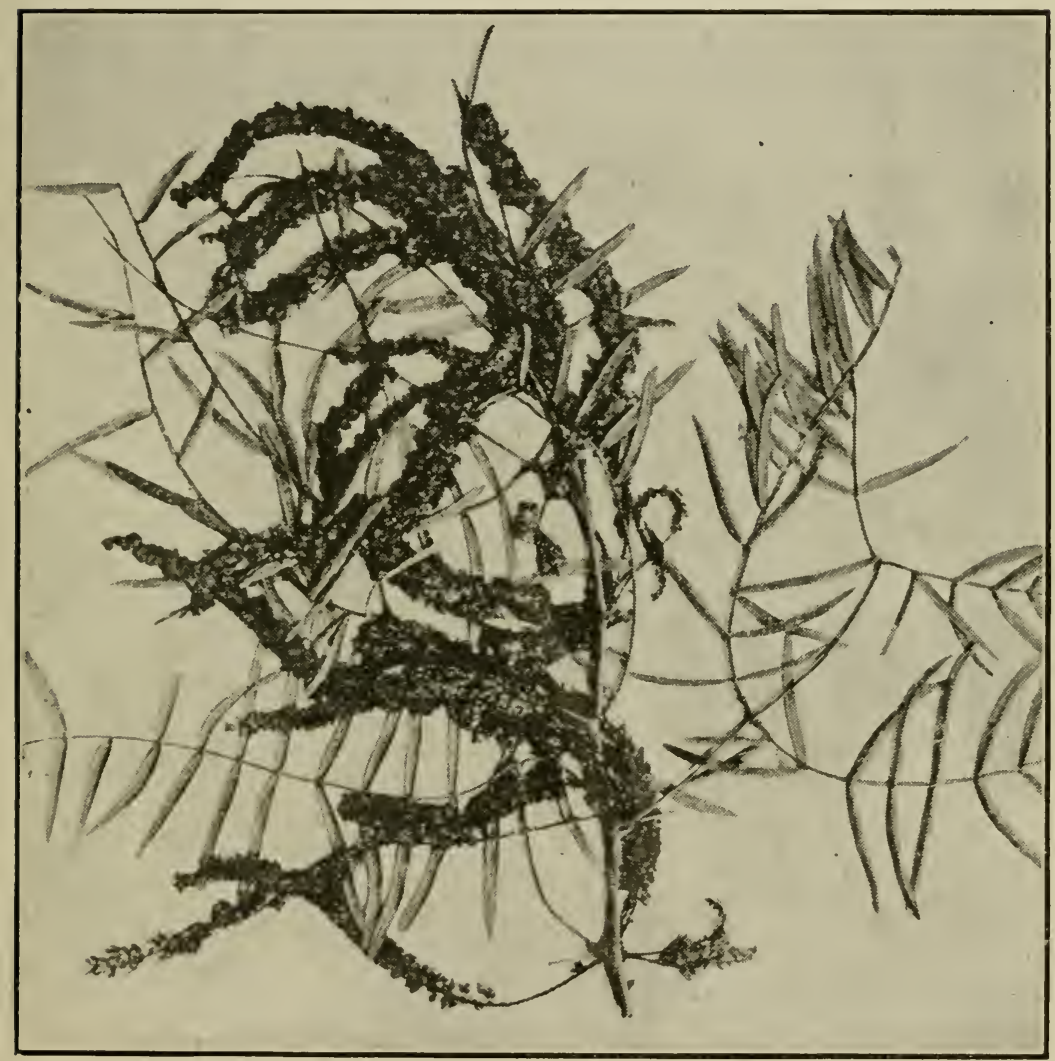

Fig. 58. Mesquite is an important source of honey in Texas. 
Huckleberry-Traccinium Spp. Locust (Honey)-Gleditsia triacanthos, L.

Prairie Clover-Trifolium carolinianum?

Palmetto-Sabal megacarpa

Partridge pea-Cassia chamaecrista, L.
Sourwood-Oxydendrum arboreum (L) DC.

Spanish needle-Bidens Spp. Sumac-Rhus Spp.

Titi-Cyrilla racemiflora Tupelo (Black) - Nyssa Spp. Willow-Salix Spp.

\section{Arkansas.}

Blackberry-Rubus

Clover (Sweet)-Melilotus alba Clover (White)-Trifolium repens

Cotton-Gossypium hirsutum Huckleberry-Vacciniaceae
Persimmon-Diospyros iirginiana

Spanish needle-Bid ns Spp. Sumac-Rhus Spp.

Tupelo-Nyssa Spp.

\section{Florida.}

Clover (Prairie)-Trifolium carolinianum?

Chinquapin-Castanea pumila Gallberry-Ilex glabra

Gum (Black) - Nyssa Spp.

Holly (White)-Ilex opaca?

Mangrove (Black)-Rhizophora mangle Linn?

Orange-Citrus Spp.

Palmetto (Saw)-Sabal megacarpa
P a $l$ metto (Cabbage)-Sabal palmetto

Partridge pea-Cassia chamaecrista, L.

Spanish needle-Bidens Spp.

Summer farewell-Aster Spp.

Sunflower (IVild)-Helianthus Spp.

Wicky (Basswood)-Tilia americana

\section{Georgia.}

Aster-Aster spp.

Black tupelo- Nyssa syliatica

Gallberry-Ilex glabra

Locust (Honey)-Cleditsia tri:canthos, L.
Huckleberry-Vaccinium spp.

Partridge pea-Cassia chamaecrista, L.

Prairie clover-Trifolium carolinianum? 
Sourwood-Oxydendrum arboreum (L) DC.

Tulip poplar-Liriodendron tulipifera, L.
Titi-Cyrilla racemiflora

White tupelo- Nyssa aquatica L

White holly-Ilex opaca

\section{Kentucky.}

Aster-Aster Spp.

Buckwheat-Fagopyrum fagopyrum

Clover (White)-Trifolium repens

Clover (Alsike) - Trifolium hybridum

Clover (Crimson)-Trifolium incarnatum

Cowpea-Vigna sinensis

Dandelion-Taraxacum taraxacum

Daisy (Whiteweed)-Chrysanthemum leucanthemum

Goldenrod-Solidago Spp.
Locust (Black)-Robinia pseudacacia

L in d e n (Linn-Basswood)Tilia americana

Melilotus (S w e e $\mathrm{t}$ Clover) - Melilotus alba

Melons (Cultivated)-Citrullus etc.

Maple-Acer rubrum

Persimmon-Diospyros airginiana

Redbud-Cercis canadensis

Tulip tree Tulip Poplar)Liriodendron tulipifera Willow-Salix Spp.

\section{Louisiana.}

Alfalfa-Medicago sativa

Boneset-Eupatorium perfoliatum

Clover (White)-Trifolium repens

Cotton-Gossypium hirsutum

Gallberry-Ilex glabra

Goldenrod-Solidago Spp.

Heartsease (Smartweed)-Persicaria persicaria

L o c u st (B lack)-Robinia Pseudoacacia, L.
Orange-Citrus Spp.

Partridge pea-Cassia chamaecrista

Peppervine-Ampelopsis arborea

Rattan-Berchemia scandens.

Saw Palmetto-Sabal megacarpa

Tupelo (Black) - Nyssa Spp.

Willow (Button)-Salix Spp. 


\section{Maryland.}

Aster-Aster Spp.

Chestnut-Castanea dentata

Clover (White)-Trifolium repens

Clover (Alsike)-Trifolium hybridum

Clover (Sweet-Melilotus) Melilotus alba

Goldenrod-Solidago Spp.

Joe pye weed (Boneset)-Eupatorium purpureum

Locust (Black)-Robinia pseudoacacia

Sumac-Rhus Spp.

Thistle (Blue )-Echiumvulgare Tulip poplar (Tulip tree)Liriodendron tulipifera.

\section{Mississippi.}

Aster-Aster Spp.

Bitterweed-(No commercial value)

Carrot (wild) -Daucus Spp.? Clover (White)-Trifolium repens

Clover (Sweet) - Melilotus alba Cotton-Gossypium hirsutum Gallberry-Ilex glabra

Gum (Tupelo) - Nyssa aquatica

Gum (Black) - Nyssa sylvatica Heartsease-Persicaria persicaria
Holly (White)-Ilex opaca?

L oc ust (Black)-Robinia Pseudoacacia, L.

Palmetto (Saw)-Sabal megacarpa

Partridge Pea-Cassia chamaecrista, L.

Sourwood-Oxydendrum arboreum

Spanish Needle-Bidens Spp. Sumac-Rhus Spp.

Titi-Cyrilla racemiflora

Willow-Salix Spp.

\section{North Carolina.}

Asters-Aster Spp.

Blackberry-Vaccinium Spp.

Clethra-Clethracae.

Gallberry-Ilex Glabra

Goldenrod-Solidago Spp.

Holly (White)-Ilex opaca?

Ironwood (White Titi)-Cyrilla racemiflora, $\mathrm{L}$.
Sourwood-Oxydendrum arboreum

Sweet Bay (Laurel Tree)Persea Borbonia, L-Spreng. Tulip poplar-Liriodendron tulipifera 


\section{Oklahoma.}

Alfalfa-Medicago sativa

Aster-Aster Spp.

Clover (Sweet)-Melilotus alba Clover (White)-Trifolium repens

Cotton-Gossypium hirsutum Goldenrod-Solidago Spp.

Heartsease (Smartweed) - Persicaria persicaria
Locust (Honey)-Gleditsia triacanthos, L.

Milkweed-Asclepias Spp.

Partridge pea-Cassia chamaecrista, L.

Persimmon-Diospyros virginiana

Sumac-Rhus Spp.

\section{South Carolina.}

Alder-Alnus Spp.

Clover (White)-Trifolium repens

Gallberry-Ilex glabra

Gum (Black) - Nyssa syliatica Gum (Tupelo)-Nyssa aquatica

Holly (White)-Ilex opaca?

Persimmon-Diospyros virginiana
Privet-Ligustrum Spp.

Tulip poplar-Liriodendron tulipifera

Sourwood-Oxydendrum arboreum

Rattan-Berchemia scandens

Vetch-Vicia Spp.

\section{Tennessee.}

Aster-Aster Spp.

Basswood-Tilia Spp.

Bitterweed-(No commercial value)

Boneset-Eupatorium perfoliatum

Clover (White)-Trifolium repens

Clover (Alsike) - Trifolium hybridum

Clover (Crimson)-Trifolium incarnatum
Goldenrod-Solidago Spp.

Heartsease (Smartweed) - Persicaria persicaria

Locust (Black)-Robinia pseudoacacia, L.

Sourwood-Oxydendrum arboreum

Spanish needle-Bidens Spp.

$\mathrm{T}$ u 1 i p poplar-Liriodendron Tulipifera 


\section{Texas.}

Cotton-Gossypium hirsutum Horsemint-Monarda punctata Mesquite-Prosopis glandulosa Huajilla-IIavardia brevifolia Catsclaw-Acacia Greggii \& Wrightii

Cactus-Opuntia Spp. Broomweed-Gutierrezia Texana
Sumac-Rhus Spp.

Persimmon (Mexican)-Diospyras Texana

Holly (Youpon)-Ilex opaca, etc.

Rattan-Berchemia scandens

White brush-Lippia ligustrina

\section{Virginia.}

Apple-Malaceae etc. (Rosaceae)

Aster-Aster Spp.

Basswood-Tilia Spp.

Blue thistle-Echium vulgare

Clover (White)-Trifolium repens

Clover (Crimson)-Trifolium incarnatum

Gallberry-Ilex glabra

Goldenrod-Solidago Spp.

Persimmon-Diospyros virginiana

Sourwood-Oxydendrum arboreum

Sumac-Rhus Spp.

Tulip poplar-Liriodendron tulipifera

\section{West Virginia.}

Aster-Aster spp.

Basswood-Tilia spp.

Buckwheat-Fagopyrum esculentum

Clover (White)-Trifolium repens

Clover (Sweet) - Melilotus alba Clover (Alsike)-Trifolium hybridum
Goldenrod-Solidago spp.

Gum (Black) - Nyssa sylvatica Red bud-Cercis canadensis Sourwood-Oxydendrum arboreum

Sumac-Rhus spp.

Tulip poplar-Liriodendron tulipifera 


\section{INDEX}

Pages

98-102-104

84

46-69

10-13

51

Aster Honey for Wintering.

Bee Pests

Beginners' Needs

30

Building Up Colonies

Color of Southern Honey.

12-13-105 ..32-39

Comb or Extracted Honey

$\ldots .55$

Combless Shipping Packages

.20

Conserving the Bees

Cotton as a Honey Plant

. .77

Cultivated Nectar Secreting Plants . .72

Deeper Brood Chambers.

.76

E. F. B. $85-97-104$

Fall Flows in the Mountains. .86

Hindrance to Disease Eradication. 100

Honey Flows, Time of.

Honey Flows, Type of

.38

Honey Shipments and Discase............102

Honey Sources:

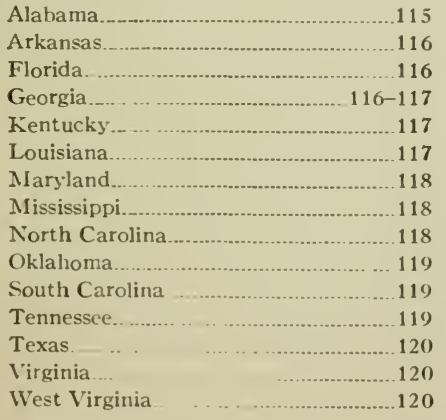

Alabama.

115

116

116

117

117

118

118

118

119

119

119

120

120

West Virginia
Pages

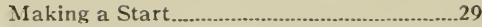

Melilotus Area .................................................

Migratory Beekeeping.......................42-43-62

Modern Hive, A

Mountain Climates

Mountain Regions. ...............................48-79

Organizations, Honey Selling ……......108-109

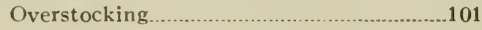

Palmettos Affected by Heat..........................62

Prices Paid for Honey.................................107

Queens for Package Bees..................................64

Rearing Queen Bees.......................................57

Seasonal Operations.........................................35

Shallow Supers as Brood Chambers.............24

Snowfall in the South.................................41

Soils and Nectar Secretion ...............61-69-80

"Southern Honey" Classifications ..............105

Style of Hive for the South....................23-26

Surplus Honey Plant, What is a …............113

Swarm Prevention.....................................53

Swarm Prevention by Packages......................56

Texas Beekeeping Notes...................................87

Time to Ship Bees

Time to Start Beekeeping in the South......30

Trees as Honey Plants..............................79

Tropical Regions.........................................45-61

Tulip Poplar Yields........................................80

Variety of Honey Plants.....................................

White Clover in the Mountains....................79

Wilder on Wintering.................................40

Winter Losses Heavy.........................................83

Winter Protection ..........................................50

Winter Stores, Greater Use of …...................23

Winter Supplies. .....................................51

Winter Temperatures, Chart of Kentucky..40

Yields of Honey in the South...............10-13

Zero Temperatures

47-76 


\section{PracticalQueen Rearing}

\section{BY FRANK C. PELLETT}

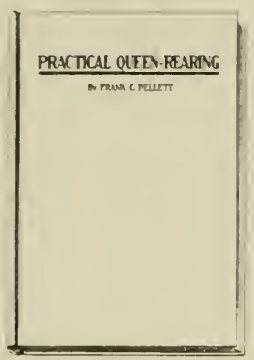

In preparation for this book Mr. Pellett visited many of America's foremost beekeepers and queen breeders, both north and south, and has described their methods fully.

The methods of the older queenbreeders and writers, Alley, Doolittle and others, are explained with the variations which are the development of later years.

Simple methods of rearing a few queens in a small apiary, as well as methods used for rearing queens in wholesale quantity, make the book valuable alike to the ordinary beekeeper and commercial queen breeder.

Cloth binding, 105 pages, 40 illustrations. Price $\$ 1$.

\section{American Honey Plants}

BY FRANK C. PELLETT

The first book in the English language on the subject of honey plants

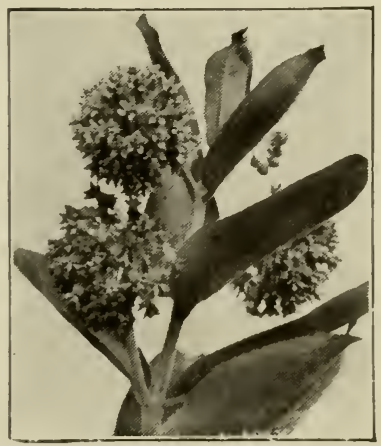

A knowledge of the sources of nec. tar is fundamental to the success of the beekeeper, as the difference of a mile or two in distance often doubles the returns from the apiary on account of better pasturage. This book is the result of years of study and visits to important hon. ey producing sections, from New Fngland to California, and from Canada to Florida and Texas.

An authoritative book by an expert beekeeper and reliable naturalist. Profusely illustrated with original photographs.

300 large pages, 155 fine illustrations, cloth bound. Price $\$ 2.50$.

AMERICAN BEE JOURNAL Hamilton, III. 


\section{OUTAPIARIES}

BY M. G. DADANT

A clear and concise explanation of the requirements for proper placing, arranging and managing outapiaries. Special chapters devoted to Apiary Sites, Basis of Placing the Apiary, Systems of Management, Moving, Autos and Trucks, Honey Houses and Equipment, with treatment of apiary work during different seasons, as applied to outapiaries.

This book is especially valuable to the beginning outapiarist and will contain many items of interest to the older veteran. Cloth Bound. 125 Pages.

Price $\$ 1.00$. Mailing weight one pound. 50 Illustrations.

\section{American Honey Plants}

\section{BY FRANK C. PELLETT}

The First Book in the English Language on the Subject of the Honey Plants

A knowledge of the sources of nectar is fundamental to the success of the beekeeper, as the difference of a mile or two in distance often doubles the returns from the apiary, because of better pasture. This book is the result of many years of study and personal visits to important honey producing districts, from New England to California and from Canada to Florida and Texas. An authoritative book by an expert beekeeper. Profusely illustrated with original photographs. 300 large 8 vo pages; 155 fine illustrations. Price \$2.50. Mailing weight 3 pounds.

\section{American Bee Journal, Hamilton, Ill.}




\title{
Langstroth on the Honeybee
}

\section{REVISED BY DADANT}

This book, originally written by Rev. L. L. Langstroth, the inventor of the movable frame hive, has been revised and kept up to date by the editor of the American Bee Journal. It is the one book that no beekeeper can afford to be without. It contains careful and accurate accounts of the life and habits of the honeybee and the mysteries of the hive. Full and reliable information concerning the detection and treatment of disease, the sources of nectar and pollen, and care of the apiary throughout the year are included. The best methods of producing and marketing large crops of honey are made clear. This book is nicely bound in attractive cloth cover and contains 575 pages. The price is very low for a book of this size and quality. Price $\$ 2.50$.

\section{First Lessons in Beekeeping}

\author{
BY C. P. DADANT
}

FIRST LESSONS

IN BEEKCEPING

C. P. DADANT

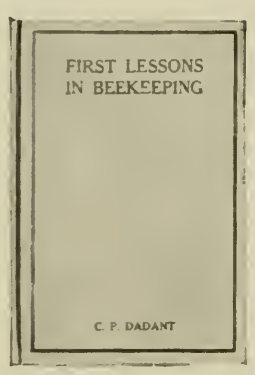

The senior editor of the American Bee Journal, who is the author of this book, has spent nearly all his life in a beekeeping atmosphere. His father, the late Charles Dadant, was an investigator who became well known on both sides of the Atantic. As a young man, the author of this book was associated with his father in honey production and assisted him in the many experiments which he conducted in his efforts to make beekeeping a practical success.

Contains just the things you want to know, in a style easily understood and with many pictures to explain the text. You may safely recommend First Lessons in Beekeeping to your friends.

167 pages, cloth bound, well illustrated. Price, $\$ 1.00$.

\section{American Bee Journal, Hamilton, Ill.}




\section{Scientific Queen Rearing}

\section{BY G. M. DOOLITTLE}

An old work that has had a big sale. Gives Doolittle's methods of queen rearing by artificial grafting. We advise "Practical Queen Rearing" as preferable, but the student or commercial breeder who desires to practice cell grafting will find this work interesting.

Price, cloth binding, $\$ 1.00$. Leatherette, 50c

\section{American Bee Journal}

Edited by C. P. Dadant and Frank C. Pellett

Oldest Bee Journal in the English Language. A 36-page Monthly Magazine

Subscription $\$ 1.50$ per year. Canadian postage $15 \mathrm{c}$;

Foreign 25c extra

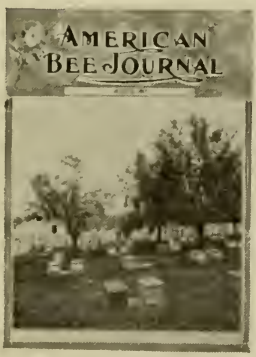

Every phase of beekeeping is covered in the Journal, every section of the country receives attention. The market page alone is worth several times the subscription price to beekeepers with honey for sale.

New methods, latest news, illustrated articles on honey plants, free legal service department, questions answered, profusely illustrated.

First and best in its field.

If the American Bee Journal is wanted in combination with any one of our bee books, add $\$ 1.25$ to the regular price of the book and both book and Journal will be sent postpaid.

\section{American Bee Journal, Hamilton, Ill.}




\title{
A Thousand Answers to Beekeeping Questions
}

\author{
BY DR. C. C. MILLER
}

For over 25 years Doctor Miller answered questions for beginners and veterans alike through the columns of the

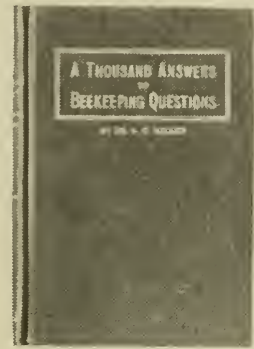

American Bee Journal. More than 10,000 of these questions have been answered in this manner. These have been sifted and more than 1,000 of them included in this new book, edited by Maurice G. Dadant.

Alphabetically arranged by subject, this book will clear up many problems not touched by other bee books.

The texts all tell a connected story of bee life and the principles of honey production, while this takes up singly the many questions which perplex the beekeeper in every-day practice about his bees.

Should be in every list of bee books.

Attractive cloth cover, 276 pages illustrated. Price $\$ 1.25$.

\section{OUTAPIARIES}

BY M. G. DADANT

A clear and concise explanation of the requirements for proper placing, arranging and managing of outapiaries.

Too many beekeepers expand into outapiary beekeeping without fundamental knowledge of its requirements. The result is that apiaries are often located improperly and have to be moved after errors are discovered by costly experience.

Special chapters are devoted to apiary sites, basis of placing the apiary, systems of management, moving, autos and trucks, honey houses and equipment, and treatment of apiary during different seasons of the year, with special apparatus used by large beekeepers.

This book is especially valuable to the beginning outapiarist, but will contain many items of value to the experienced outyard man.

The book is cloth bound, has 125 pages and 50 illustrations, and is printed on fine paper. Price $\$ 1.00$.

\section{American Bee Journal, Hamilton, Ill.} $620 C 15$ 


